\title{
Fault Tolerance Analysis of L1 Adaptive Control System for Unmanned Aerial Vehicles
}

\author{
Kiruthika Krishnamoorthy
}

Follow this and additional works at: https://researchrepository.wvu.edu/etd

\section{Recommended Citation}

Krishnamoorthy, Kiruthika, "Fault Tolerance Analysis of L1 Adaptive Control System for Unmanned Aerial Vehicles" (2015). Graduate Theses, Dissertations, and Problem Reports. 6015.

https://researchrepository.wvu.edu/etd/6015

This Thesis is protected by copyright and/or related rights. It has been brought to you by the The Research Repository @ WVU with permission from the rights-holder(s). You are free to use this Thesis in any way that is permitted by the copyright and related rights legislation that applies to your use. For other uses you must obtain permission from the rights-holder(s) directly, unless additional rights are indicated by a Creative Commons license in the record and/ or on the work itself. This Thesis has been accepted for inclusion in WVU Graduate Theses, Dissertations, and Problem Reports collection by an authorized administrator of The Research Repository @ WVU. For more information, please contact researchrepository@mail.wvu.edu. 
Fault Tolerance Analysis of L1 Adaptive Control System for Unmanned Aerial Vehicles

Kiruthika Krishnamoorthy

Thesis submitted to the

Benjamin M. Statler College of Engineering and Mineral Resources

at West Virginia University

in partial fulfillment of the requirements

for the degree of

Master of Science

in

Aerospace Engineering

Larry E. Banta, Ph.D.,

Mridul Gautam, Ph.D.,

Mario G. Perhinschi, Ph.D., Chair

Jennifer Wilburn, Ph.D.,

Department of Mechanical and Aerospace Engineering

Morgantown, West Virginia

2015

Keywords: fault tolerant control laws, L1 adaptive control, UAV 


\section{AbSTRaCT \\ Fault Tolerance Analysis Using L1 Adaptive Control System for Unmanned Aerial Vehicles \\ Kiruthika Krishnamoorthy}

Trajectory tracking is a critical element for the better functionality of autonomous vehicles. The main objective of this research study was to implement and analyze L1 adaptive control laws for autonomous flight under normal and upset flight conditions. The West Virginia University (WVU) Unmanned Aerial Vehicle flight simulation environment was used for this purpose. A comparison study between the L1 adaptive controller and a baseline conventional controller, which relies on position, proportional, and integral compensation, has been performed for a reduced size jet aircraft, the WVU YF-22. Special attention was given to the performance of the proposed control laws in the presence of abnormal conditions. The abnormal conditions considered are locked actuators (stabilator, aileron, and rudder) and excessive turbulence. Several levels of abnormal condition severity have been considered. The performance of the control laws was assessed over different-shape commanded trajectories. A set of comprehensive evaluation metrics was defined and used to analyze the performance of autonomous flight control laws in terms of control activity and trajectory tracking errors. The developed L1 adaptive control laws are supported by theoretical stability guarantees. The simulation results show that L1 adaptive output feedback controller achieves better trajectory tracking with lower level of control actuation as compared to the baseline linear controller under nominal and abnormal conditions. 


\section{ACKNOWLEDGEMENT}

I would like to extend my sincere thanks to my Professor Mario Perhinschi for his patient guidance. His continual feedback, suggestions have driven me achieve and learn things better.

I would like to thank Dr. Larry Banta, Dr. Jennifer Wilburn and Dr. Mridul Gautam for their valuable suggestions. I would like to thank Dr. Hever Moncayo for his support.

I would extend my thanks to my team mate Brenton Wilburn for his great suggestions and help. I would like to thank my parents and sister for their moral support. 


\section{Table of Contents}

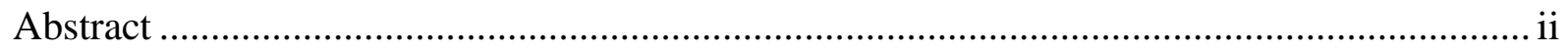

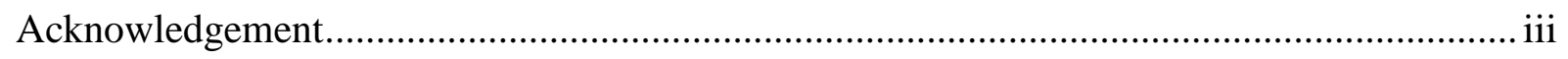

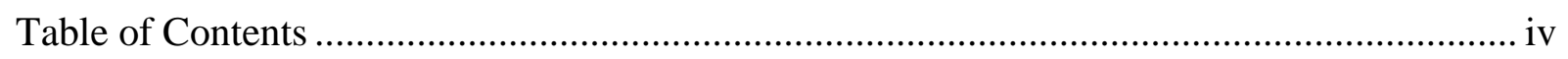

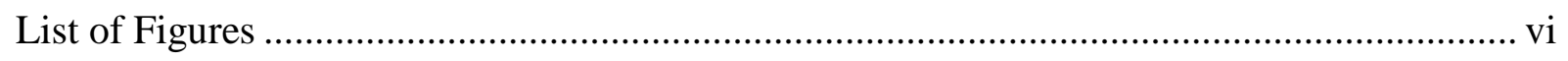

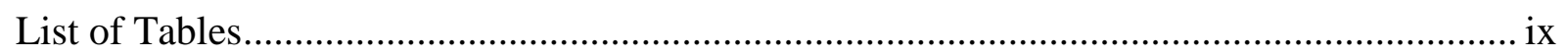

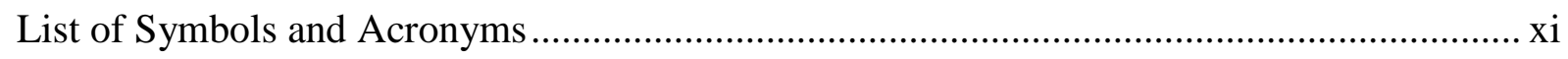

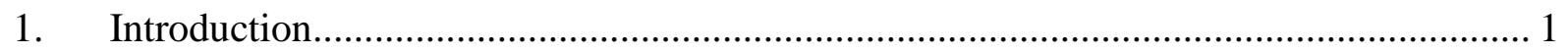

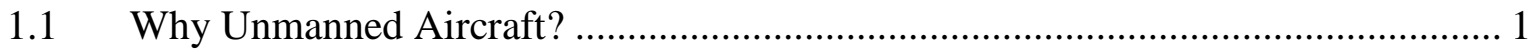

1.2 Failure Statistics of Manned and Unmanned Aircraft ........................................ 2

1.3 Control Laws for Autonomous Flight ....................................................... 5

$1.4 \quad$ Research Objectives ............................................................................... 5

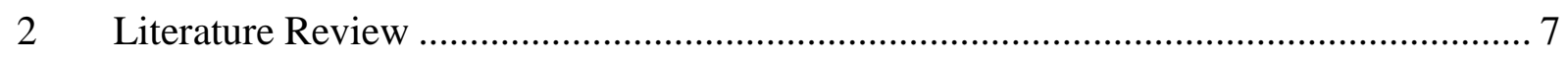

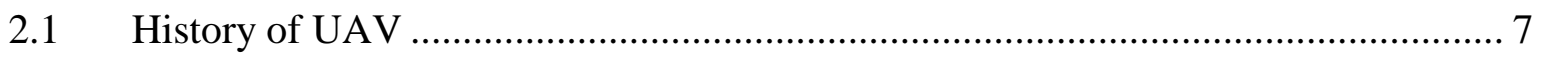

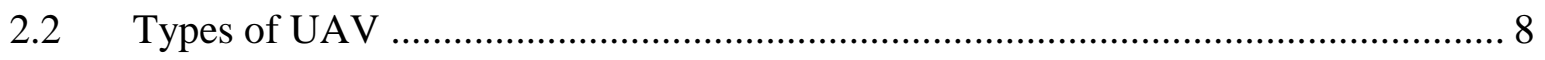

2.3 UAV Sub-system Failures ..................................................................... 9

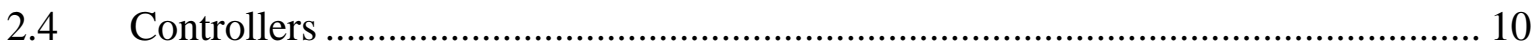

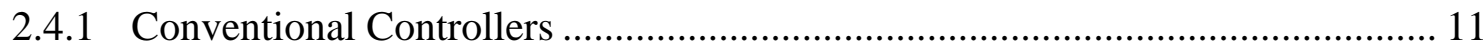

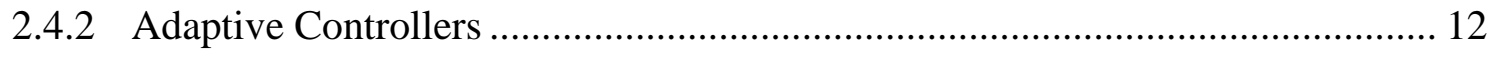

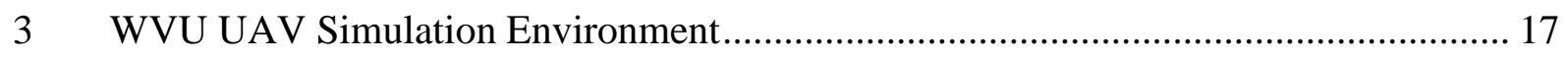

3.1 Graphical User Interface (GUI) for Simulation Setup................................... 17

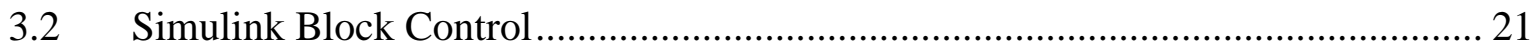

Flight Path Visualization .......................................................................... 23 


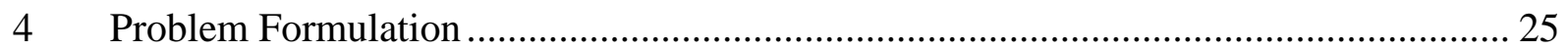

4.1 Geometry of the Trajectory Tracking Problem …………………........................ 25

$4.2 \quad$ Outer Loop Controller ....................................................................................... 27

4.3 Inner Loop Controller …………………………........................................ 28

4.3.1 Proportional Integral Derivative Controller ………........................................... 28

4.3.2 Architecture of L1 Adaptive Feedback Controller............................................. 28

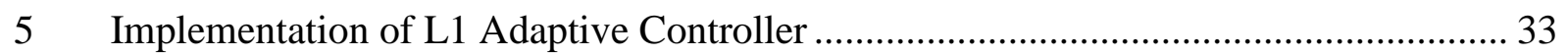

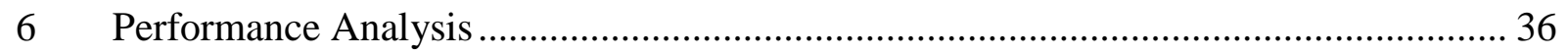

6.1 Experimental Design for Control Laws Performance Analysis ............................... 36

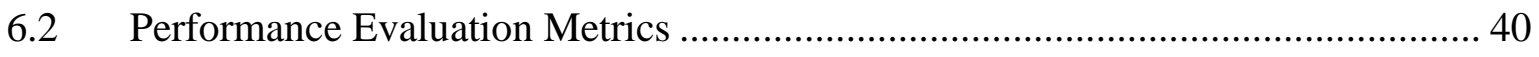

6.2.1 Trajectory Tracking Indices ............................................................................. 40

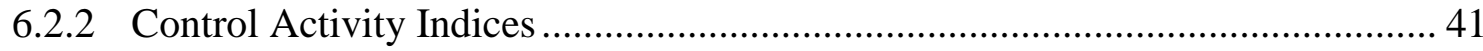

6.2.3 Total Performance Index (PI) ........................................................................ 42

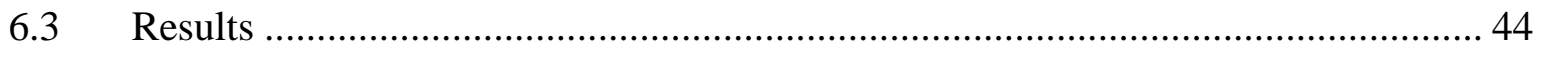

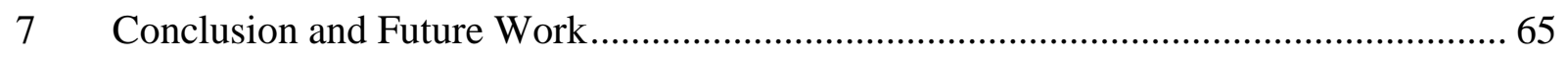

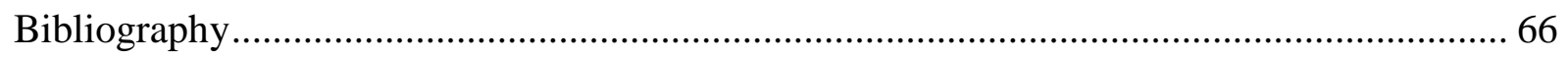

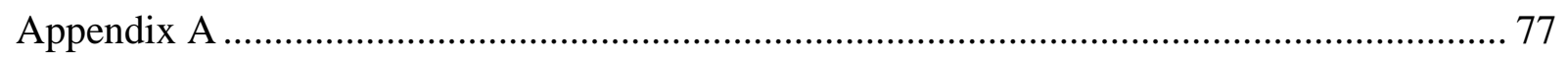

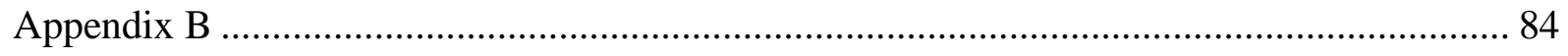

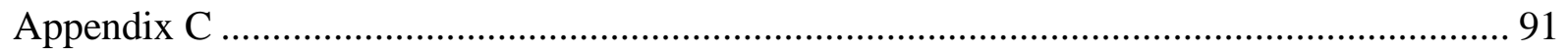

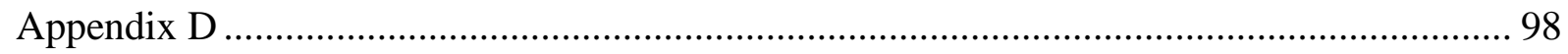




\section{LIST OF FIGURES}

Figure 1. Manned Aircraft Accident Cause Distribution ...................................................... 3

Figure 2. UAV Accident Cause Distribution ................................................................ 4

Figure 3. Average Sources of System Failures for IAI UA Fleet ........................................... 9

Figure 4. General Structure of Adaptive Controller .......................................................... 13

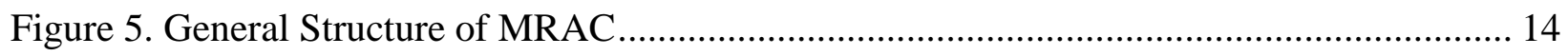

Figure 6. General Structure of L1 Adaptive Controller ..................................................... 15

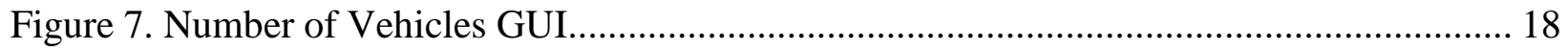

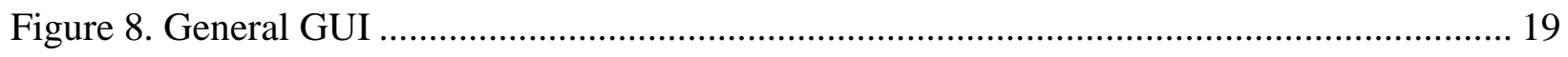

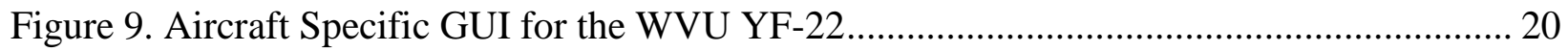

Figure 10. Aircraft Specific Failure GUI for the WVU YF-22 ........................................... 20

Figure 11. Simulink Model for the WVU YF-22 Aircraft .................................................. 21

Figure 12. Selection of On-line Visualization of Main Parameters Variation........................... 22

Figure 13. Selection Menu for Post-Simulation Data Analysis ............................................. 23

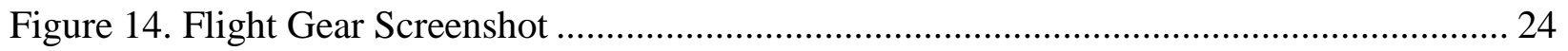

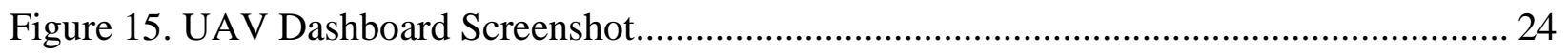

Figure 16. General Architecture of Control Laws .......................................................... 25

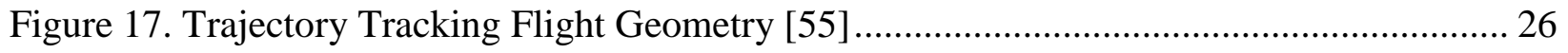

Figure 18. Architecture of L1 Adaptive Output Feedback Controller ..................................... 31

Figure 19. General Architecture of Control Laws ............................................................... 33

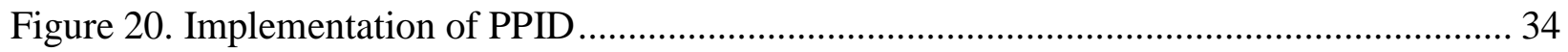

Figure 21. Implementation of Longitudinal Channel L1 Adaptive Output Feedback Controller 34

Figure 22. Implementation of L1 Adaptive Output Feedback Controller-State Predictor ........... 35

Figure 23. Implementation of L1 Adaptive Output Feedback Controller-Control Law ............... 35

Figure 24. Implementation of L1 Adaptive Output Feedback Controller-Adaptive Law ........... 35

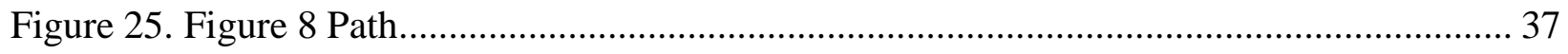

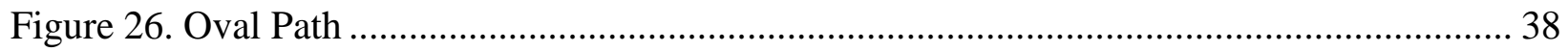

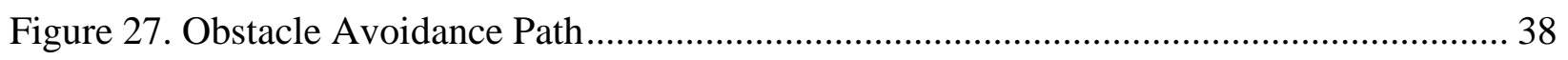

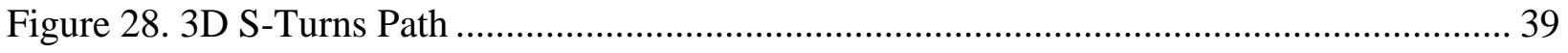


Figure 29. Trajectory Tracking Performance Index of PPID and L1 Adaptive Controller for Figure

8 Path 49

Figure 30. Trajectory Tracking Performance Index of PPID and L1 Adaptive Controller for Oval Path 49

Figure 31. Trajectory Tracking Performance Index of PPID and L1 Adaptive Controller for OA Path 50

Figure 32. Trajectory Tracking Performance Index of PPID and L1 Adaptive Controller for 3D S Turns Path 50

Figure 33. Controller Activity Performance Index of PPID and L1 Adaptive Controller for Figure 8 Path 52

Figure 34. Controller Activity Performance Index of PPID and L1 Adaptive Controller for Oval Path 52

Figure 35. Controller Activity Performance Index of PPID and L1 Adaptive Controller for OA Path 53

Figure 36. Controller Activity Performance Index of PPID and L1 Adaptive Controller for 3D S Turns Path 53

Figure 37. Total Performance Index of PPID and L1 Adaptive Controller for Figure 8 Path...... 55

Figure 38. Total Performance Index of PPID and L1 Adaptive Controller for Oval Path ........... 55

Figure 39. Total Performance Index of PPID and L1 Adaptive Controller for OA Path .............. 56

Figure 40. Total Performance Index of PPID and L1 Adaptive Controller for 3D S-Turns Path 56 Figure 41. Total Performance Index of PPID and L1 Adaptive Controller for Aileron Failures . 57 Figure 42. Total Performance Index of PPID and L1 Adaptive Controller for Stabilator Failures 58

Figure 43. Total Performance Index of PPID and L1 Adaptive Controller for Rudder Failures . 58 Figure 44. Total Performance Index of PPID andL1 Adaptive Controller under Turbulence

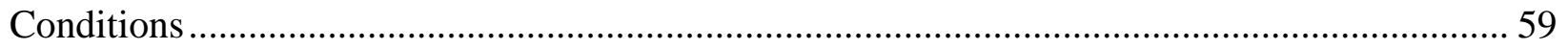

Figure 45. Performance Indices per Type Failure of PPID and L1 Adaptive Controller ............. 60 Figure 46. Average Trajectory Tracking Performance Index of Four Paths for PPID and L1

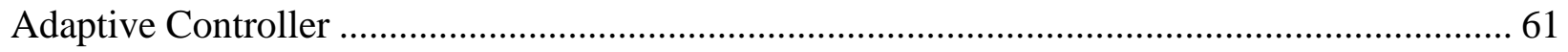

Figure 47. Average Controller Activity Performance Index of Four Paths for PPID and L1 Adaptive Controller 62 
Figure 48. Average Total Performance Index of Four Paths for PPID and L1 Adaptive Controller 64

Figure 49. Percentage Total PI Increase of L1 Adaptive Controller over PPID....................... 64 


\section{LIST OF TABLES}

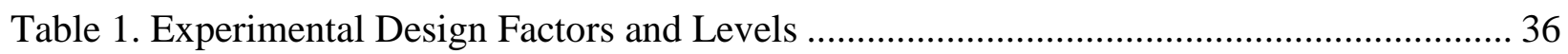

Table 2. Description of Abnormal Condition Severities .......................................................... 39

Table 3. Performance Index Weights and Normalization Cut-offs ............................................. 43

Table 4. Percentage Increase of TTI for all Four Paths .............................................................. 48

Table 5. Percentage Increase of CAI for all Four Paths ........................................................ 51

Table 6. Percentage Increase of PI for all Four Paths ................................................................. 54

Table 7. Average Trajectory Tracking Performance Index of Four Paths for PPID and L1 Adaptive Controller 61

Table 8. Average Controller Activity Performance Index of Four Paths for PPID and L1 Adaptive Controller 62

Table 9. Average Total Performance Index of Four Paths for PPID and L1 Adaptive Controller63

Table A1. Maximum Tracking Errors of PPID and L1 Adaptive Controller for Figure 8 Path. .67

Table A2. Mean Tracking Errors of PPID and L1 Adaptive Controller for Figure 8 Path.........68

Table A3. Standard Deviation of Tracking Errors of PPID and L1 Adaptive Controller for Figure 8 Path.

Table A4. Integral of Control Surface Deflection Rate of PPID and L1 Adaptive Controller for

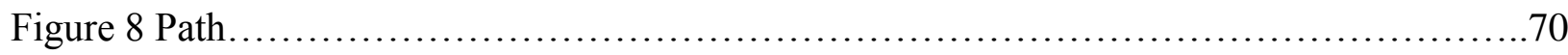

Table A5. Saturation Index of PPID and L1 Adaptive Controller for Figure 8 Path...............71

Table A6. Performance Indices of PPID and L1 Adaptive Controller for Figure 8 Path...........72

Table B1. Maximum Tracking Errors of PPID and L1 Adaptive Controller for Oval Path........74

Table B2. Mean Tracking Errors of PPID and L1 Adaptive Controller for Oval Path.............75

Table B3. Standard Deviation of Tracking Errors of PPID andL1 Adaptive Controller for Oval

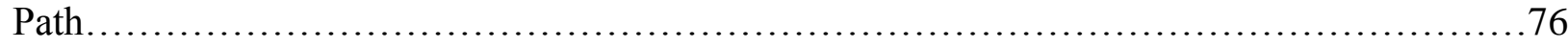


Table B4. Integral of Control Surface Deflection Rate of PPID and L1 Adaptive Controller for Oval Path.

Table B5. Saturation Index of PPID and L1 Adaptive Controller for Oval Path................78

Table B6. Performance Indices of PPID and L1 Adaptive Controller for Oval Path...............79

Table C1. Maximum Tracking Errors of PPID and L1 Adaptive Controller for OA Path...........81

Table C2. Mean Tracking Errors of PPID and L1 Adaptive Controller for OA Path................82

Table C3. Standard Deviation of Tracking Errors of PPID and L1 Adaptive Controller for OA

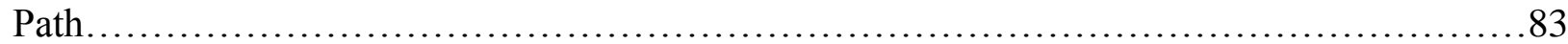

Table C4. Integral of Control Surface Deflection Rate of PPID and L1 Adaptive Controller for OA

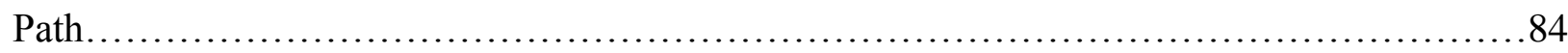

Table C5. Saturation Index of PPID and L1 Adaptive Controller for OA Path.................85

Table C6. Performance Indices of PPID and L1 Adaptive Controller for OA Path.............86

Table D1. Maximum Tracking Errors of PPID and L1 Adaptive Controller for 3D S-

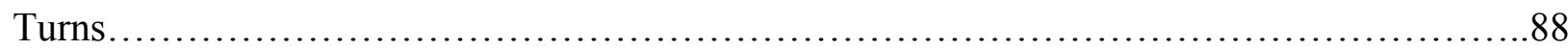

Table D2. Mean Tracking Errors of PPID and L1 Adaptive Controller for 3D S Turns...........89

Table D3. Standard Deviation of Tracking Errors of PPID and L1 Adaptive Controller for 3D S

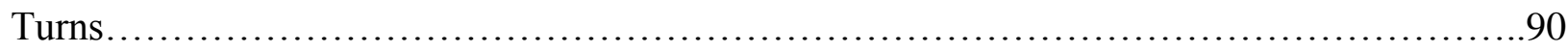

Table D4. Integral of Control Surface Deflection Rate of PPID and L1 Adaptive Controller for 3D

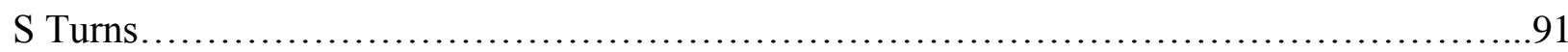

Table D5. Saturation Index of PPID and L1 Adaptive Controller for 3D S Turns................92

Table D6. Performance Indices of PPID and L1 Adaptive Controller for 3D S Turns............93 


\section{LIST OF SYMBOLS AND ACRONYMS}

\begin{tabular}{|c|c|c|}
\hline A & State-Space System Matrix & \\
\hline B & State-Space Control Matrix & \\
\hline C & State-Space Output Matrix & \\
\hline P & Roll Rate & $\mathrm{deg} / \mathrm{s}$ \\
\hline q & Pitch Rate & $\mathrm{deg} / \mathrm{s}$ \\
\hline $\mathrm{r}$ & Yaw Rate & \\
\hline $\mathrm{u}$ & Vector of Inputs & $\mathrm{m} / \mathrm{s}$ \\
\hline V & Velocity & \\
\hline X & Vector of State Variables & \\
\hline$x_{r}$ & Vector of State Variables of the Reference Model & \\
\hline y & Vector of Output Variables & \\
\hline
\end{tabular}

\section{Greek Letters}

\begin{tabular}{|c|c|c|}
\hline$\alpha$ & Angle of Attack & deg \\
\hline$\beta$ & Sideslip Angle & $\operatorname{deg}$ \\
\hline$\gamma$ & Slope Angle & $\operatorname{deg}$ \\
\hline$\delta_{a}$ & Deflection of the Aileron Surfaces & $\operatorname{deg}$ \\
\hline$\delta_{e}$ & Deflection of the Elevator Surfaces & $\operatorname{deg}$ \\
\hline$\delta_{r}$ & Deflection of the Rudder Surfaces & $\operatorname{deg}$ \\
\hline$\theta$ & Pitch Angle & $\operatorname{deg}$ \\
\hline$\phi$ & Roll Angle & $\operatorname{deg}$ \\
\hline$\psi$ & Yaw Angle & $\operatorname{deg}$ \\
\hline
\end{tabular}




\section{Acronyms}

\begin{tabular}{|c|c|}
\hline DOD & Department Of Defense \\
\hline FAA & Federal Aviation Administration \\
\hline FTCL & Fault Tolerant Control Laws \\
\hline GUI & Graphical User Interface \\
\hline IAI & International Association for Identification \\
\hline ILC & Inner Loop Controller \\
\hline LAT & Longitudinal Dynamics \\
\hline LON & Linear Quadratic Regulator \\
\hline LQR & Model Reference Adaptive Control \\
\hline MRAC & Outer Loop Controller \\
\hline OLC & Position Proportional Integral and Derivative control \\
\hline PPID & Research ANd Development \\
\hline RAND & Unmanned Aircraft \\
\hline UA & Unmanned Aerial Systems \\
\hline UAS & Unmanned Aerial Vehicle \\
\hline UAV & West Virginia University \\
\hline WVU &
\end{tabular}




\section{INTRODUCTION}

The unmanned aerial vehicle (UAV) can either be remotely controlled outside the visual field by a pilot at a ground station or it can fly autonomously driven by an advanced auto pilot system [1]. Adequate trajectories reaching targets and avoiding obstacles and interdiction zones must be precomputed or established on-line during operation. UAVs have become prominent in a variety of civilian and military applications. Civilian UAVs are used in a wide variety of situations such as: pipeline monitoring, oil and gas infrastructure security, wildfire detection and management, law enforcement, TV broadcast relay, pollution monitoring, public event security, traffic monitoring, disaster relief, fisheries management, meteorology phenomena(storm) tracking, remote aerial mapping and transmission line inspection [2] [3] [4] [5]. The military applications of UAVs are equally diverse and include, without being limited to, search and rescue, hostile activity monitoring, weapon impact assessment and management, telecommunications, equipment and munitions delivery, combat, security and control, aerial reconnaissance and surveillance, aerial traffic coordination, battlefield management, chemical, biological, radiological and nuclear conditions management [6] [7] [8] [9].

The Federal Aviation Administration (FAA) uses the concept of Unmanned Aerial System (UAS) in reference to advanced complex systems of multiple agents that include the ground stations, communication systems, human operators, and potentially numerous vehicles in the air, on the surface, and/or under the sea with different levels of intelligence and autonomy [1]. A large number of research efforts have been recently directed towards increasing the performance, robustness, safety, and reliability of UAVs and UASs [10]. The main objective of this thesis is to implement and analyze an efficient fault tolerant control system that can provide good UAV trajectory tracking under normal and abnormal operational conditions.

\subsection{Why Unmanned Aircraft?}

In general, unmanned aircraft are used in "dull or dirty or dangerous missions" where the operation of manned aircraft may be undesirable, inefficient, expensive, or limited [10]. Long duration operations that are low workload and intensity are best suited for UAVs. Such tasks can be automated with minimum human supervision resulting in significant savings. For example, in 
1999, the B-2 flight with two pilots took 30hours to make a round trip from Missouri to Serbia [11]. The post-Kosovo RAND (Research ANd Development) assessment recommended doubling the number of pilots for such missions, which results in doubling the need for resources associated with training and operation. UAVs can provide an inexpensive alternative for such missions.

Operation in contaminated environment such as collecting radioactive samples after nuclear tests or explosions is another example when UAV use proves extremely beneficial. In 1948, Air force and Navy used manned aircraft to collect radioactive samples immediately after nuclear tests with two crew wearing 60-pound lead suits [12]. Unfortunately the crew died because of the long term exposure to radiation. UAV is also used for airborne sampling or observation mission related to chemical, biological, radiological, and nuclear defense.

UAV scan also be used effectively in dangerous military missions such as operations involving reconnaissance over enemy territory or combat, which often may result in loss of human lives. A Predator UAV launched Hellfire missile, which destroyed a vehicle carrying suspected terrorists in Yemen in November 2002 [12]. This mission was completed without putting American lives at risk.

UAVs are also used frequently by fire brigades for detecting and monitoring fires in inaccessible locations or when smoke and flames would make the presence of humans too dangerous [10]. Other examples of UAV include rescue missions, support of littoral maneuver, range of electronic warfare tasks, and air to air refueling tanker [13][14].

\subsection{Failure Statistics of Manned and Unmanned Aircraft}

According to FAA, the main threats to aircraft safety are human errors, sensor failures, mechanical and structural failures, subsystem failures, and adverse weather conditions [15]. FAA has a set of codes of regulations that is mandatory for all manned aircraft. The FAA certification process ensures the adequate level for aircraft design and operation safety [16]. As a consequence, the rate of failure has decreased in recent times for manned aircraft. In the case of UAV, there is no specific code of regulations and the rate of failure for these systems is one hundred times higher than that of manned aircraft. The estimated UAV failure rate is one in every one thousand flight hours. This high failure rate is primarily due to the flexible design methods and low system reliability [17]. To 
improve the system reliability, significant efforts have been directed towards the development of fault tolerant control laws in recent years[17].

Figure 1 shows the distribution of accident causes for manned aircraft obtained from reference [18] accident database. The accident database includes 1085 fatal accidents of commercial aircraft from 1950 to 2010. The accidents are classified as due to pilot error, pilot error related to mechanical and weather conditions, other human error, weather, mechanical failure, sabotage, and other causes. Figure 1 shows that the failure due to the pilot error is the most frequent, that is $60 \%$ to $70 \%$. It seems reasonable to assume that automatic aircraft without human pilot would produce fewer accidents. However, the statistics of UAV accidents show the opposite. The failure rate in UAV is higher as compared to manned aircraft. It is estimated that UAVs experience one serious safety incident every 1000 hours of flight. The reliability and robustness of UAV should be increased and one primary way to achieve that is by improving the autopilot system used in the UAV.

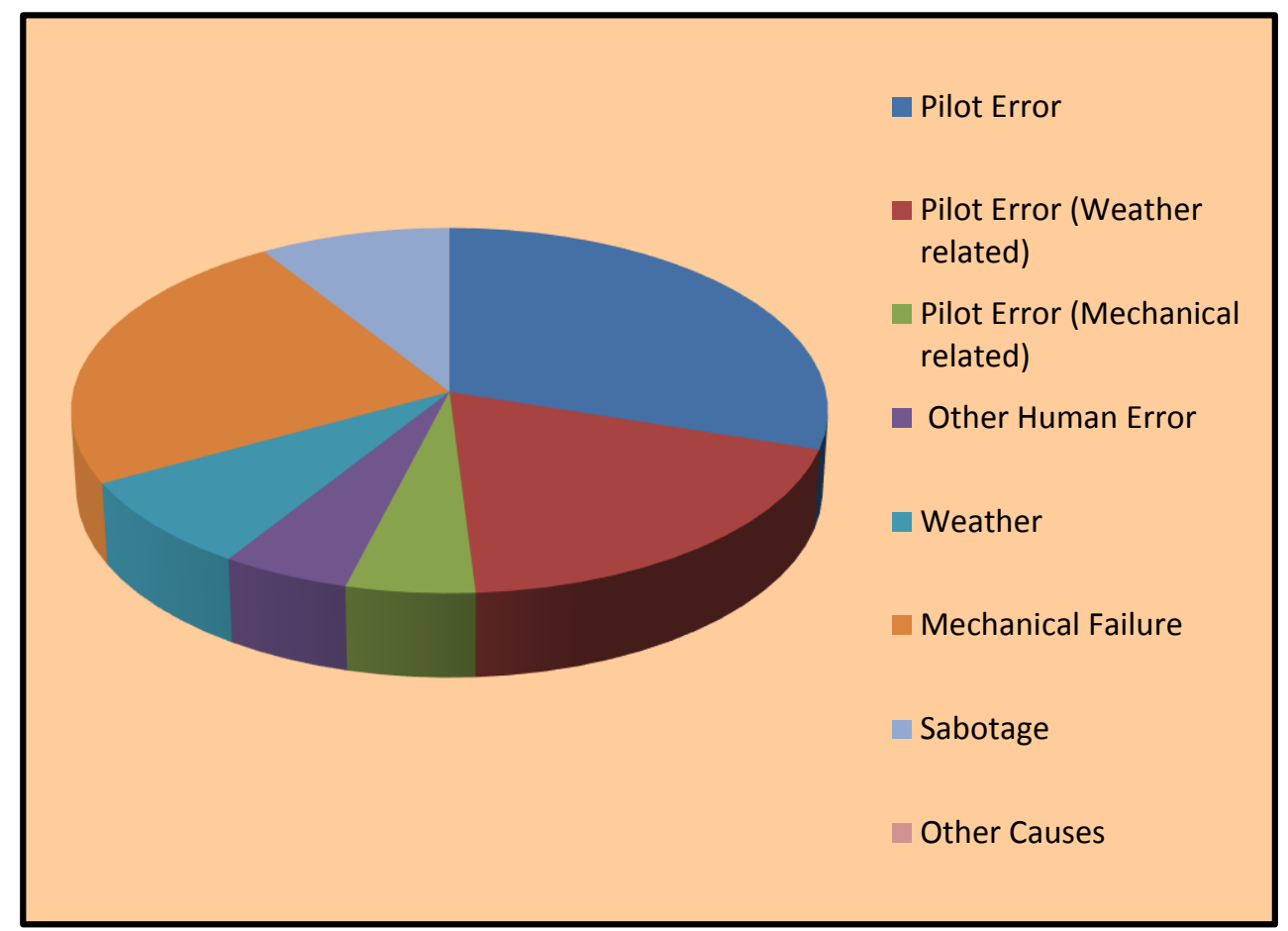

Figure 1. Manned Aircraft Accident Cause Distribution

UAV accidents are primarily caused by conflicting interactions between human, machine, and environment. At the end of a failure investigation, three questions should be answered: what 
happened, why did it happened, and what to do in future to avoid repetition [19]. The most frequent failures are due to material failure, environment, design flaws, and human error. Very often, accidents result through a combination of several system root causes. The US Army UAV accident database includes fifty six accident cases from 1995 to 2005. Figure 2 shows the distribution of failure causes of unmanned aircraft. According to Figure 2, thirty seven percent of all UAV failures are due to material mishaps, eleven percent to pilot error, thirty two percent is the result of a combination of human error, design flaw and material failure and thirty percent are due to unknown causes [19].

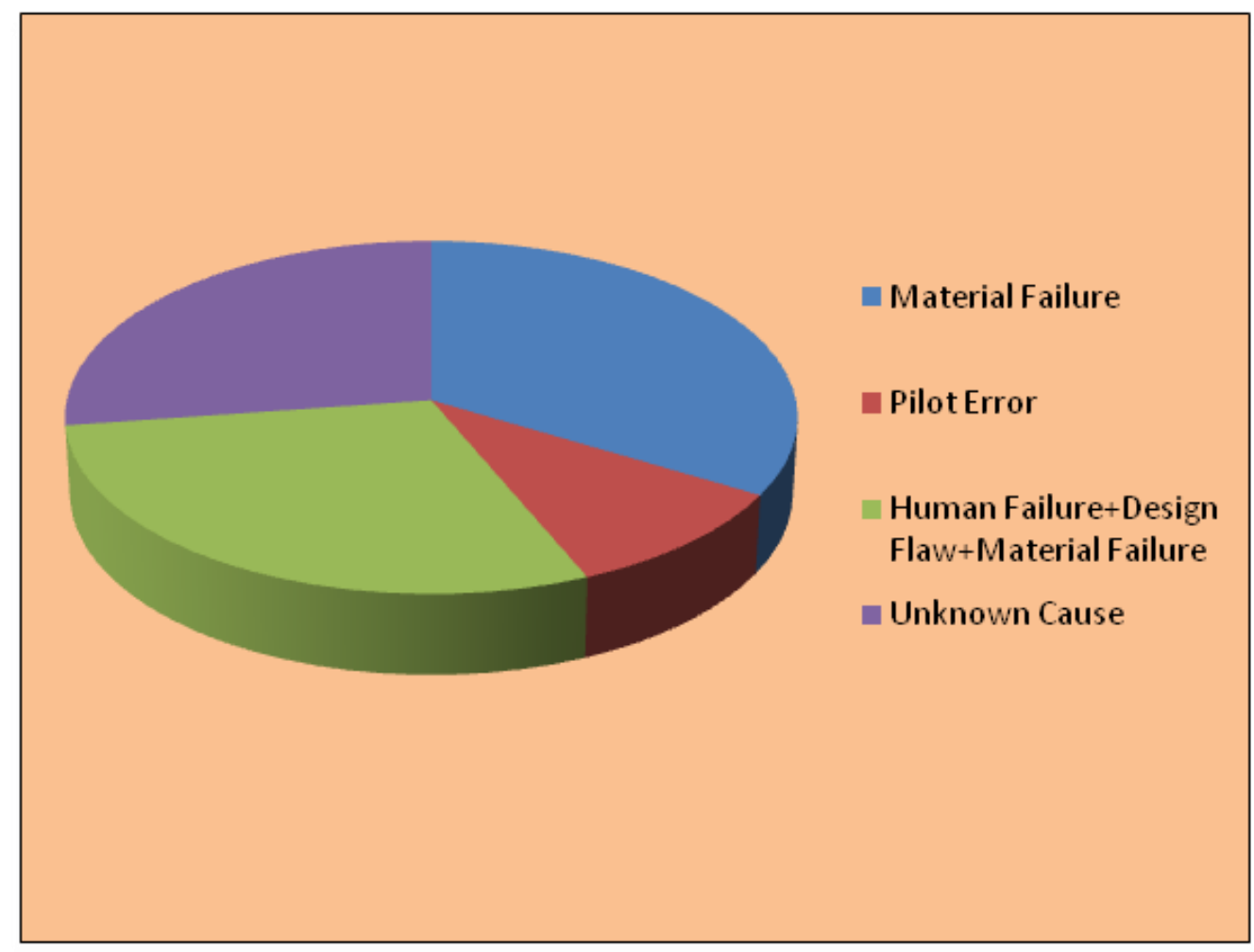

Figure 2. UAV Accident Cause Distribution

The number of material failures can be reduced through better maintenance. The design flawrelated accidents could be reduced through FAA regulations on the design process considering that, while such regulations are inexistent for UAV, they prove quite effective for manned aircraft. Recent proposals are to implement an FAA standard for UAV. One other set of prominent accidents are caused by errors of the pilot who remotely controls the aircraft via telecommunication linkages. A large number of UAV mishaps turned up during the takeoff and landing where pilot 
commands are directly and critically involved. Alternatively, increasing the autonomy of UAV through the development and implementation of advanced fault tolerant control laws is expected to significantly improve the operational safety.

\subsection{Control Laws for Autonomous Flight}

A critical element for the good performance of UAVs in all their applications consists of following the required trajectory with good accuracy. Designing trajectory tracking control laws with good performance and robustness represents a challenging, but critical task. There are two large categories of controllers: conventional controllers and adaptive controllers. Conventional controllers use fixed structure and parameters. They are typically designed for limited operational conditions and rely on intrinsic robustness for adequate operation outside design ranges. Strong mathematical backgrounds have been developed for this category of control laws that provide certain levels of guarantees in terms of stability and performance. Adaptive controllers have the capability to modify their structure and/or the values of their internal parameters according to changes in the environment. In particular, significant progress has been recorded recently in the development of control laws that modify the values of their internal gains in response to changes in the flight conditions, thus featuring a type of dynamic robustness that is very promising ensuring good performance over the entire flight envelope at both normal and abnormal conditions. The adaptive controllers are expected to be more robust and reliable; however, a solid theoretical background is still under construction and consistent certification procedures are still to be developed and accepted, which currently prevents the adaptive control technologies from being used in commercial applications.

\subsection{Research Objectives}

The objective of this research effort is to implement autonomous flight L1 adaptive control laws in the WVU UAV flight simulation environment and to perform a comparison study between the L1 adaptive controller and the baseline conventional controller, which relies on position proportional and integral compensation. Special attention is given to the performance of the proposed control laws in the presence of abnormal conditions. The abnormal conditions considered are locked actuators (stabilator, aileron, and rudder) and excessive turbulence. A set of comprehensive evaluation metrics is used to analyze the performance of autonomous flight control 
laws in terms of control activity and trajectory tracking errors. It should be noted that the effects of various factors on the performance of the baseline controller and the adaptive augmentation are analyzed in order to identify if they have an impact on the relative ranking of the two sets of control laws. The implementation is performed using MATLAB/Simulink within the WVU UAV simulation environment [20] [21].

The thesis is organized as follows: Chapter II presents a literature review of current fault tolerant control laws in manned and unmanned aircraft. This chapter includes a brief introduction to different controllers and outlines the advantages of the L1 approach over other controllers. Chapter III describes the architecture of the WVU UAV simulation environment and the integration of L1 within the environment. Chapter IV describes the development of the L1 control laws. This chapter refers to the mathematical proofs of the $\mathrm{L} 1$ controller in the Appendix A. The implementation of L1 adaptive controller is described in Chapter V. Chapter VI presents the analysis of the performance of the adaptive control laws. This chapter includes the experimental design, definition of evaluation metrics, testing, numerical results, and analysis of the performance of L1 versus a conventional baseline controller. Chapter VII summarizes the conclusions of this research effort and provides some suggestions for future work involving the L1 adaptive controller. 


\section{LITERATURE REVIEW}

\subsection{History of UAV}

The history of UAV is vast and diverse from the early years of aviation to the current days. The first UAV can be considered to be the balloon loaded with explosives that flew over Venice in 1849 [22]. In 1916, the first heavier than air UAV, the Hewitt-Sperry Automatic Airplane was demonstrated. It was named right after the inventors, Hewitt and Sperry [22]. This aircraft become a reality with the previous work of Sperry on gyroscopic devices that were required to provide flight stabilization [22]. Other remarkable early UAVs are Curtiss-Sperry Aerial Torpedo and Liberty Eagle Aerial Torpedo [23].

In Britain, the experiments with UAV begin with RAE Target, in 1921 [23]. The British Royal Navy used basic radio controlled UAVs, Queen Bee, in 1930. Queen Bee could be landed and reused and could reach speeds of up to $160 \mathrm{~km} / \mathrm{h}$ [24]. Queen Bee is the modified version of the DeHavilland Tiger Moth biplane [22].

Remote operation of aerial vehicles, required the perfection of radio control, which was proposed in 1895 by Tesla [24]. The private industry "Reginald Denny Hobby Shops" started selling radio controlled airplanes in 1934. A few years later the US Army developed a successful target drone which was extensively used during World War II. The SD-1, known as the MQM-57 Falconer, was developed in 1950 [25]. MQM-57 Falconer was remotely operated, carried a camera, and after a 30 minute flight returned to base and it was recovered using a parachute [25].

The drones for reconnaissance missions by US over China, Vietnam, and other countries in the 1960s and 70s [24] were based on the Ryan Model 147. The Ryan Model 147, also known as the Lightning Bug, was the first unmanned aircraft that could withstand today's definition of a UA. In the meantime, the US Navy acquired a helicopter drone called the QH-50 DASH [23] which was preferred because it could be launched from smaller vessels. QH-50 DASH was used to launch antisubmarine torpedoes, to perform surveillance, for cargo transport, and for other applications. QH-50 DASH was reliable, but still it had issues with its electrical system that led to large number of losses [25]. 
The Soviet Air Force developed its own reconnaissance drones. A first drone was TBR-1. TBR-1, was followed by the DBR-1 that allowed for higher range and capabilities [25]. The DBR-1 was less used because of the operational costs.

In Europe, the unmanned system CL-89 Midge was designed to follow a pre-programmed course, take photographs and return to base to be recovered by parachute [25]. In the late 1970, the CL289 was developed for better performance [25].

Israeli Aircraft Industries developed the Scout and Mastiff [25] in the 70's. Pioneer, Predator, and Shadow UAS [26] are based on these designs.

In more recent years, the RQ-4 Global Hawk was designed as a large, high altitude, long endurance system. The MQ-9 Reaper was specifically designed as a combat UAV or a "hunter killer" and has been extensively used on battlefields. The DRS-RQ-15 Neptune is a reconnaissance UAV designed to operate over water. In Britain, the BAE Phoenix is used for combat surveillance, while the French-built SPERWER supports a number of other European armed forces [26]. In the Russian Federation, there are several companies involved with UAS development. Although numerous Unmanned Combat Aircraft Systems (UCAS) are in experimental stages, there are several that are operational, besides the ones mentioned. They includes the Neuron, the Barracuda, the Italian Sky-X, the MiG Skat, the General Atomics Avenger, the BAE Mantis, and the Northrop Grumman X-47 system. UAS based on rotary wing aircraft include the A-160 Hummingbird, the APID55, the Schiebel S-100, and the MQ-8 Fire scout [26]. A large number of long endurance systems are also used for civilian applications. For example, NASA employs Helios, Altair, and Ikhana.

\subsection{Types of UAV}

There are different types of UAV: target and decoy, reconnaissance, combat, research and development, civil and commercial. The target and decoy involve the unmanned vehicle used on earth and in air to destroy the foe vessels. Reconnaissance UAVs are used to gather intelligence, perform mapping, or assess status after events such as earthquakes or hurricanes. The unmanned combat air vehicle is used for the high risk missions on the battlefield. The civil and commercial UAV are uniquely designed for commercial purposes, such as product delivery or advertising. The 
research and development UAVs provide inexpensive but flexible platforms for design and testing of new technologies [27].

\subsection{UAV Sub-system Failures}

Figure 3 shows the source distribution of system failures causing major UAV safety incidents provided by the International Association for Identification for a RQ-1A/Predator fleet over 100,000 hours of operation in 2002 [28]. The primary sources of catastrophic UAV failures are: propulsion system, flight controls, human error, and communication system and link.

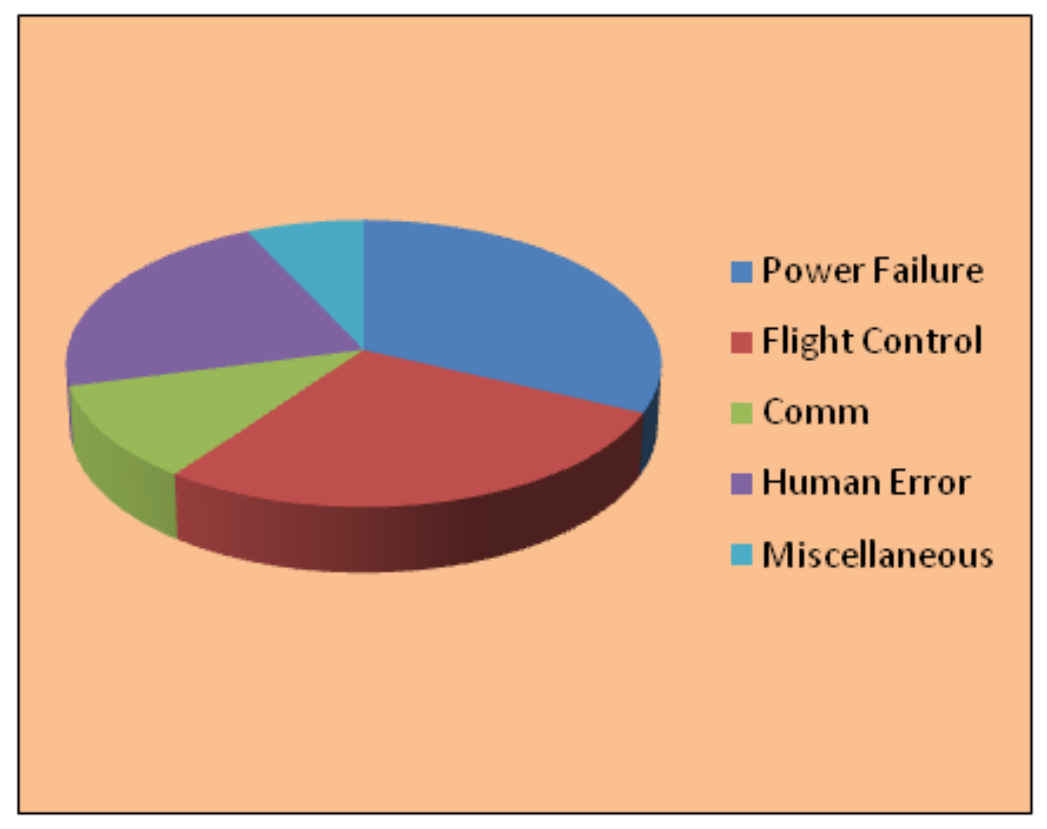

Figure 3. Average Sources of System Failures for IAI UA Fleet

The most frequent cause for UAV accidents is power or propulsion failure, which occurs due to mishaps in the engine, provision of power, transmission, propeller, electrical system, generators, or other secondary devices. From Figure 3, it is estimated that thirty two percent of the total number of failures are propulsion failures. For example, the solar powered Helios crashed during a test flight in 2003. The test was carried out at night to ensure that the solar powered wing can manage to deliver the power without any interruption. The planned flight was about forty hours but the Helios crashed into the Pacific Ocean near the island of Kauai [29]. An MQ-1B Predator collapsed on Aug 22, 2012 in Afghanistan. According to [30] report mishap was due to failure of dual alternator. 
The second frequent failure affects the flight control system. The flight control devices include avionics, air data system, servo-actuators, control surfaces, on-board software, navigation instrumentation, and other associated accessories. For example, the experimental X-51A crashed into the Pacific Ocean on 14 August, 2012 due to a failure of the control fin. After sixteen seconds into the flight, sensors detected the malfunction of the control fin, which prevented the crew from maintaining control of the aircraft [31]. Actuator failures may include locked control surface, missing or damaged control surface, free floating surface, reduced control effectiveness, or combinations of them. Actuator failures affect primarily the linkage system and the aerodynamic control surfaces. They can occur due to a variety of causes ranging from collision with an external object to acute structural failures with calamitous separation of elements. The RQ-4A Global Hawk UAV crashed on June 11, 2012 near the Naval Air Station Patuxent River in Maryland

during flight training. The accident occurred because of the failure of the right ruddervator actuator [32]. Sometimes the source of the actuator malfunction may reside with the ground station. The P175 Polecat UAV crashed during a Nevada test in December 2006 [33]. During the flight, the primary console PPO-1 locked up and it was necessary to switch to the back-up console PPO-2. When switching between two consoles, the control configurations of the two consoles should match. It didn't happen that day, resulting in a fuel cut off position that lead to the accident [33].

A drone crashed during a trip to Panama because of human error, the next category of most frequent UAV accident causes. The crew set the drone to 'fly-by-wire' instead of 'receiver failsafe'. As soon as the UAV flew out of radio range, control was lost and the aircraft collapsed within seconds [33].

The fourth most common cause of UAV incidents is the malfunction of the communication link between UAV and the ground station. For example, an MQ-1B Predator crashed on September 18, 2012 due to failure of the satellite data link [30].

Several other miscellaneous sources such as operating and scheduling problems, non-technical factors, or weather are also reported to produce major incidents and accidents [34].

\subsection{Controllers}

Autopilots or automatic pilots are devices for controlling the vehicles without constant human intervention [35]. These control systems are typically categorized as conventional or fixed- 
parameter controllers and adaptive controllers. A typical commonly used architecture for trajectory tracking consists of an inner/outer loop structure [36] [37]. The inputs to the outer loop are trajectory-defining variables such as waypoints and desirable vehicle velocity. Kinematic equations are used to obtain necessary attitude angles and rates, which are the inputs to the inner loop. These are then converted into deflections of the aircraft aerodynamic control surfaces.

\subsubsection{Conventional Controllers}

Conventional controllers play a vital role in the industry because of their transparent structure, simplicity, and adequate performance. Extensive theoretical background and design methodologies are typically available for a variety of different approaches [38], such as pole placement, linear quadratic optimal regulator controller and proportional, integral, and derivative (PID) [39].

The pole placement or pole assignment technique is a linear approach based on locating the poles of the closed loop system such that the desirable dynamic response is ensured. It is applicable to systems that are completely observable and controllable. A dynamic feedback linear controller using pole placement and Kalman filtering is used to control a UAV in [40]. In many problems, exact pole placement is not necessary, it is sufficient to locate the pole of the closed loop system in a sub-region of the complex left half plane [41].

Linear quadratic control approaches have been widely used for both fixed wing [42] and rotary wing UAVs [43]. The linear quadratic regulator (LQR) has been demonstrated to be effective in numerous UAV applications [44]. In [45] a gain-scheduled LQR controller is developed for an autonomous airship. The augmentation of LQR control laws with Kalman filtering has been shown to improve disturbance rejection and the overall effectiveness of the control system [46].

Due to their simplicity, effectiveness, and solid theoretical background, PID controllers are a very popular solution for UAV applications [47] [48], including fixed wing [49], rotary wing [50], quadrotors [51] [52] [53], and lighter-than-air UAVs [54]. Both inner and outer loop can be designed based on PID compensation [49]. A simple approach uses altitude and heading as inputs; however, better tracking performance can be achieved with waypoint inputs [55]. 
Kinematic and dynamic aircraft models can be used to obtain the required states and controls given desired position and velocity, through a model inversion process [56]. Typically, inversion is used for the outer loop, while other control design methods are used for the inner loop [57] [58] [59]. However, improved performance can be obtained if the inversion approach is extended to the inner loop as well [60].

\subsubsection{Adaptive Controllers}

An adaptive controller has the capability to modify its structure and/or parameters (gains) depending on current operational conditions. While modifying the structure of the controller is possible, most design methodologies for adaptive control systems consider only the variation of the gains. Aircraft operate over wide ranges of speed and altitude and their dynamics are time varying and non-linear. This makes them primary candidates to benefit from adaptive control laws.

Control system design in linear domain requires that, for a given aircraft speed and altitude, the complex dynamic equations are approximated by a linear model. For example, at operating point $\mathrm{i}$, the equations of motion are:

$$
\begin{gathered}
\dot{x}(t)=A_{i} x(t)+B_{i} u(t), x(0)=x_{0}, \\
y(t)=C_{i}{ }^{T} x(t)+D_{i} u(t)
\end{gathered}
$$

where $A_{i}, B_{i}, C_{i}, D_{i}$ are state space constant matrices at operating point. As the aircraft flies to a different operating point, these matrices change. The control system designed for one operating point may not be adequate at a different operating point. Therefore, the parameters of the control laws must be adjusted depending on current operational conditions. Figure 4 shows the feedback controller with adjustable gains and the plant. A variety of methodologies can be used to achieve the variation of the controller gains in response to variations in the plant and external conditions [61]. 


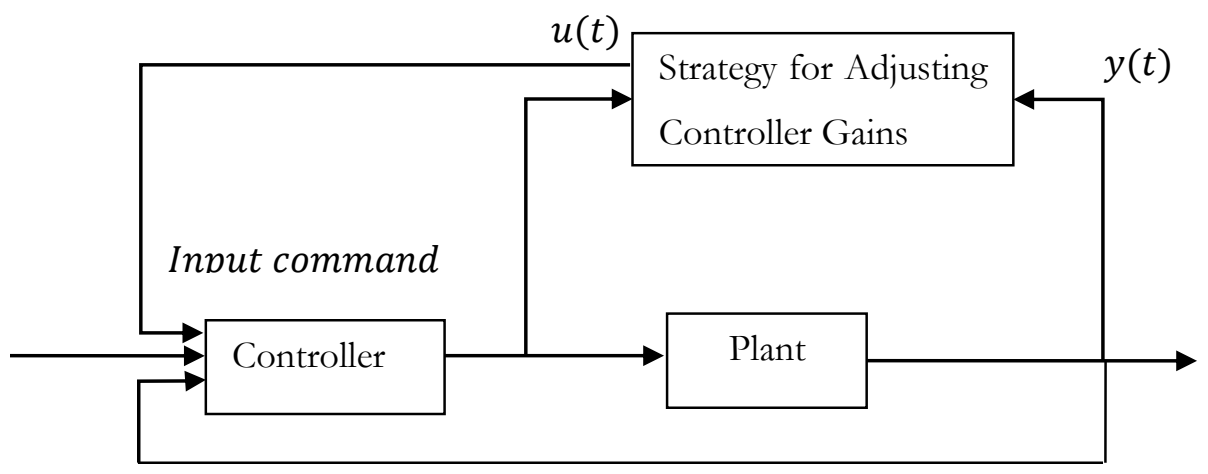

Figure 4. General Structure of Adaptive Controller

Gain scheduling [62] [63] can be considered as the simplest adaptive technique. It consists of selection and use of appropriate gains from a set of gain values that has been pre-computed. By selecting suitable gain values depending on the operating point, the performance of the controller may be greatly improved. The previously designed linear controllers may each satisfy strict robustness and performance criteria at a given operating point. The advantage of gain scheduling resides in the potential of achieving optimal operation at the design operating points. One significant disadvantage of the approach is the need for, possibly, frequent and rapid changes of controller gains, which may deteriorate performance in the transition and even lead to instability. One other limitation is the high design and implementation costs, which increase rapidly with the number of operating points.

One of the most popular methods for aircraft control system design is feedback linearization. The non-linear dynamic inversion (NLDI) [64] calculates the non-linear control signal using an inverse transformation. For a high fidelity plant model, the cancellation of non-linearity is achieved through the transformation. However, for high-performance practical applications, modeling uncertainties and errors must be compensated for by using adaptation mechanisms. Artificial neural networks [65] have been used to augment NLDI control laws [66]. The artificial neuron is a simple computational unit inspired by the biological neuron. In a similar manner as its biological counterpart, the artificial neural network possesses significant capabilities for distributed information processing and parallel computing [67]. It can accurately approximate complicated multi-dimensional non-linear functions by "learning" the input/output relationships of large sets of experimental data. Therefore, it can model and predict complex dynamics and provide adequate 
adaptive control compensation when the controlled system changes due to external or internal conditions [68].

Fuzzy logic [69] has been used for aircraft adaptive control including UAV. As opposed to binary logic where a statement can only be true or false, within fuzzy logic, a statement can be true, false, or anything in between. This allows the transfer of human operator control experience formulated through common language as "IF-THEN" conditional propositions. Fuzzy logic has been applied to nonlinear systems [70], which lack complete analytical models. The dynamics of a system can be constructed from knowledge of similar systems using fuzzy logic arguments, and a fuzzy controller can be constructed via conditional proposition decisions [71] [72].

The Model Reference Adaptive Control (MRAC) methodology [73] is derived from the model reference control (MRC) approach. Figure 5 shows the architecture of MRAC. The main aim of MRC is to find the feedback control law that changes the structure and dynamics of the plant to obtain a desired response, which is represented by the reference model. MRAC has the ability to recover nominal performance in the presence of uncertainties, but is typically subject to time delay. One attractive characteristic of MRAC architecture is that rigorous stability proofs are available [74].

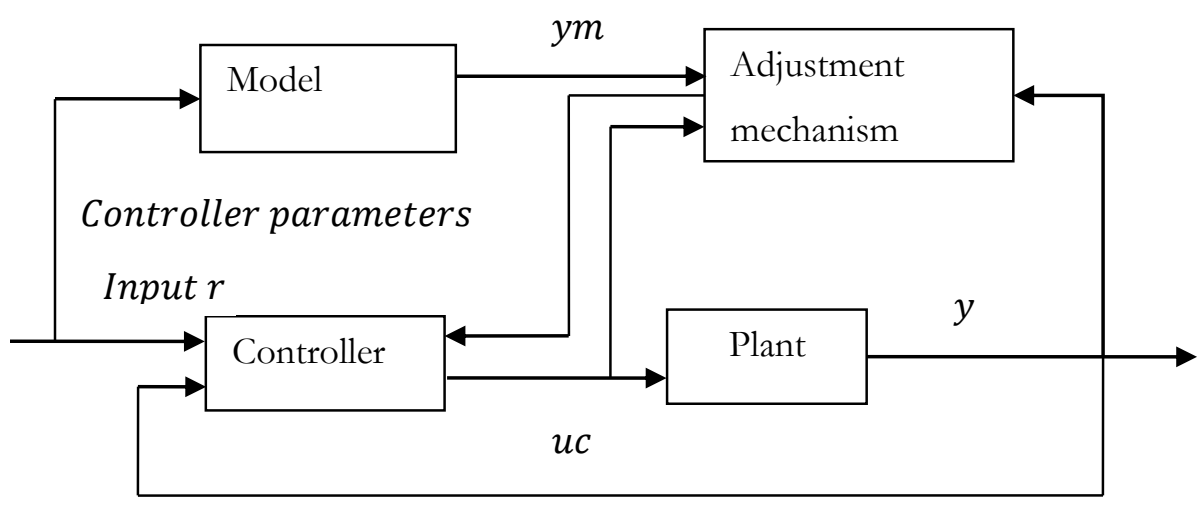

Figure 5. General Structure of MRAC

This increases the use of MRAC in many aeronautical applications [75]. To ensure robustness of the MRAC, dead zone have been proposed [76]. The main disadvantage of dead zone is time delay and slow convergence of the tracking error [69] [77]. The tendency to increase output frequency 
of the control unit increases the adaptation rate. As a consequence, the speed of convergence decreases [78]. To mitigate these issues, a filtered version of MRAC has been proposed known as L1 adaptive controllers [79] [80] [81]. Figure 6 shows the architecture of L1 adaptive controller. The low pass filter used in L1 ensures a bandwidth limited control signal and high adaptation rate [82] [83]. The main advantage of L1 adaptive controller over MRAC is that L1 clearly separates performance, robustness, and high adaptation rate [84]. The L1 architecture permits robustness of the system in the presence of fast adaptation. L1 adaptive control has three distinct components. First, a state predictor law models the system's desired performance. Second, an adaption law ensures the plant and state estimates are same. Finally, a control law utilizes a low pass linear filter to eliminate high frequency in the control channel. This allows the use of high gains without the adverse effect on robustness.

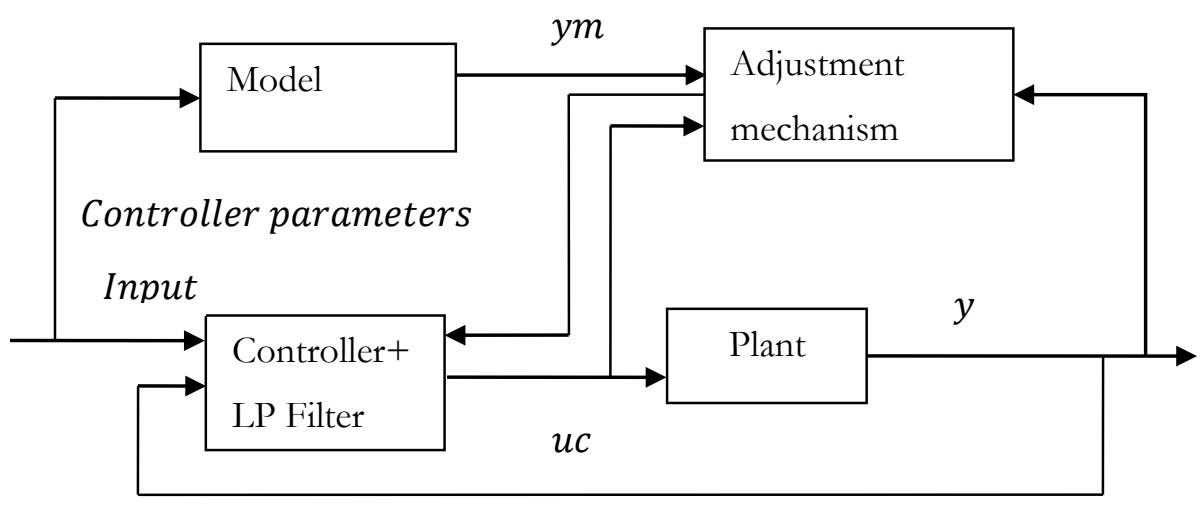

Figure 6. General Structure of L1 Adaptive Controller

L1 control could be implemented to obtain faster response compared with the conventional methods. The design of L1 adaptive controller reduces tuning of gains to achieve desired characteristics in presence of failures. The techniques used for the convergence are Lyapunov or passivity techniques and averaging theory [85] [86] [87] [88]. The Lyapunov method of developing adaptive laws is based on the direct method of Lyapunov and its relationship with positive real functions [89] [90] [91] [92]. In this method, the problem of designing an adaptive law is approached as a stability problem where the differential equation of the adaptive law is chosen such that certain stability conditions based on Lyapunov theory are satisfied. In addition, some 
studies suggest that the Lyapunov-based adaptive control schemes achieve higher performance than MIT rule-based schemes [93] [94] [95] [96] [97] [98].

L1 has been successfully demonstrated on drilling systems [99], wing rock compensation [100], and other flight control systems [55]. Additionally, adaptive control has been successful tested on NASA's AirSTAR test vehicle [101]. On June 2nd 2010, a test flight of the AirSTAR was performed with an all-adaptive flight control system in Fort Pickett, VA. The adaptive controller guaranteed safe operation of the vehicle during the flight, and the pilot satisfactorily flew the specified tasks. 


\section{WVU UAV SIMULATION ENVIRONMENT}

The WVU UAV simulation environment is developed in MATLAB and Simulink to provide maximum flexibility and portability and allow for easy updating, extension, and implementation of new algorithms. The simulation environment is interfaced with Flight Gear [102] software package for visualization and with a $\mathrm{C \#}$ customized map generator and visual feedback environment referred to as UAV dashboard [103] .

The WVU UAV Simulation environment currently includes five aircraft models. Each aircraft model is connected within a specific Simulink model. Nonlinear equations of motion and aerodynamic models are implemented. The Simulink block of each aircraft accepts pilot control commands such as elevator, aileron, rudder, and throttle and inputs from the outside environment like steady wind, gusts, and turbulence. A variety of sensor, actuator, and propulsion system failures, as well as structural damages can be simulated. Extensive on-line data visualization and recording for later analysis are available. The simulation environment is a valuable tool for UAV control system design, verification, analysis, and comparison. Path planning and trajectory tracking are critical parts of the simulation environment. Several path planning algorithms are implemented ranging from simple grid-based approaches 3-dimensional Dubins and clothoidbased methods. Several trajectory tracking algorithms included in the simulation environment are designed to possess fault tolerant capabilities in the presence of abnormal conditions. Both fixedparameter or conventional algorithms and variable-parameter or adaptive algorithms are implemented.

\subsection{Graphical User Interface (GUI) for Simulation Setup}

The first step in operating the WVU UAV simulation environment is to setup the simulation scenario and initialize all the necessary variables. The Matlab script "WVUUAV.m" is executed first. It prepares the Matlab work space and opens the first interactive menu for the selection of a single or multiple vehicle simulation session. This menu is presented in Figure 7. It directs to the general GUI, where the user can select the other necessary parameters to run the simulation. The

user is required to provide input on the general GUI for each of the vehicles involved in the simulation. 


\title{
WVU UAV Simulation Environment
}

\author{
Version 2.0.6
}

Number of Vehicles:

(c) Single

Multiple

\author{
LAUNCH
}

\section{Figure 7. Number of Vehicles GUI}

Figure 8 shows the general GUI of the WVU UAV simulation environment. Several main simulation features must be selected here. The first one is type of aircraft to be simulated. There are five different aircraft implemented: WVU YF22, NASA GTM, Pioneer, Tiger Shark and OX. The only currently available map is San Francisco Bay Area. The navigation and control scenario includes options for trajectory generation and trajectory tracking. The generation of the commanded trajectory can be performed automatically with numerous methods, can consist of a pre-recorded path, or can be generated by a leading aircraft, which is flown manually. The trajectory tracking can be performed manually or autonomously using a variety of control laws algorithms, both conventional and adaptive. The "LOAD" button on the general GUI will ensure that all simulation scenario parameters are recorded. Activating the "VISUALS" button will start the two main visualization tools: FlightGear and UAV dashboard. FlightGear provides pilot view or aircraft external view with scenery associated with the current map. The UAV dashboard allows user definition of obstacles and restriction zones. Finally, the "LAUNCH" button navigates the user to the aircraft specific GUI for the selected UAV [20]. 


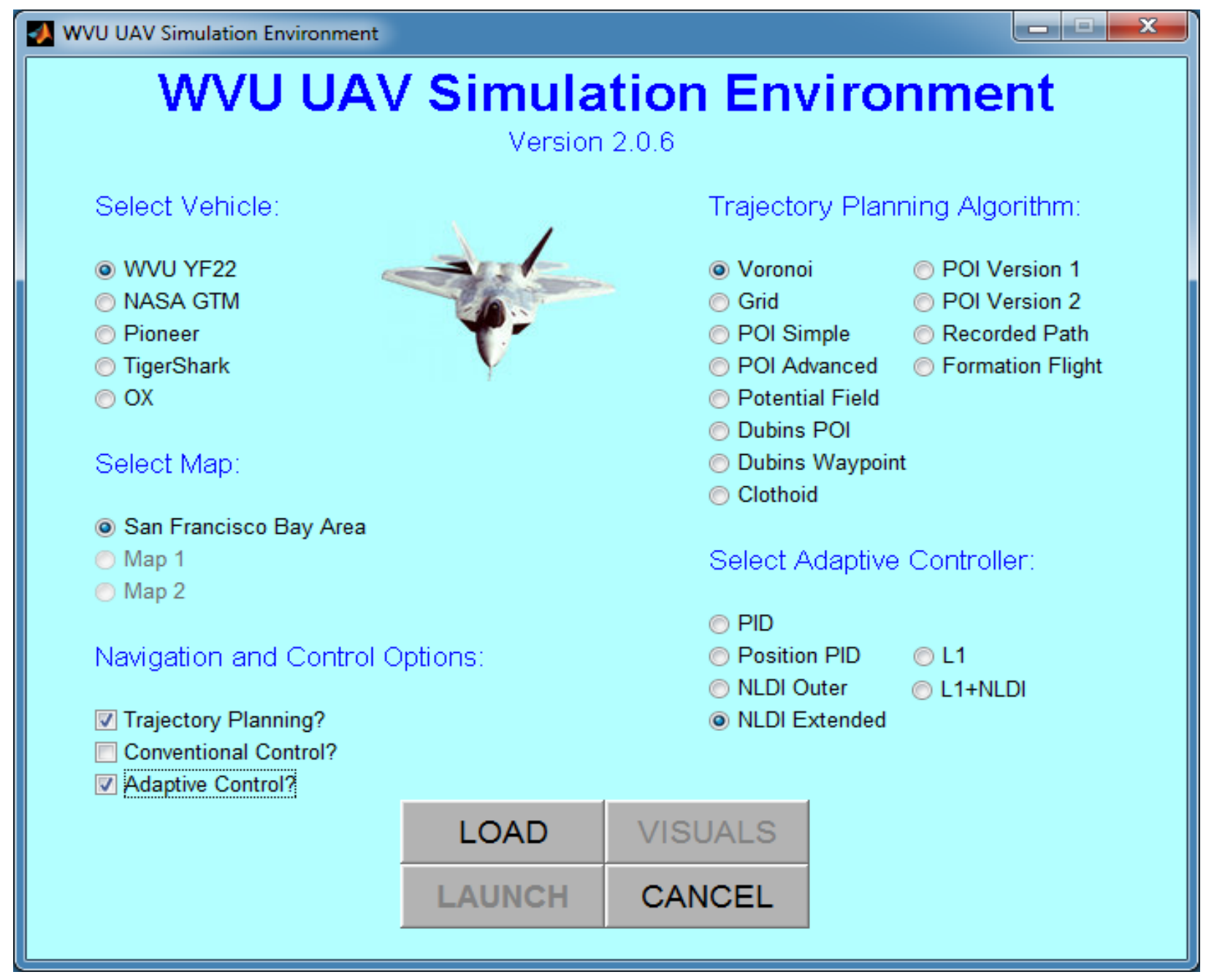

Figure 8. General GUI

The model of WVU YF-22 will be used within this research effort. This aircraft is a small UAV powered by a miniature jet engine with limited fuel capacity allowing about 12 minutes of flight [21]. The WVU YF-22 research UAV was designed based on the prototype of the U.S Air Lockheed/Boeing F-22 fighter aircraft. The aim of designing the WVU UAV was mainly for testing various fault tolerant control algorithms in flight.

Several path planning algorithms are included in the WVU UAV Simulation environment. Some allow for risk zone avoidance, while others ensure that desired points of interest are reached. A variety of different approaches are implemented ranging from grid, Voronoi, and potential field methods to 2- and 3-dimensional Dubins and clothoid-based methods. For more information about 
these algorithms, refer to [104]. In this research, different 2-D and 3-D recorded paths were considered [105].

The aircraft specific GUI allows the user to select the parameters for abnormal conditions that would affect the selected aircraft. Figure 9 shows the selection menu for control surface failure or sensor failure. The control surface failure option includes locked and/or missing aerodynamic control surfaces (left or right stabilator, aileron, or rudder) and sensor failure option includes a variety of malfunctions of the GPS and gyros. The user must select the type, severity, and moment of occurrence of the failure as shown in Figure 10.

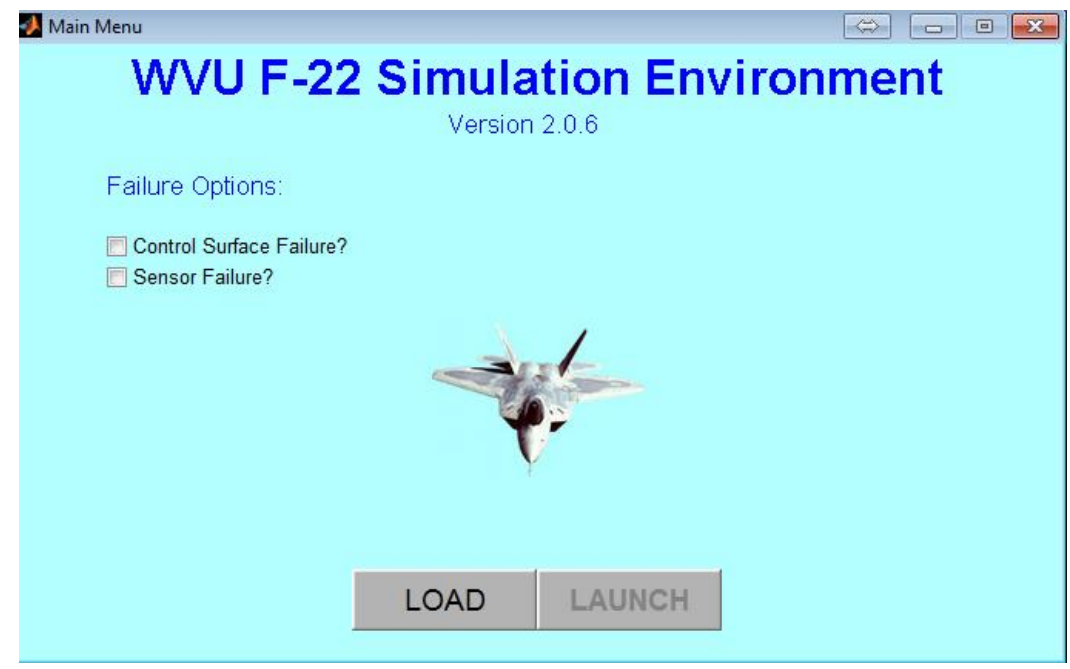

Figure 9. Aircraft Specific GUI for the WVU YF-22

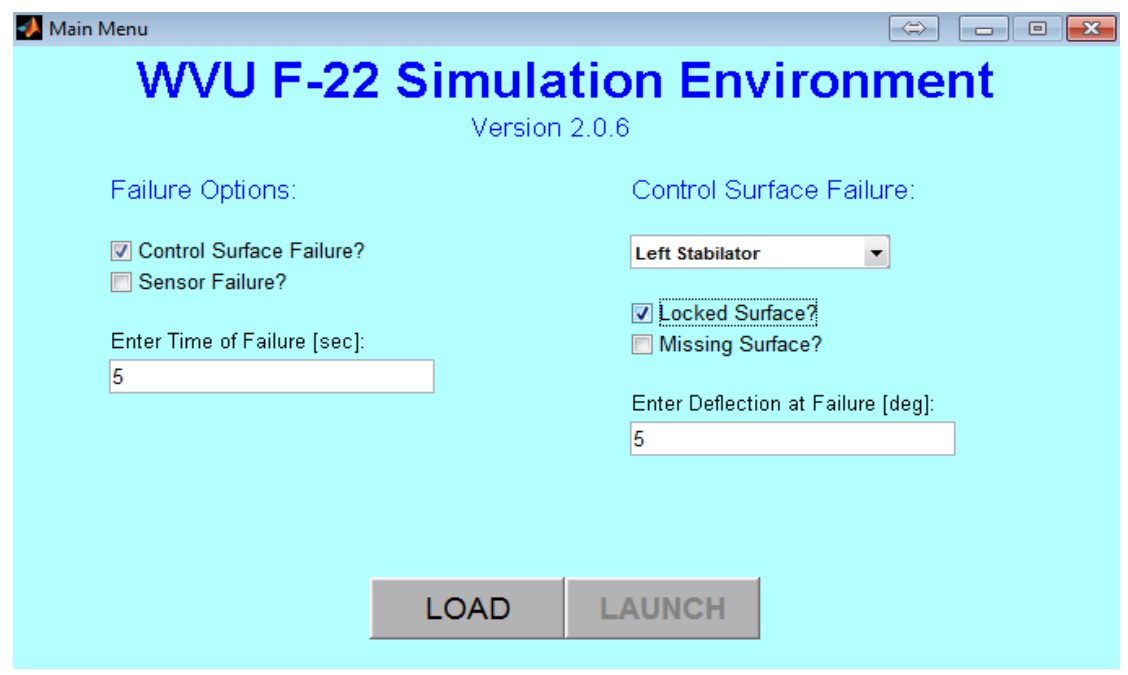

Figure 10. Aircraft Specific Failure GUI for the WVU YF-22 


\subsection{Simulink Block Control}

The Simulink block model presented in Figure 11 allows enhanced user-simulation interaction. At times, the user has to test the simulation for a different case. It is inconvenient to reinitialize all the parameters for the UAV and the simulation scenario. Therefore, the Simulink block within the UAV environment allows the user to make different selections just by clicking on the Simulink blocks. While performing a series of tests, the most common task is to switch the trajectory model. Therefore, WVU UAV Simulation environment is designed in such a way that the switching of the algorithm is very easy.

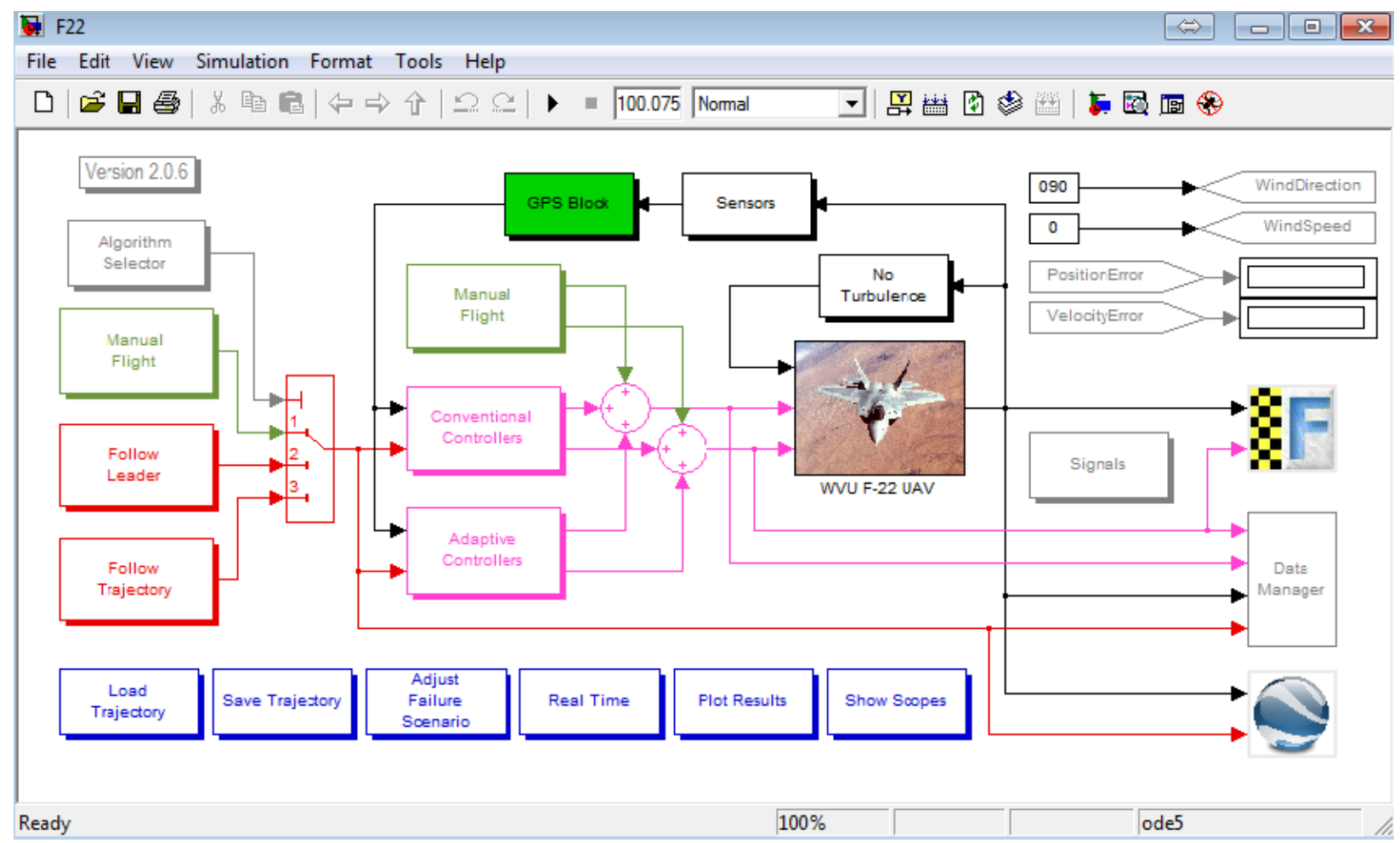

Figure 11. Simulink Model for the WVU YF-22 Aircraft

The magnitude and direction of the wind and the level of turbulence can be set in the simulation environment by adjusting the "Wind and Turbulence" Simulink block. Five severity levels in terms of standard deviations of air velocity are associated to the implemented turbulence Dryden model.

Within the WVU UAV Simulation environment, simulations can be run in real time or accelerated time. By default, the real time simulation is enabled; however, the accelerated time option can run the simulation at the maximum speed allowed by the computer. 
Simulink on-line scopes can be used to visualize certain parameters and their variations in real time. As shown in Figure 12, there are 22 scopes that are used to visualize a variety of state, controlled, and control variables. In addition to this, after the simulation, several plots can be generated allowing for the investigation of particular parameters. Figure 13 presents the selection menu for post-simulation data presentation and analysis. Time histories are generated for significant variables such as the 2-D and 3-D trajectory, controller errors, aircraft states, and pilot commands. Within the data manager block all these variables, are also saved to disk for later use and analysis.

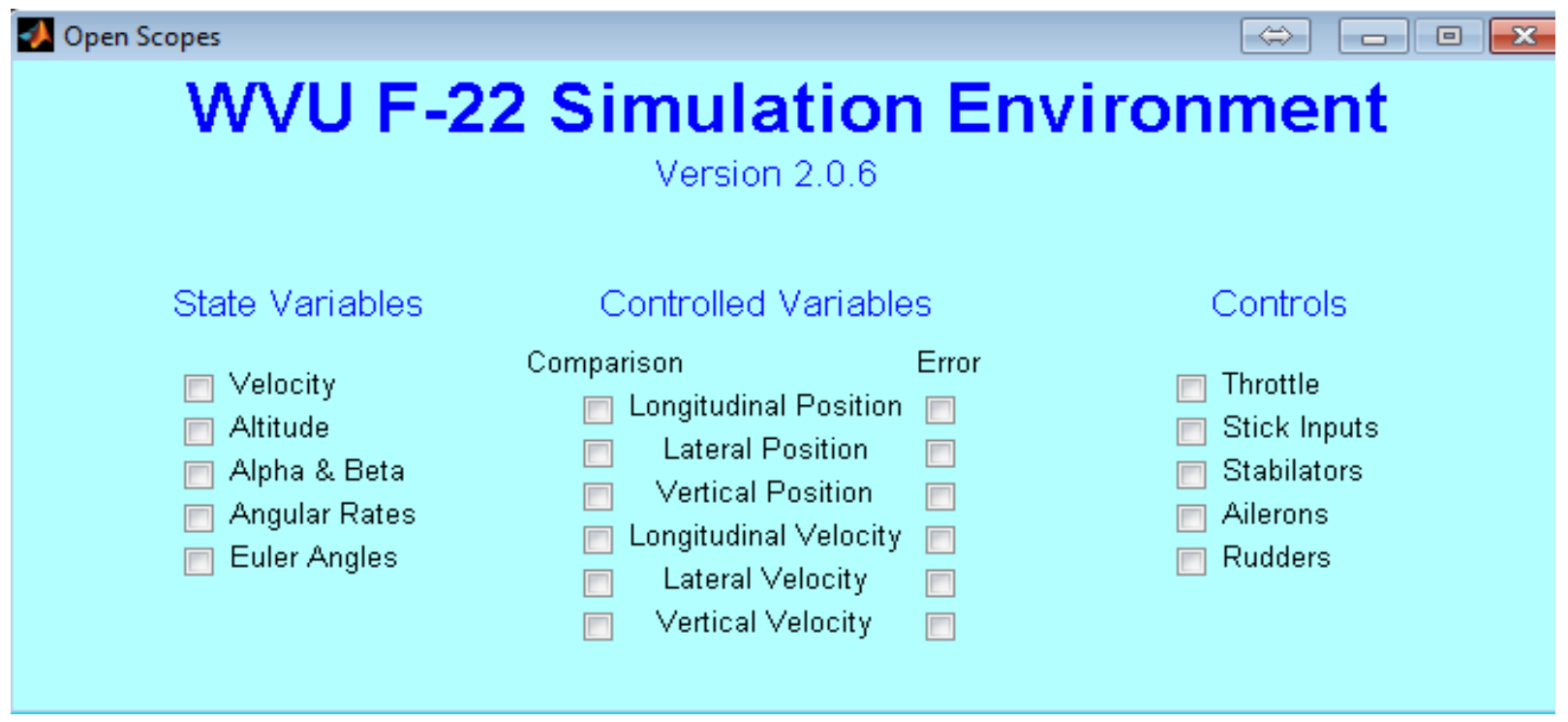

Figure 12. Selection of On-line Visualization of Main Parameters Variation

At times, it is very useful to manually fly a certain trajectory and save it for consequent evaluation of trajectory tracking algorithms. The trajectory generated in this way can be saved and used later as a commanded trajectory. Pre recorded paths generated manually or analytically are stored in a library and can be used for trajectory tracking algorithm testing. The interactive windows for FlightGear and UAV Dashboard can be opened from the Simulink model without going through the GUI setup process. 


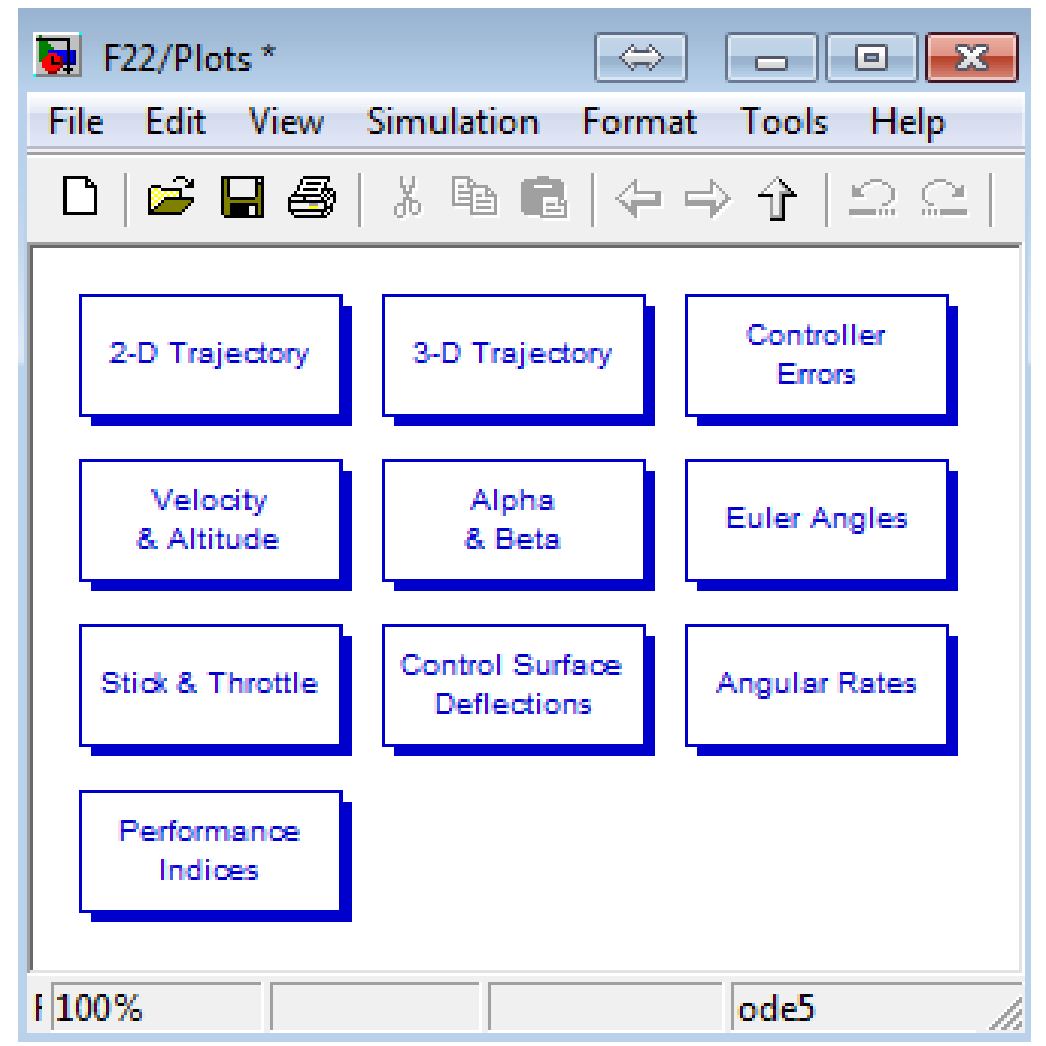

Figure 13. Selection Menu for Post-Simulation Data Analysis

\subsection{Flight Path Visualization}

Within the WVU UAV simulation environment, the flight path visualization is performed using Flight-Gear and UAV Dashboard. The Flight-Gear software package is used to visualize the 3-D motion of the UAV in a high quality visual environment. Figure 14 presents an example of external visual cues provided by Flight-Gear. Figure 15 shows the UAV dashboard utility, which generates the flight map, allows the user to locate obstacles and risk zones, and displays both the commanded and the actual 2-dimensional aircraft trajectory. Obstacle configurations can be saved and re-used for repeated tests under modified conditions. The UAV Dashboard shows the position and orientation of the moving UAVs with respect to the risk zones allowing the user to qualitatively evaluate the performance of the controllers. 


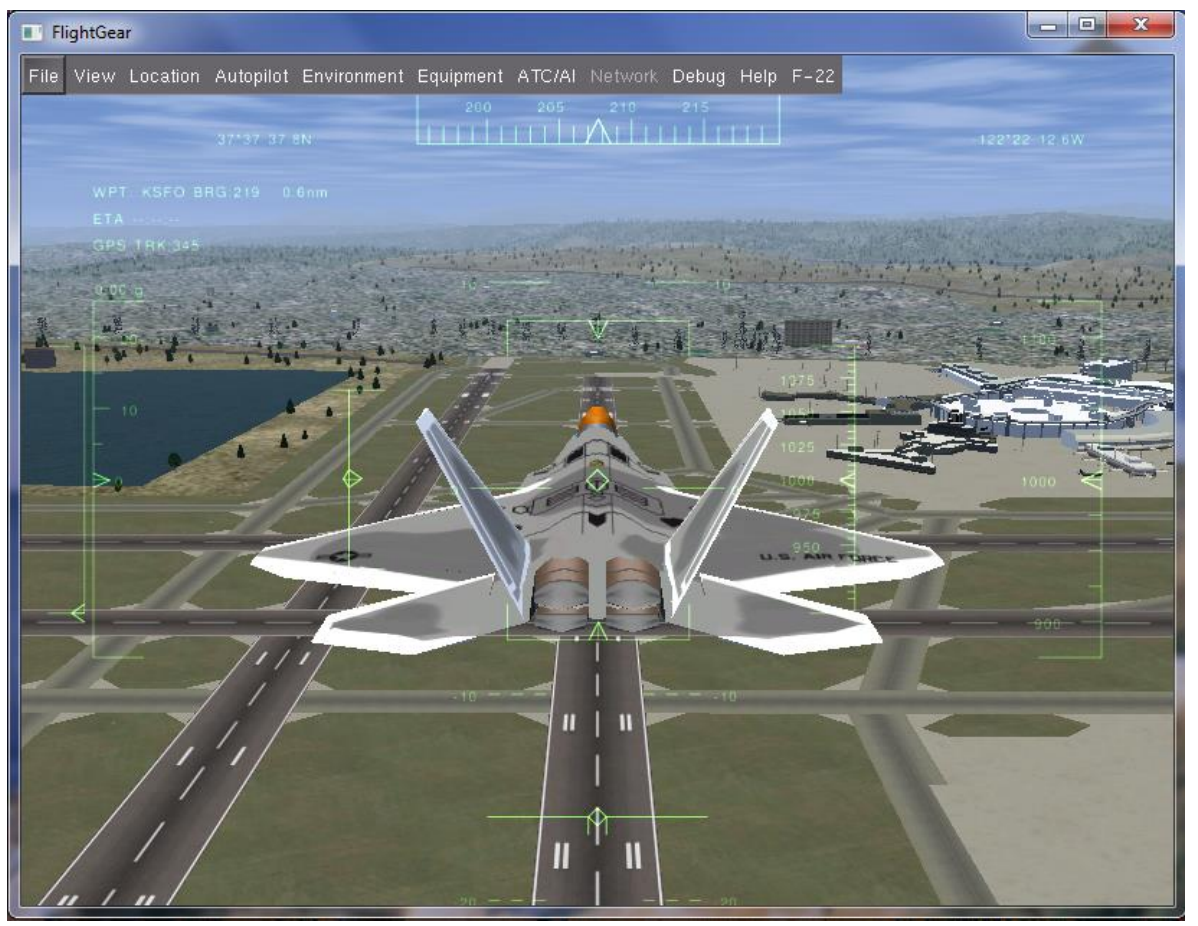

Figure 14. Flight Gear Screenshot

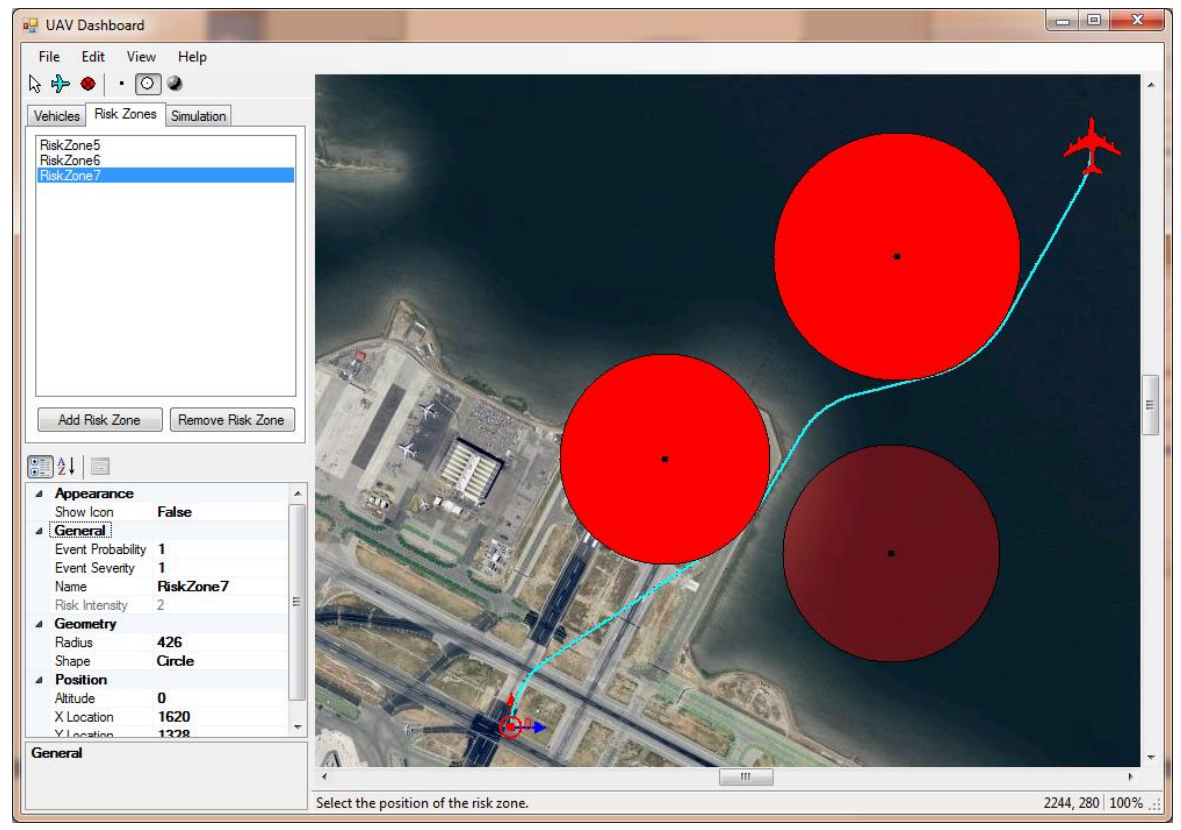

Figure 15. UAV Dashboard Screenshot 


\section{Problem Formulation}

The main challenge of autonomous flight consists of accurately tracking the trajectory under normal and adverse conditions. In this thesis, L1 adaptive control laws have been implemented and analyzed within the WVU UAV simulation environment. The L1 adaptive components augment a conventional position proportional integral and derivative (PPID) baseline controller and a performance comparison is performed between the baseline and the augmented set of control laws. The proposed adaptive control laws are based on inner-outer loop control architecture as presented in Figure 16. The three main components (trajectory geometry, outer loop, and inner loop) are described next.

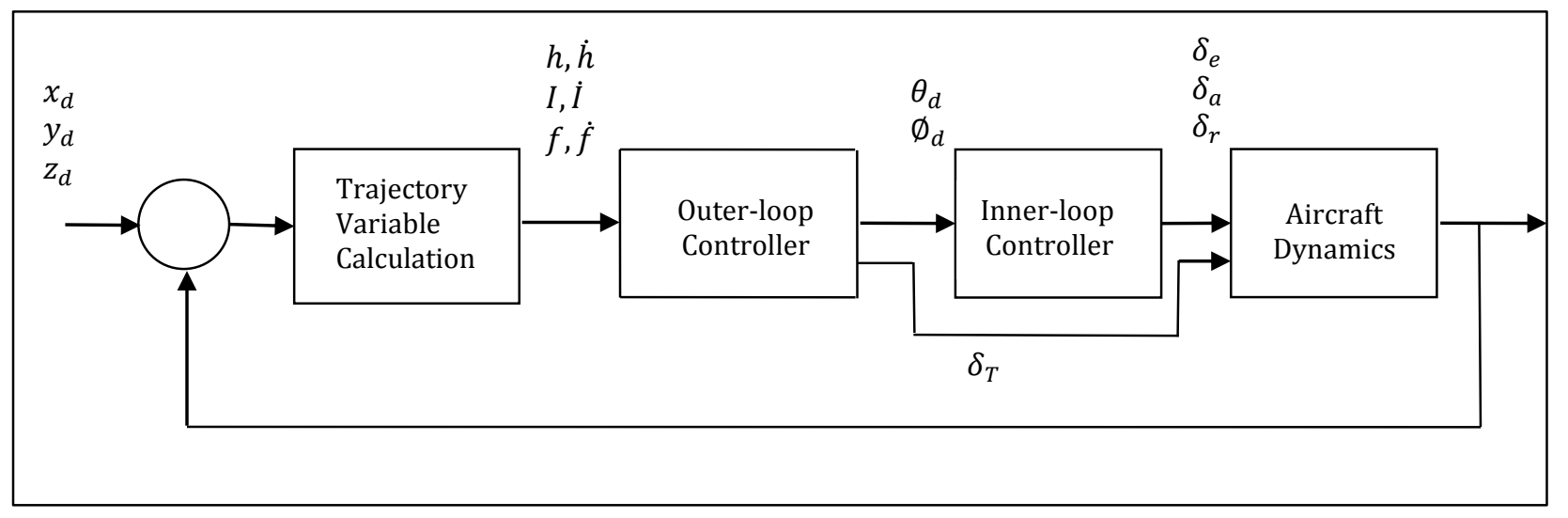

Figure 16. General Architecture of Control Laws

\subsection{Geometry of the Trajectory Tracking Problem}

The trajectory variable calculation can be separated into two problems: a horizontal-plane tracking problem and a vertical-plane tracking problem, as shown in Figure 17. The forward distance error $f$ and lateral distance error $l$ can be calculated from position and velocity using the following relationships:

$$
\begin{gathered}
l=\frac{V_{L y}\left(x_{L}-x_{w}\right)-V_{L x}\left(y_{L}-y_{w}\right)}{V_{L x y}}-l_{c} \\
f=\frac{V_{L x}\left(x_{L}-x_{w}\right)+V_{L y}\left(y_{L}-y_{w}\right)}{V_{L x y}}-f_{C}
\end{gathered}
$$


where $V_{L x y}=\sqrt{V_{L x}{ }^{2}+V_{L y}^{2}}$ is the projection of desired trajectory velocity onto x-y plane $V_{L x}, V_{L y}$ are the projections of reference trajectory along $\mathrm{x}$ and $\mathrm{y}$ axes of Earth fixed frame; $l_{c}$ and $f_{c}$, are clearance parameters. The clearance parameters will be zero for the purpose of this study.

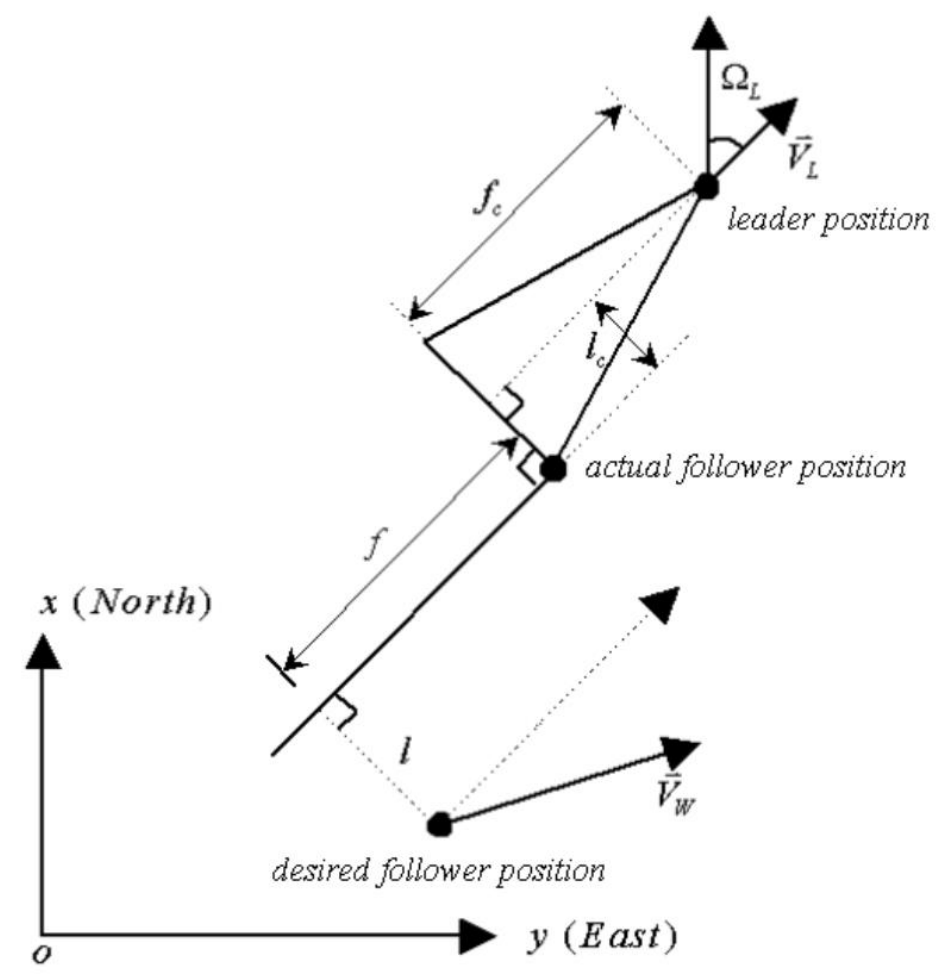

Figure 17. Trajectory Tracking Flight Geometry [88]

Therefore, the lateral distance error $l$ and the forward distance error $f$ can further be expressed as:

$$
\left[\begin{array}{l}
l \\
f
\end{array}\right]=\left[\begin{array}{cc}
\sin \left(\chi_{L}\right) & -\cos \left(\chi_{L}\right) \\
\cos \left(\chi_{L}\right) & \sin \left(\chi_{L}\right)
\end{array}\right]\left[\begin{array}{l}
x_{L}-x_{L} \\
y_{L}-y
\end{array}\right]
$$

where $\chi_{V}$ is given by:

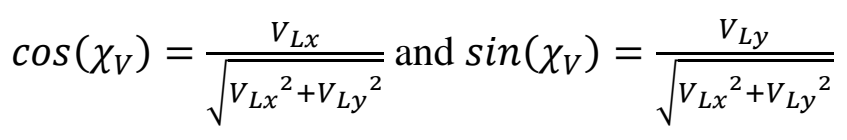

The relative forward and lateral speeds of aircraft are obtained from time derivatives of the forward and lateral distance, respectively: 


$$
\begin{gathered}
\dot{l}=\frac{V_{L x} V_{w y}-V_{L y} V_{w y}}{V_{L x y}}+\Omega_{L} f \\
\dot{f}=V_{L x y}-\frac{V_{L x} V_{L}-V_{L w} V_{w}}{V_{L x y}}+\Omega_{L} l
\end{gathered}
$$

where $\Omega_{L}=\frac{\left(q_{L} \sin \phi_{L}+r_{L} \cos \phi_{L}\right)}{\cos \theta_{L}}$ is the trajectory projected angular velocity in the x-y plane, which is assumed to be zero. Equations (7) and (8) can be written as:

$$
\left[\begin{array}{l}
i \\
\dot{f}
\end{array}\right]=\left[\begin{array}{c}
V_{x y} \sin \left(\chi-\chi_{V}\right) \\
V_{V_{x y}}-V_{x y} \cos \left(\chi-\chi_{V}\right)
\end{array}\right]+\Omega_{L}\left[\begin{array}{c}
f \\
-l
\end{array}\right]
$$

For the vertical geometry, the vertical distance error $h$ and vertical speed $\dot{h}$ can be calculated as:

$$
\begin{gathered}
h=z_{L}-z_{w} \\
\dot{h}=V_{L x}-V_{w x}
\end{gathered}
$$

\subsection{Outer Loop Controller}

The outer loop controller used is the positional proportional integral and derivative controller. The PPID gains have been optimized with an evolutionary algorithm [86] using as optimization criterion a combined performance index based on tracking errors and control activity. The outer loop controller is expected to convert position commands on the three channels (longitudinal, lateral, and vertical) into required throttle, bank angle, and pitch angle, respectively. Proportional and integral relationships are used for this purpose. Equation (12), Equation (13) and Equation (14) represents the generation of the desired bank angle, throttle command and pitch angle.

$$
\begin{gathered}
\phi_{d}=K_{\dot{l}} \dot{l}+K_{l} l \\
\delta_{T}=K_{\dot{f}} \dot{f}+K_{f} f \\
\theta_{d}=K_{\dot{h}} \dot{h}+K_{h} h
\end{gathered}
$$




\subsection{Inner Loop Controller}

The inner loop is expected to generate the aerodynamic control surface deflections necessary to achieve the commanded bank and pitch angles produced by the outer loop. Two different approaches for the inner loop are involved in this study: PPID [55], and L1 adaptive feedback [87] [79] [80]. The implemented L1 adaptive controller in WVU UAV Simulation environment is different from the previous implementations in terms of the design and parameters of the L1 filter as well as additional compensation on the yaw channel.

\subsubsection{Proportional Integral Derivative Controller}

The desired aileron, rudder and elevator deflections are obtained using primarily the desired bank angle, yaw rate, and desired pitch angle, respectively.

The lateral controller generates aileron and rudder deflection using equations (15) and (16).

$$
\begin{gathered}
\delta_{a}=K_{p} p+K_{\phi}\left(\phi-\phi_{d}\right) \\
\delta_{r}=K_{r} r
\end{gathered}
$$

Equation (17) provides the elevator deflection using the desired pitch angle and pitch rate.

$$
\delta_{e}=K_{q} q+K_{\theta}\left(\theta-\theta_{d}\right)
$$

where $\mathrm{p}, \mathrm{q}, \mathrm{r}, \phi$ are the actual roll rate, pitch rate, yaw rate and bank angle respectively, $\phi_{d}$ and $\theta_{d}$ are the desired bank and pitch angles.

\subsubsection{Architecture of L1 Adaptive Feedback Controller}

The first step in the development of L1 adaptive control laws is the creation of a linear model of the UAV [87] [79] [80]. The desired natural frequency and damping ratio of the longitudinal and lateral channels are found, in order to create the reference system.

L1 adaptive controller can be designed following the assumption of decoupled longitudinal and the lateral-directional aircraft dynamics. This implies that the dynamics of the vehicle can be expressed by two different decoupled linear systems shown below: 


$$
\begin{aligned}
& x_{\text {lon }}(t)=A_{\text {lon }} x_{\text {lon }}(t)+B_{\text {lon }} u_{\text {lon }}(t) \\
& x_{\text {lat }}(t)=A_{\text {lat }} x_{\text {lat }}(t)+B_{\text {lat }} u_{\text {lat }}(t)
\end{aligned}
$$

The longitudinal and lateral systems are independent. The states and the control input vectors of the longitudinal dynamics are given below

$$
\begin{gathered}
x_{\text {lon }}=\left[\begin{array}{cccc}
v & \alpha & q & \theta
\end{array}\right]^{T} \\
u_{\text {lon }}=\delta_{e}
\end{gathered}
$$

where the states are velocity, angle of attack, pitch rate, and pitch attitude angle. The control $\delta_{e}$ is the deflection of the elevator.

The states and the control input vectors of the lateral-directional dynamics are given below:

$$
\begin{gathered}
x_{\text {lat }}=[\beta \text { pr } \phi]^{T} \\
u_{\text {lat }}=\left[\delta_{a} \delta_{r}\right]^{T}
\end{gathered}
$$

where the states are sideslip angle, roll rate, yaw rate, and roll attitude angle and the inputs are $\delta_{a}$, deflection of the aileron and $\delta_{r}$, the deflection of the rudder.

The state space equations of the aircraft (WVU YF-22) are obtained from reference [88]. The linear model is obtained at a steady state and level flight with $\mathrm{V}=42 \mathrm{~m} / \mathrm{s} \mathrm{H}=120 \mathrm{~m}$ at trim conditions $\alpha=\theta=3^{\circ}$ with $\delta_{e}=-1^{\circ}, \delta_{a}=\delta_{r}=0$ and thrust force along $\mathrm{x}$ axis $\mathrm{T}=54.62 \mathrm{~N}$. Since the inner loop does not process the turbulence, the created reference model uses the actuator deflections as input.

The resultant continuous time longitudinal and lateral-directional linear models are:

$$
\begin{gathered}
{\left[\begin{array}{c}
\dot{v} \\
\dot{\alpha} \\
\dot{q} \\
\dot{\theta}
\end{array}\right]=\left[\begin{array}{cccc}
-0.2835 & -23.0959 & 0 & -0.1711 \\
0 & -4.1172 & 0.7781 & 0 \\
0 & -33.8836 & -3.5729 & 0 \\
0 & 0 & 1 & 0
\end{array}\right]\left[\begin{array}{l}
v \\
\alpha \\
q \\
\theta
\end{array}\right]} \\
+\left[\begin{array}{c}
20.1681 \\
0.5435 \\
-39.0847 \\
0
\end{array}\right] \delta_{e}
\end{gathered}
$$




$$
\left[\begin{array}{c}
\dot{\beta} \\
\dot{p} \\
\dot{r} \\
\dot{\phi}
\end{array}\right]=\left[\begin{array}{cccc}
0.4299 & 0.0938 & -1.0300 & 0.2366 \\
-67.3341 & -7.9485 & 5.6402 & 0 \\
20.5333 & -0.6553 & -1.9955 & 0 \\
0 & 1 & 0 & 0
\end{array}\right]\left[\begin{array}{l}
\beta \\
p \\
r \\
\phi
\end{array}\right]+\left[\begin{array}{cc}
0.2724 & -0.7713 \\
-101.8446 & 33.4738 \\
-6.2609 & -24.3627 \\
0 & 0
\end{array}\right]\left[\begin{array}{c}
\delta_{a} \\
\delta_{r}
\end{array}\right]
$$

From this, the necessary natural frequency and damping ratio of the longitudinal and lateral channels are the following: $\omega_{q}=4.5, \zeta_{q}=0.7 \omega_{r}=4.2, \zeta_{r}=0.4$

The reference models $M_{q}(s)$ and $M_{r}(s)$ are designed such that desired dynamic response is achieved.

$$
\begin{aligned}
& M_{q}=\frac{\omega_{q}^{2}}{s^{2}+2 \zeta_{q} \omega_{q}+\omega_{q}^{2}} \\
& M_{r}=\frac{\omega_{r}^{2}}{s^{2}+2 \zeta_{r} \omega_{r}+\omega_{r}^{2}}
\end{aligned}
$$

The architecture of the L1 adaptive controller is described in Figure 18 . L1 adaptive controller consists of three blocks: control law, state predictor, and adaptive law.

The state predictor estimates the system output. Consider that the desired output of the system is expressed as:

$$
\theta(s)=M_{q}(s)\left(\theta_{a d}(s)+\sigma_{q}(s)\right)
$$

where $\sigma_{q}(s)$ includes the uncertainty of the plant and its departure from the desired response and $\theta_{a d}(t)$ is the compensation produced by the control law. 


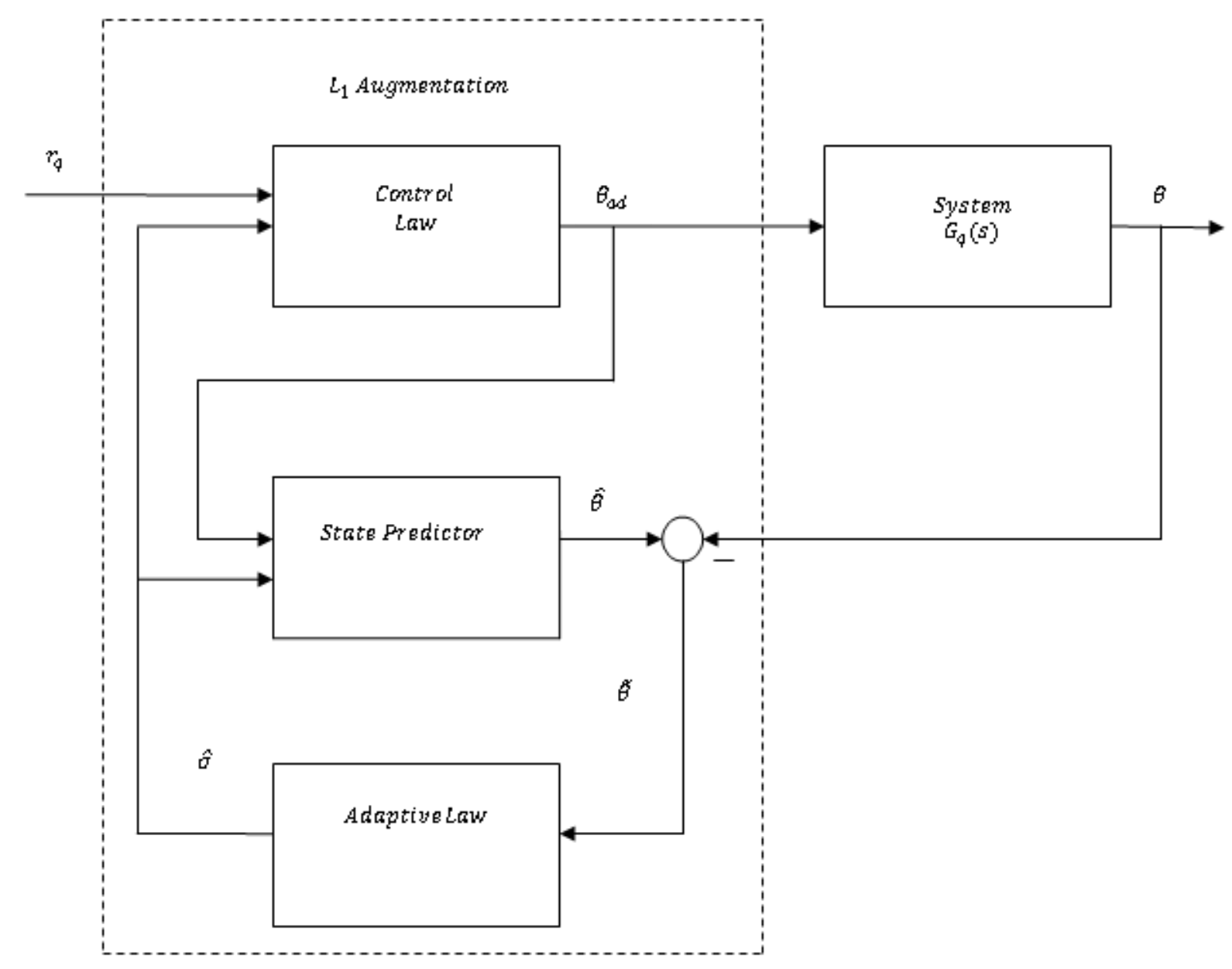

Figure 18. Architecture of L1 Adaptive Output Feedback Controller

The state space system of equations is given as:

$$
\begin{gathered}
\dot{x}(t)=\mathrm{A}_{\mathrm{m}_{\mathrm{q}}} x(t)+\mathrm{B}_{\mathrm{m}_{\mathrm{q}}}\left(\theta_{a d}(t)-\sigma_{q} x(t)\right) \\
\theta(t)=\mathrm{C}_{\mathrm{m}_{\mathrm{q}}}{ }^{T} x(t)
\end{gathered}
$$

The state predictor is formulated as:

$$
\begin{gathered}
\hat{\dot{x}}(t)=\mathrm{A}_{\mathrm{m}_{\mathrm{q}}} \hat{x}(t)+\mathrm{B}_{\mathrm{m}_{\mathrm{q}}} \theta_{a d}(t)+\hat{\sigma}_{q}(t) \\
\hat{\theta}(\mathrm{t})=\mathrm{C}_{\mathrm{m}_{\mathrm{q}}}{ }^{T} \hat{x}(t)
\end{gathered}
$$


where $\hat{\sigma}_{q}(\mathrm{t}) \in \mathrm{R} * \mathrm{R}$ is the result of the adaptation. Note also that, $\mathrm{A}_{\mathrm{m}_{\mathrm{q}}}, \mathrm{B}_{\mathrm{m}_{\mathrm{q}}}, \mathrm{C}_{\mathrm{m}_{\mathrm{q}}}{ }^{T}$ are the minimal realization of $M_{q}(s)$ in controllable canonical form. The adaptive law estimates $\hat{\sigma}_{q}(t)$ are given as:

$$
\hat{\sigma}_{q}(i T)=-\left(\int_{0}^{T} e^{\Lambda_{q} \mathrm{~A}_{\mathrm{m}_{\mathrm{q}}} \Lambda_{q}^{-1}(T-\tau)} \Lambda_{q} d \tau\right)^{-1}\left(e^{\Lambda_{q} \mathrm{~A}_{\mathrm{m}_{\mathrm{q}}} \Lambda_{q}^{-1}(T-\tau)} I_{1} \tilde{\theta}(i T)\right)
$$

where $I_{1}=\left[\begin{array}{ll}0 & 1\end{array}\right], \Lambda_{q}=\left[\begin{array}{c}C m_{q}{ }^{T} \\ D_{q} \sqrt{p_{q}}\end{array}\right], \mathrm{i}$ is the sample index and the estimation error is $\tilde{\theta}(t)=\hat{\theta}(\mathrm{t})-$ $\theta(\mathrm{t})$, while T is signal sampling time interval. $p_{q}$ is the solution to the algebraic Lyapunov equation $\mathrm{A}_{\mathrm{m}_{\mathrm{q}}}{ }^{T} p_{q}+p_{q} \mathrm{~A}_{\mathrm{m}_{\mathrm{q}}}=-\mathrm{Q}_{\mathrm{q}}$, where $\mathrm{Q}_{\mathrm{q}}=\left|\begin{array}{ll}1 & 0 \\ 0 & 0\end{array}\right|$. The obtained $p_{q}$ should satisfy the condition: $p_{q}=\sqrt{p_{q}{ }^{T}} \sqrt{p_{q}} . D_{q}$ is the nullspace of $C m_{q}{ }^{T}\left(\sqrt{p_{q}}\right)^{-1}$, that is $D_{q}\left(C m_{q}{ }^{T}\left(\sqrt{p_{q}}\right)^{-1}\right)^{T}=0$.

The control law generates $\theta_{\mathrm{ad}}$ and is given as:

$$
\theta_{\mathrm{ad}}(\mathrm{s})=\mathrm{C}_{\mathrm{q}}(\mathrm{s}) \mathrm{r}_{\mathrm{q}}(\mathrm{s})-\frac{\mathrm{C}_{\mathrm{q}}(\mathrm{s})}{\mathrm{M}_{\mathrm{q}}(\mathrm{s})} \mathrm{c}_{\mathrm{q}}^{\mathrm{T}}\left(\mathrm{sI}-\mathrm{A}_{\mathrm{m}_{\mathrm{q}}}\right)^{-1} \hat{\sigma}_{q}(\mathrm{~s})
$$

where $r_{q}(t)$ is a bounded reference signal with bounded first and second order derivatives. $c_{q}(s)$ is a strictly proper low pass filter with $C_{q}(0)=1$ such that $\frac{C_{q}(s)}{M_{q}(s)} C_{m_{q}}^{T}\left(s I-A_{m_{q}}\right)^{-1}$ is a proper transfer function. A low pass filter offers easy passage to low frequency signal and attenuates high frequency signal components. The low pass filter eliminates external or internal disturbances faster. The effect of adding the low pass filter consists in limiting the bandwidth of the control signal. Larger gains and hence faster adaptation and response are possible, without penalty on robustness. 


\section{IMPLEMENTATION OF L1 AdAPTIVE CONTROLLER}

The Simulink implementation of the L1 adaptive control laws is organized in three main blocks: trajectory variable calculation, outer loop controller and inner loop controller. Figure 19 represents the general implementation of the control laws. The aircraft actual states and the commanded path are used as input to the trajectory variables calculation. The outer loop calculates the required bank angle, pitch angle, and the throttle command. The inner loop controller generates the deflections of lateral and longitudinal aerodynamic control surfaces.

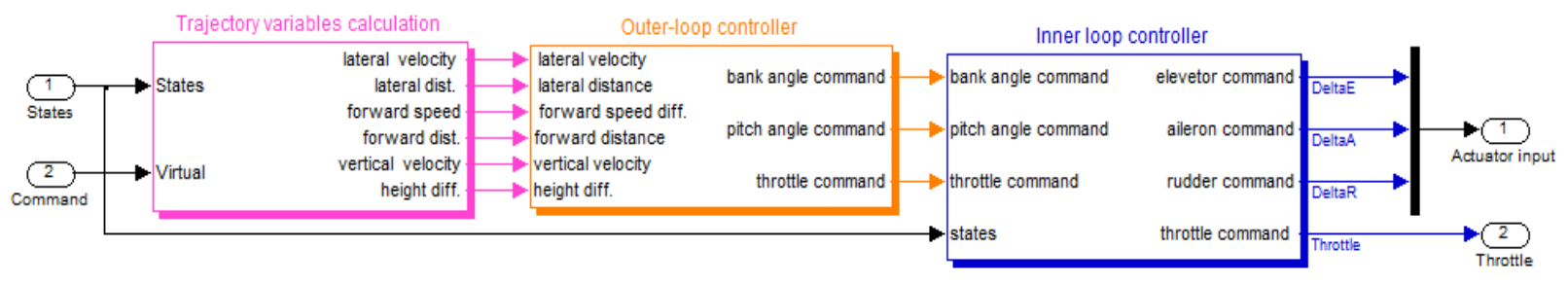

\section{Figure 19. General Architecture of Control Laws}

The first implementation is the inner loop PPID followed by the implementation of L1 adaptive output feedback controller. Figure 20 represents the implementation of PPID. The pitch angle and bank angle are used to generate deflections of elevator, rudder, and aileron. Figure 21 represents the implementation of L1 adaptive output feedback controller on the longitudinal channel. The architecture of the lateral channel implementation is the same. 


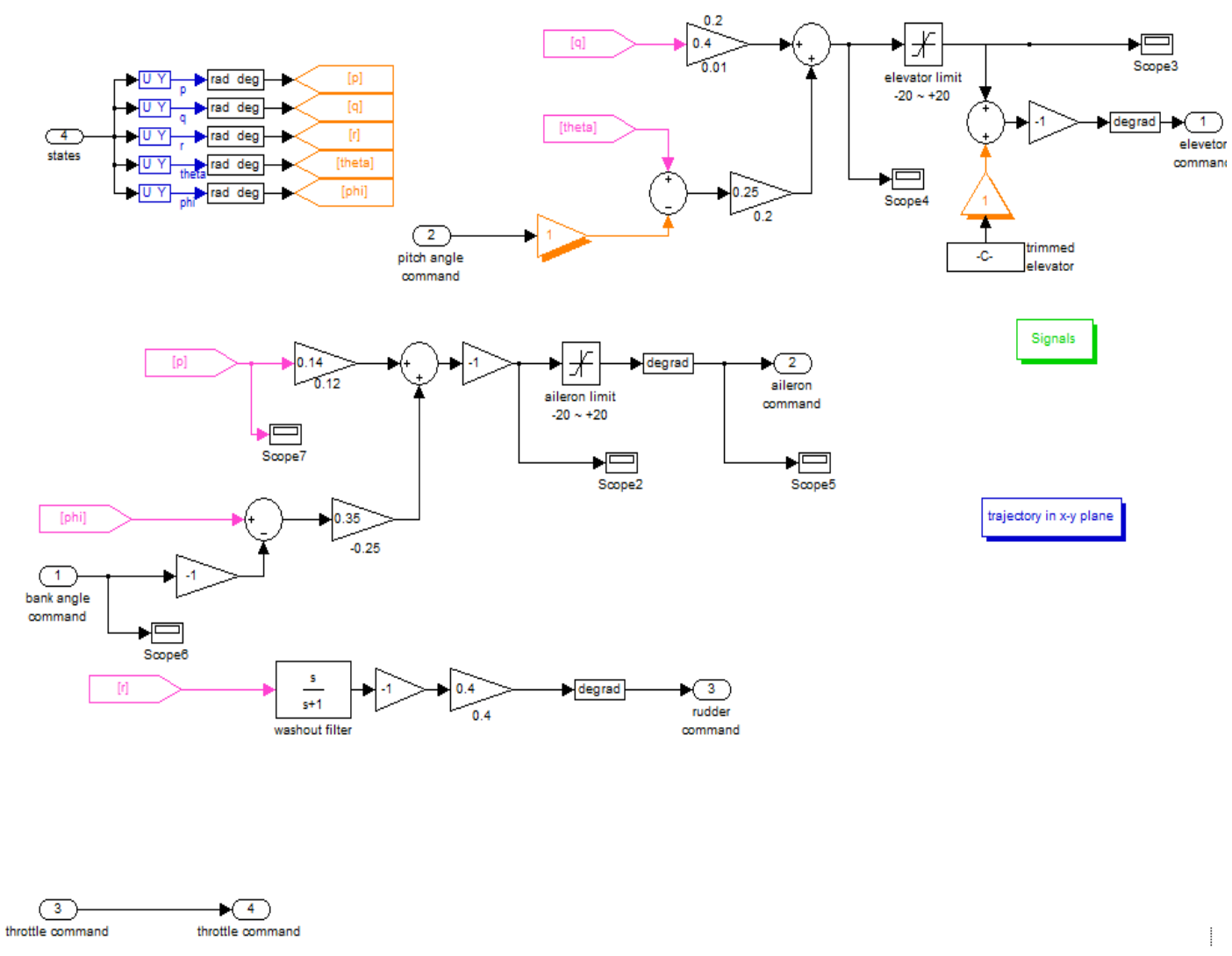

Figure 20. Implementation of PPID

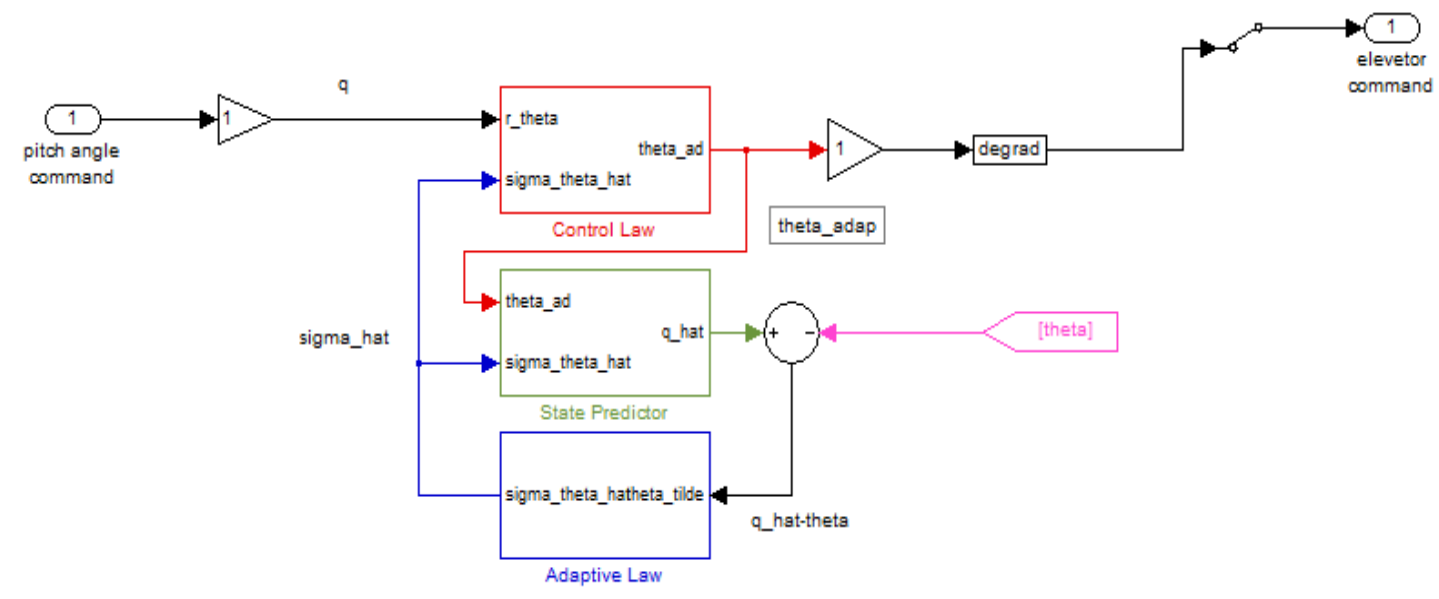

Figure 21. Implementation of Longitudinal Channel L1 Adaptive Output Feedback Controller

The implementations of the state predictor, control law and adaptive law are shown in 
Figure 22, Figure 23, and Figure 24, respectively. From these figures, it can be clearly seen that the L1 output feedback adaptive controller uses the pitch angle in the feedback loop.

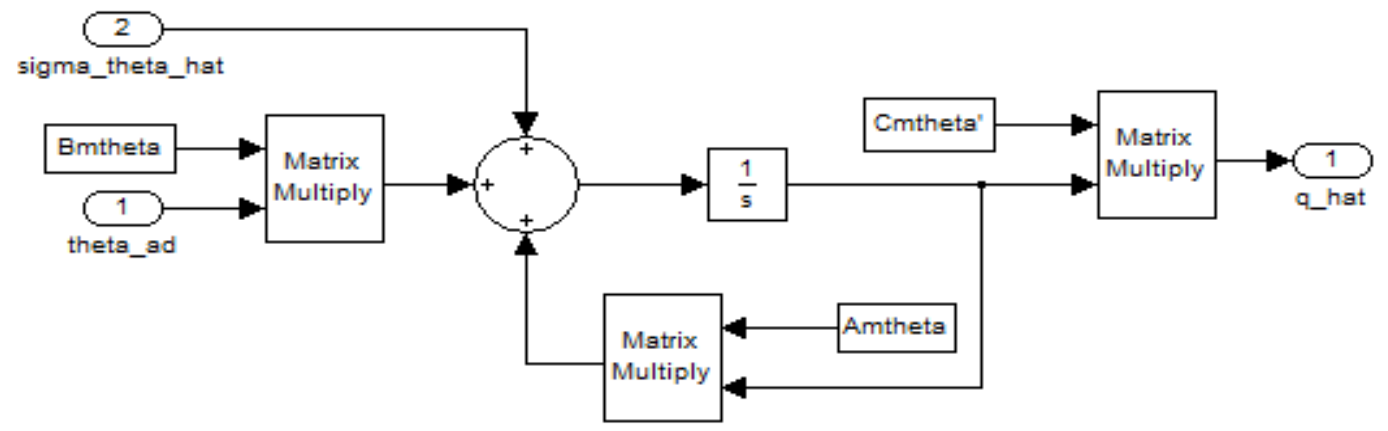

Figure 22. Implementation of L1 Adaptive Output Feedback Controller-State Predictor

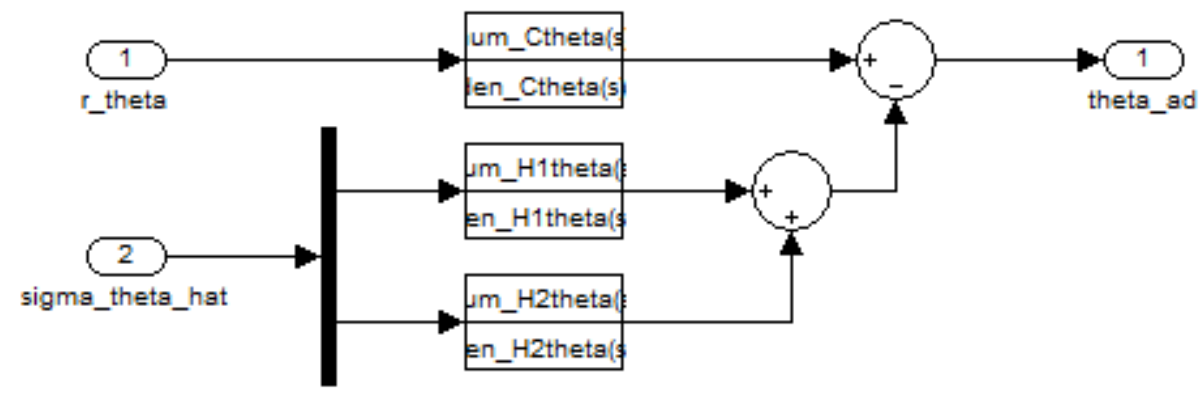

Figure 23. Implementation of L1 Adaptive Output Feedback Controller-Control Law

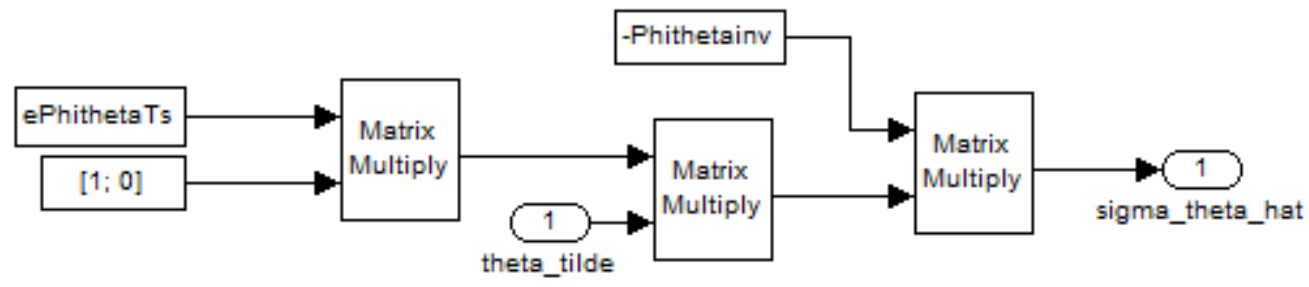

Figure 24. Implementation of L1 Adaptive Output Feedback Controller-Adaptive Law 


\section{Performance Analysis}

In order to assess the impact of the L1 adaptive control laws and their fault tolerance capabilities, the L1 adaptive controller and the PPID control laws were tested at nominal conditions and under a variety of abnormal conditions. The performance evaluation metrics used are expected to be comprehensive with respect to critical elements of autonomous flight performance, such as trajectory tracking and control activity. The use of weighting factors may introduce some subjectivity; however, this is mitigated by considering component performance indices in on conjunction with global ones. The experimental design has considered 4 different paths with different levels of complexity and locked actuator failures on all control channels as well as turbulence. The abnormal conditions were evaluated at three different levels of severity.

\subsection{Experimental Design for Control Laws Performance Analysis}

All simulation tests were performed at a point in the flight envelope starting at a velocity of 77.8 knots and altitude of 1000 feet. Constant commanded velocity is considered in all tests. Both constant and variable altitude cases were simulated. Table 1 presents the factors and the corresponding levels of the experimental design. The factors considered are commanded trajectory tracking control laws, commanded paths, flight condition, and abnormal condition severity.

\section{Table 1. Experimental Design Factors and Levels}

\begin{tabular}{|l|l|l|l|}
\hline $\begin{array}{l}\text { Trajectory Tracking } \\
\text { Control Laws }\end{array}$ & Commanded Path & Flight Condition & Severity \\
\hline PPID & Figure 8 Path & Normal & Nominal \\
\hline L1 Adaptive Controller & Oval Path & Locked Stabilator & Low \\
\hline & $\begin{array}{l}\text { Obstacle Avoidance } \\
\text { Path }\end{array}$ & Locked Aileron & Medium \\
\hline & 3D S Turns Path & Locked Rudder & High \\
\hline & & Turbulence & \\
\hline
\end{tabular}

The control laws are PPID and L1 adaptive output feedback controller. The control laws have been discussed in the previous chapters in more detail. Four generic paths of varying complexity have been considered [55]: Figure 8 (Figure 25), Oval (Figure 26), Obstacle avoidance (Figure 27), and 3D S-turns (Figure 28). Each trajectory tracking algorithm is used to track the above paths under 
normal and abnormal conditions. The flight conditions include nominal, locked aerodynamic surface (stabilator, aileron, or rudder) and atmospheric turbulence. Since the aircraft is symmetric about the vertical plane of the body axes, locked right aerodynamic surface is assumed equivalent to locked left surface. In this thesis, only the locked right surface case is considered, without any loss of generality.

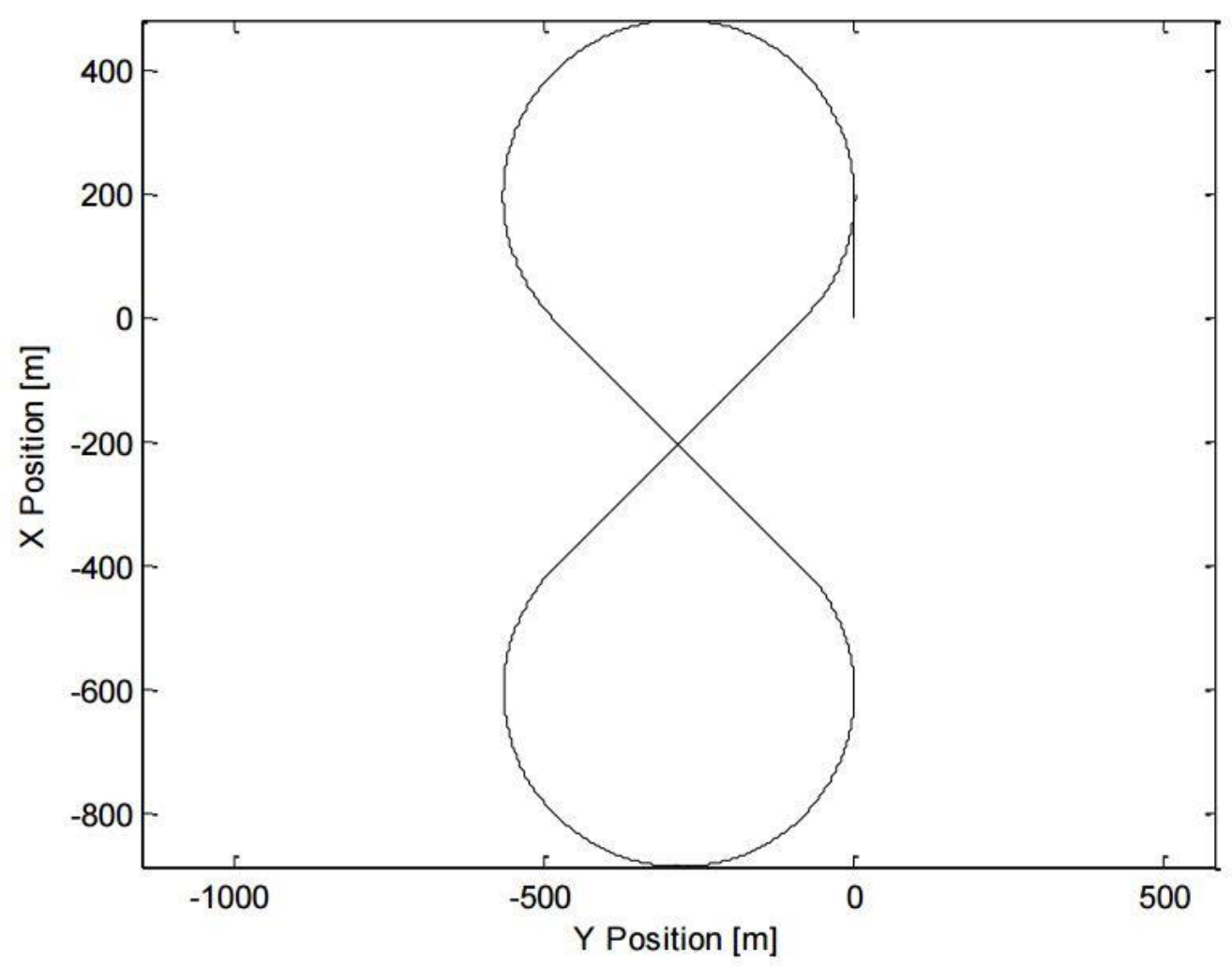

Figure 25. Figure 8 Path [55] 


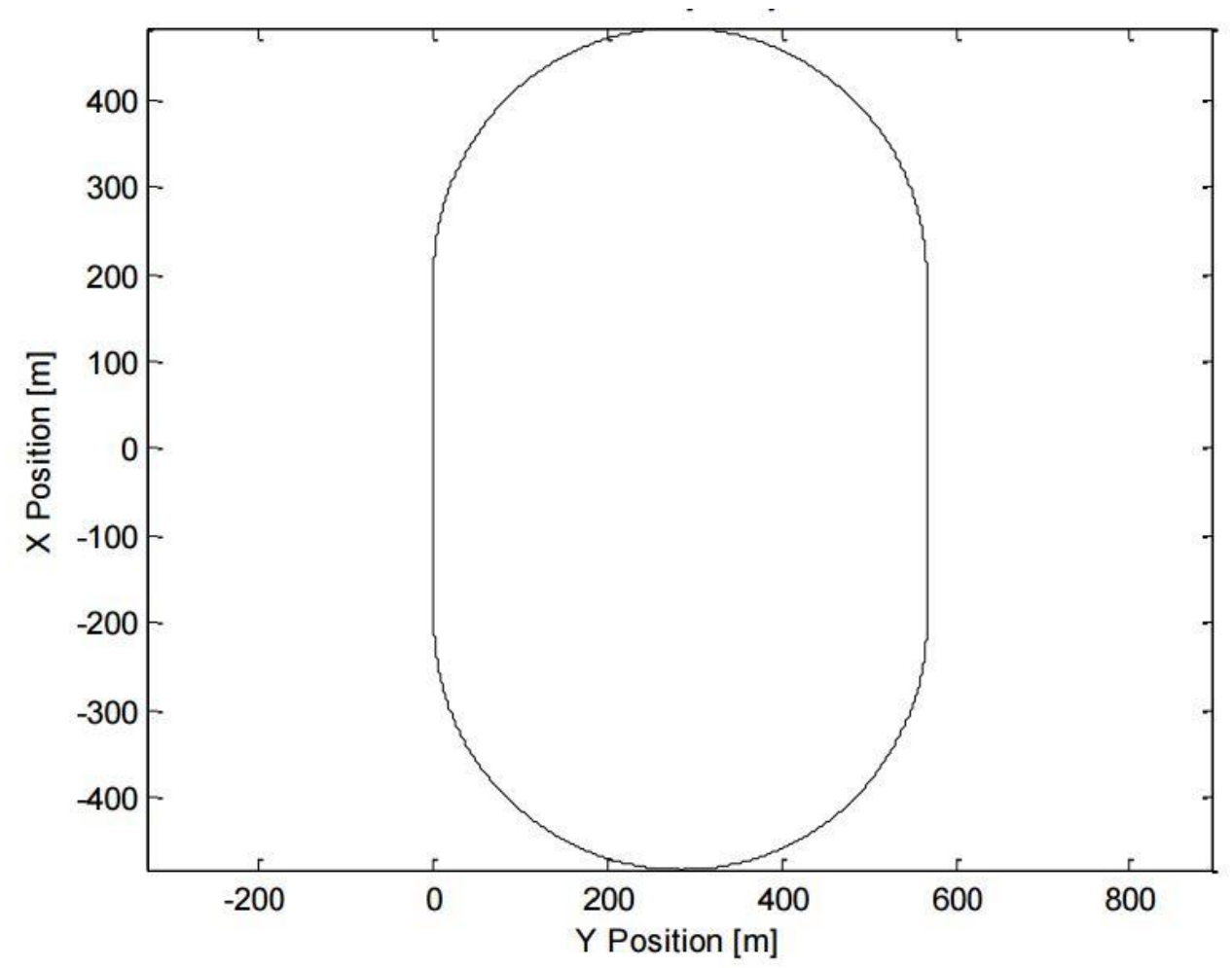

Figure 26. Oval Path [55]

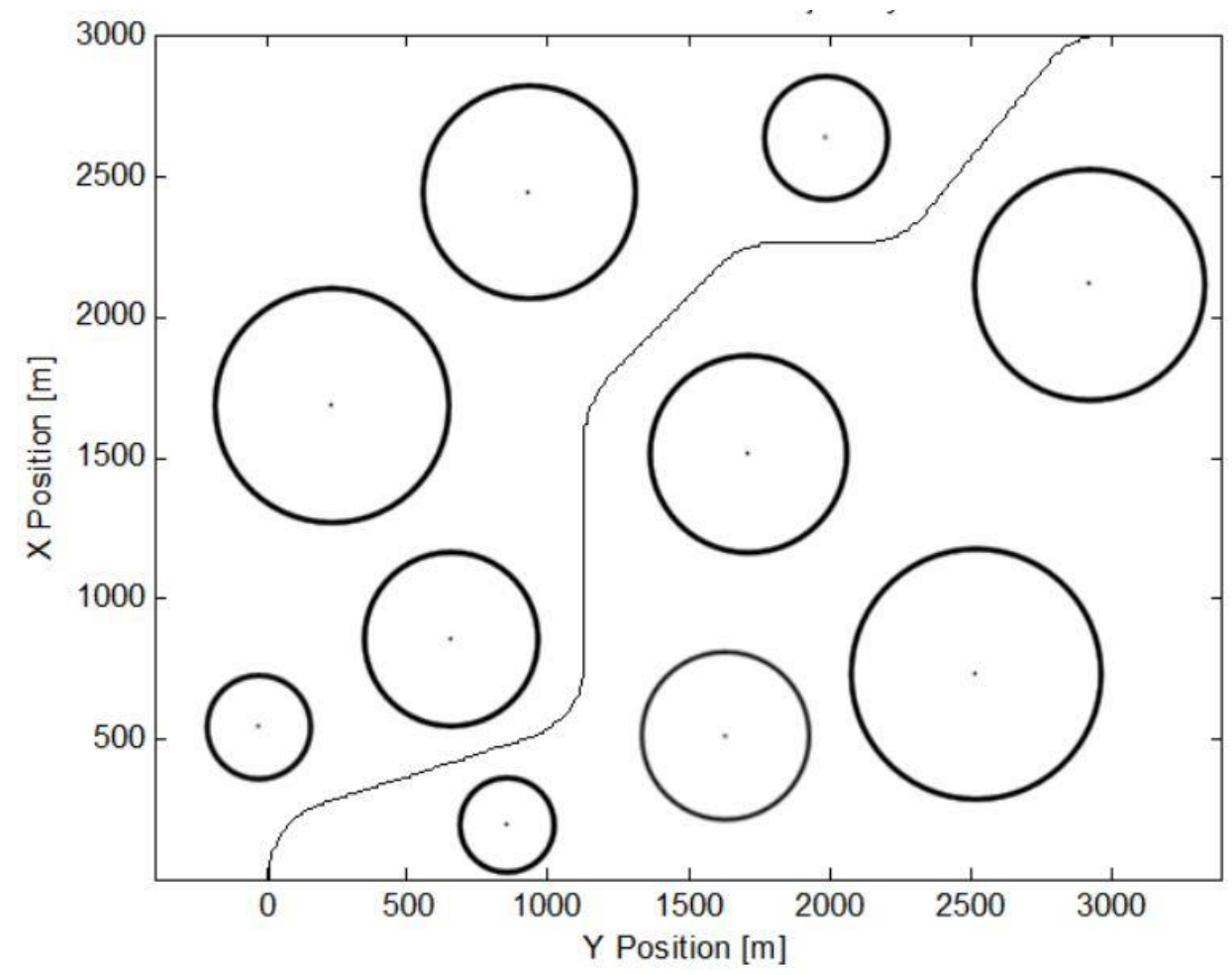

Figure 27. Obstacle Avoidance Path [55] 


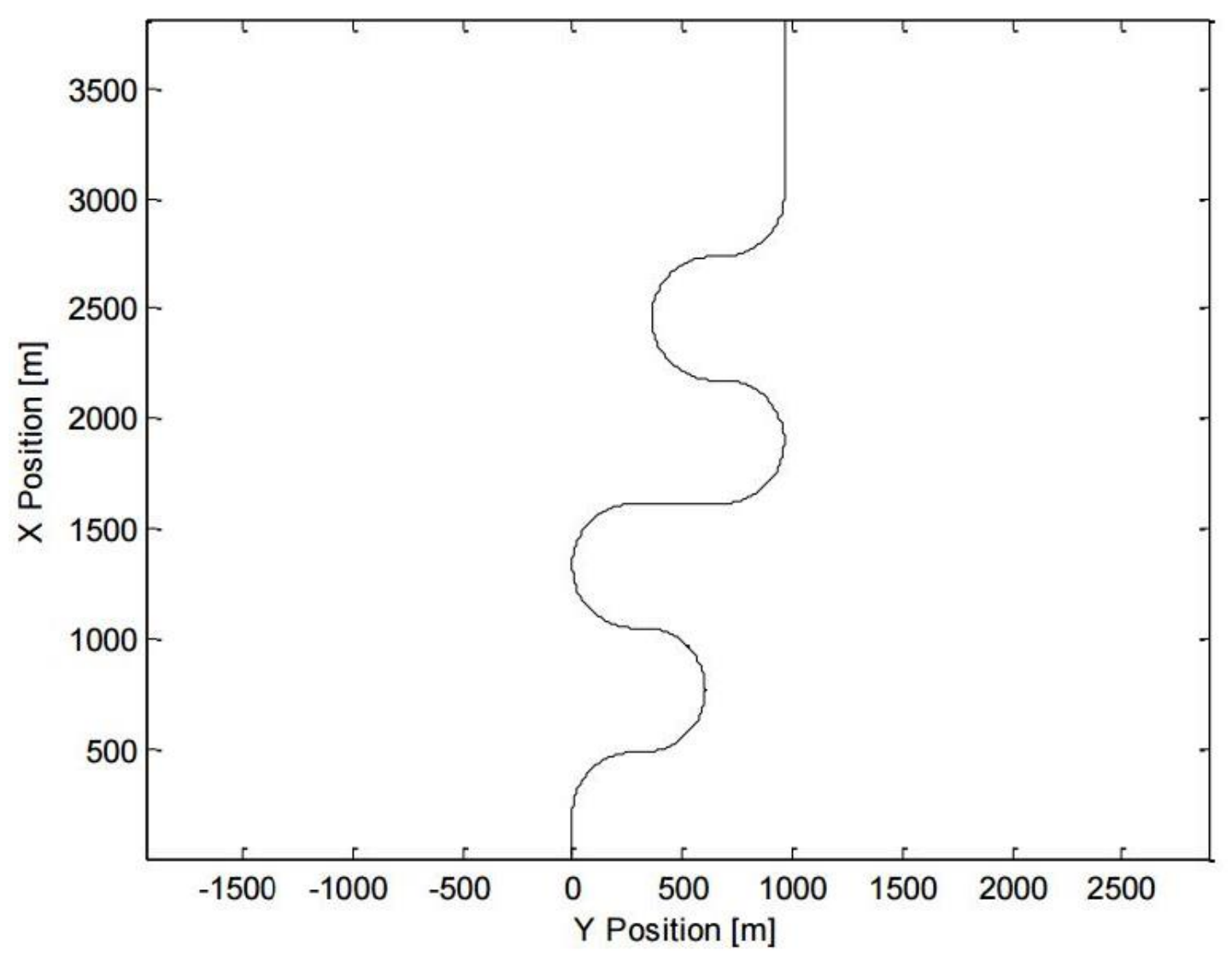

Figure 28. 3D S-Turns Path [55]

The lockage of the aerodynamic surface occurs after 5 seconds into the simulation. The performance of the controller was evaluated at three different levels of severity of the abnormal conditions as presented in Table 2. The severity levels of the failure are low, medium, and high. The corresponding deflection values vary from 2 degrees to 8 degrees. The standard deviation of relative air velocity due to turbulence varies between 5 and $15 \mathrm{ft} / \mathrm{sec}$.

Table 2. Description of Abnormal Condition Severities

\begin{tabular}{|l|l|l|l|l|}
\hline Severity & Stabilator & Aileron & Rudder & Turbulence \\
\cline { 2 - 5 } & (degrees) & (degrees) & (degrees) & (ft/sec) \\
\hline Low & 2 & 2 & 2 & 5 \\
\hline Medium & 5 & 5 & 5 & 10 \\
\hline Severe & 8 & 8 & 8 & 15 \\
\hline
\end{tabular}

The outcomes of the experiments include all system states and inputs necessary to calculate the performance evaluation metrics as described in Section 6.2. 


\subsection{Performance Evaluation Metrics}

The overall performance of a controller is defined using two primary performance criteria [55]. The first criterion is based on the trajectory tracking accuracy with minimum errors on individual axes and globally. The second criterion is based on the amount of control actuation. The control activity indices assess performance in terms of the controller's ability to keep track of the trajectory with minimum control surface excursions and without reaching saturation.

\subsubsection{Trajectory Tracking Indices}

The trajectory tracking performance is evaluated using maximum, mean, and standard deviation of the trajectory tracking errors in the horizontal XY plane, along the vertical Z-axis, and in the 3D physical space. This results in a total of 9 indices. Let $x(t), y(t)$, and $z(t)$ be the commanded trajectory point at time $\mathrm{t}$ and $x_{a}(t), y_{a}(t)$, and $z_{a}(t)$ the actual aircraft position at the same time. First, the three tracking errors are defined as:

$$
\begin{gathered}
x y_{\text {error }}=\sqrt{\left[x_{a}(t)-x(t)\right]^{2}+\left[y_{a}(t)-y(t)\right]^{2}} \\
z_{\text {error }}=\sqrt{\left[z_{a}(t)-z(t)\right]^{2}} \\
x y z_{\text {error }}=\sqrt{\left[x_{a}(t)-x(t)\right]^{2}+\left[y_{a}(t)-y(t)\right]^{2}+\left[z_{a}(t)-z(t)\right]^{2}}
\end{gathered}
$$

Then, for the total simulation time or for a pre-defined length of time, all the nine trajectory tracking indices can be defined as follows.

The maximum tracking error is:

$$
\begin{aligned}
x y_{\text {max error }} & =\max \left(\left|x y_{\text {error }}\right|\right) \\
z_{\text {maxerror }} & =\max \left(\left|z_{\text {error }}\right|\right) \\
x y z_{\text {max error }} & =\max \left(\left|x y z_{\text {error }}\right|\right)
\end{aligned}
$$

The average tracking error is:

$$
x y_{\text {Aveerror }}=\operatorname{mean}\left(\left|x y_{\text {error }}\right|\right)
$$




$$
\begin{aligned}
z_{\text {Aveerror }} & =\operatorname{mean}\left(\left|z_{\text {error }}\right|\right) \\
x y z_{\text {Aveerror }} & =\operatorname{mean}\left(\left|x y z_{\text {error }}\right|\right)
\end{aligned}
$$

The standard deviation of the tracking error is:

$$
\begin{aligned}
x y_{\text {errorstd }} & =\operatorname{std}\left(x y_{\text {error }}\right) \\
z_{\text {errorstd }} & =\operatorname{std}\left(z_{\text {error }}\right) \\
x y z_{\text {errorstd }} & =\operatorname{std}\left(x y z_{\text {error }}\right)
\end{aligned}
$$

\subsubsection{Control Activity Indices}

The control activity indices are defined using two important parameters: the integral of the absolute value of the rate of change of actuator deflection, and the actuator saturation percentage. Therefore, a total of 8 indices result for the 4 actuators considered: stabilator, aileron, rudder, and throttle.

Let $\delta_{a}, \delta_{e}, \delta_{r}$, and $\delta_{t}$ be the actual deflections of the stabilator, aileron, rudder, and throttle, respectively; then the control activity indices are defined as follows [55].

Denoting the total test duration by $\mathrm{T}$, the integral of aileron, stabilator, rudder deflection and throttle rate of change is:

$$
\begin{aligned}
& I_{\dot{\delta}_{a}}=\frac{1}{T} \int_{0}^{T}\left|\dot{\delta}_{a}(t)\right| d t \\
& I_{\dot{\delta}_{e}}=\frac{1}{T} \int_{0}^{T}\left|\dot{\delta}_{e}(t)\right| d t \\
& I_{\dot{\delta}_{r}}=\frac{1}{T} \int_{0}^{T}\left|\dot{\delta}_{r}(t)\right| d t \\
& I_{\dot{\delta}_{t}}=\frac{1}{T} \int_{0}^{T}\left|\dot{\delta}_{t}(t)\right| d t
\end{aligned}
$$

The stabilator saturation index assuming non-symmetric positive and negative extreme deflections is defined as: 


$$
S_{\delta e}=\frac{100}{T} \int_{0}^{T}\left(\tilde{\delta}_{e 1}(t)+\tilde{\delta}_{e 2}(t)\right) d t
$$

where $\tilde{\delta}_{e 1}=\left\{\begin{array}{l}0 \text { for } \delta_{e}<\delta_{\text {emax }} \\ 1 \text { for } \delta_{e} \geq \delta_{\text {emax }}\end{array} \quad \tilde{\delta}_{e 2}=\left\{\begin{array}{l}0 \text { for } \delta_{e}>\delta_{\text {emin }} \\ 1 \text { for } \delta_{e} \leq \delta_{\text {emin }}\end{array}\right.\right.$

The aileron saturation index with symmetric extreme deflections is defined as:

$$
S_{\delta a}=\frac{100}{T} \int_{0}^{T} \tilde{\delta}_{a}(t) d t
$$

where $\tilde{\delta}_{a}=\left\{\begin{array}{l}0 \text { for }\left|\delta_{a}\right|<\delta_{\text {amax }} \\ 1 \text { for }\left|\delta_{a}\right| \geq \delta_{\text {amax }}\end{array}\right.$

The rudder saturation index is defined as:

$$
S_{\delta r}=\frac{100}{T} \int_{0}^{T} \tilde{\delta}_{r}(t) d t
$$

where $\tilde{\delta}_{r}=\left\{\begin{array}{l}0 \text { for }\left|\delta_{r}\right|<\delta_{\text {rmax }} \\ 1 \text { for }\left|\delta_{r}\right| \geq \delta_{\text {rmax }}\end{array}\right.$

The throttle saturation index is defined as:

$$
S_{\delta t}=\frac{100}{T} \int_{0}^{T} \tilde{\delta}_{t}(t) d t
$$

where $\tilde{\delta}_{t}=\left\{\begin{array}{l}0 \text { for } \delta_{t}<\delta_{\text {tmax }} \\ 1 \text { for } \delta_{t} \geq \delta_{\text {tmax }}\end{array}\right.$

\subsubsection{Total Performance Index (PI)}

To analyze the performance of the different controllers, all trajectory tracking indices and control activity indices are considered. A normalization and weighted sum process applied to the 17 individual indices is used to obtain one overall PI. The normalization values for each of the 17 indices were chosen based on the performance of all the controllers, while the weights of each index were chosen based on the importance of that index towards the total performance index (Table 3). 
Table 3. Performance Index Weights and Normalization Cut-offs [55]

\begin{tabular}{|c|c|c|c|c|c|c|c|c|c|c|}
\hline & \multicolumn{9}{|c|}{ Trajectory Tracking Performance } & \multirow[t]{3}{*}{ Global PI Weight } \\
\hline & \multicolumn{3}{|c|}{ Max } & \multicolumn{3}{|c|}{ Mean } & \multicolumn{3}{|c|}{ Standard Deviation } & \\
\hline & $\mathrm{XY}$ & $\mathbf{z}$ & $\mathrm{XYZ}$ & $\mathbf{X Y}$ & $\mathbf{Z}$ & $\mathrm{XYZ}$ & $\mathbf{X Y}$ & Z & $\mathrm{XYZ}$ & \\
\hline Normalization Cut-off & 50 & 50 & 50 & 10 & 10 & 10 & 5 & 5 & 5 & \\
\hline$w_{T T}$ & 0.06 & 0.08 & 0.06 & 0.12 & 0.16 & 0.12 & 0.12 & 0.16 & 0.12 & \\
\hline \multirow[t]{4}{*}{$\bar{w}_{T T}$} & & & & & & & & & & 0.7 \\
\hline & \multicolumn{8}{|c|}{ Control Activity Performance } & & \\
\hline & \multicolumn{4}{|c|}{ Surface Activation Index } & \multicolumn{4}{|c|}{ Saturation Index } & & \\
\hline & Elevator & Aileron & Rudder & Throttle & Elevator & Aileron & Rudder & Throttle & & \\
\hline Normalization Cut-off & 0.5 & 0.5 & 0.5 & 20 & 100 & 100 & 100 & 100 & & \\
\hline$w_{C A}$ & 0.1 & 0.1 & 0.1 & 0.2 & 0.1 & 0.1 & 0.1 & 0.2 & & \\
\hline $\bar{w}_{C A}$ & & & & & & & & & & 0.3 \\
\hline
\end{tabular}

A total trajectory tracking index (TTI) is computed based on the 9 individual indices pertinent to trajectory tracking performance. TTI takes values between 1 and 0 . TTI values close to 1 indicate the trajectory tracking is achieved with minimal error, whereas TTI close to 0 indicates that the controller produces large tracking errors leading to loss of control and/or crash. A similar approach is applied to the total control activity index (CAI), which is obtained as a weighted sum of the 8 individual indices pertinent to control usage. CAI values close to 1 indicate that the controller is achieving the task with a small amount of control actuator activity without reaching the extreme deflections, whereas values close to 0 indicate that the controller is commanding large control activity, possibly with saturation. The total performance index (PI) was calculated using the constant weight method for the total length of the path. A set of constant weights was selected to sum the overall trajectory tracking and the overall control activity index into the total performance index. The set of weights used were 0.7 for the trajectory tracking index and 0.3 for the control activity index, which is considered to be a typical distribution adequate for numerous tasks and missions [55]. For the given weights, PI above 0.6 generally provides "good" tracking with little deviation from the commanded path and limited control actuation. Performance indices in the range of 0.3 to 0.6 typically provide worse tracking with intensive control actuation and some saturation. Performance indices below 0.3 are generally obtained when the tracking errors are very large despite excessive control activity. In many of these situations, the aircraft cannot complete the entire mission. 


\subsection{Results}

Extensive flight simulation tests have been performed for all four paths and the results obtained are discussed in this section. Complete result tables are included in Appendices A, B, C, and D for figure 8 path, 3D s-turns, oval path, and OA path, respectively.

Tables A1, B1, C1, and D1 present the maximum tracking error values achieved with the PPID control laws and the PPID augmented with the L1 adaptive output feedback controller for all four paths, respectively. Tracking error values are computed along the vertical axis $\mathrm{Z}$, in the horizontal plane $\mathrm{XY}$, and in three dimensions, $\mathrm{XYZ}$, under nominal conditions, aileron failures, stabilator failures, and rudder failures. Results under turbulence of different intensity are also included.

For figure 8 path, in all cases considered, the L1 augmentation consistently reduces the values of the maximum tracking errors. The relative reduction is more significant on the vertical channel. It should be noted that the L1 augmentation can handle the more demanding cases when PPID alone cannot provide adequate compensation, such as the locked aileron and rudder at 8 degrees. In particular, under rudder failure, the maximum tracking error with PPID is $478 \mathrm{~m}$, while the error with L1 is $14.3 \mathrm{~m}$, which is close to the value of $13.8 \mathrm{~m}$ recorded for nominal flight. It can be noticed that in terms of maximum tracking error, the L1 control laws are more robust with respect to abnormal conditions maintaining the values reached under nominal conditions.

The superior robustness of the L1 control laws as compared to PPID can be noticed for the 3-D sturns as well. However, at nominal conditions and under mild failure conditions, the non-adaptive control laws achieve lower maximum tracking errors. For example, for the PPID control laws, the maximum tracking error is 26.6. $\mathrm{m}$ at nominal conditions, 28.9 for aileron stuck at 2 degrees, 35.7 $\mathrm{m}$ for aileron stuck at 5 degrees, and $849 \mathrm{~m}$ for aileron stuck at 8 degrees. The L1 control laws maintain a value of $35.4 \mathrm{~m}$ for all these cases. This makes the 3-D s-turns path the most demanding in terms of this performance parameter.

The same trends observed for the figure 8 path are present for the oval path, with the exception of stabilator failure cases, where the values of the maximum tracking errors for the two sets of control laws are very close to each other. It should be noted that the oval path appears to be less demanding and the values of the maximum error vary less with the severity of the abnormal condition. 
However, a maximum error of $49 \mathrm{~m}$ is reached by the PPID under aileron failure, while the L1 controller maintains a value of $16 \mathrm{~m}$.

The OA path is the second most demanding task. L1 control laws achieve a maximum tracking error around $20 \mathrm{~m}$ for all cases considered exhibiting the same robustness with respect to abnormal conditions as previously noted. Control is lost with PPID under aileron stuck at 8 degrees; however, with L1 the tracking performance is maintained close to nominal conditions.

Tables A2, B2, C2, and D2 present the mean of the tracking error values achieved with the PPID control laws and the PPID augmented with the L1 adaptive output feedback controller for all four paths, respectively. Tracking error values are computed along the vertical axis $\mathrm{Z}$, in the horizontal plane $X Y$, and in three dimensions, XYZ, under nominal conditions, aileron failures, stabilator failures, and rudder failures. Results under turbulence of different intensity are also included. Tables A3, B3, C3, and D3 present corresponding values of the standard deviation of the tracking errors.

For all four paths, the trends recorded for the maximum tracking errors are also present for the mean and the standard deviation of the tracking errors. The ranking of the four paths with respect to the mean tracking errors is preserved, with the 3-D s-turns being the most demanding, followed in order by the OA, oval, and figure 8 paths. In terms of standard deviation, the largest values are recorded for the 3-D s-turns, followed by the oval, OA, and figure 8 paths.

The controller activity index is comprised of two parameters: integral of control surface deflection rate and saturation index. These two parameters should be minimum in order to attend the maximum controller activity index. It should be noted that the maximum controller activity can be simply achieved by not activating any of the control surfaces, which might result in very poor tracking or even the crash of the aircraft. Therefore, these metrics should be considered in conjunction with the tracking performance such that better trajectory tracking is achieved with limited and gradual changes in the control surface deflections.

Tables A4, B4, C4, and D4 present the integral of control actuation rate achieved with the PPID control laws and the PPID augmented with the L1 adaptive output feedback controller for all four paths, respectively. These tables include the integrals of control surface deflection rates for stabilator, aileron, and rudder as well as the integral of throttle rate. From the tables, it can be 
noticed that the deflection rates of stabilator and aileron for L1 adaptive controller are not as gradual as the PPID controller, whereas the deflection rates of rudder and throttle for L1 adaptive controller are more gradual than the PPID controller under nominal and all abnormal conditions. The result of high aileron and stabilator deflection rates of L1 adaptive controller is the superior trajectory tracking. L1 adaptive controller tracks better than PPID with a slight increase in the deflection rates. The same trends observed for the figure 8 path are present for the oval path and OA path. The most demanding case is 3D S Turns. The deflection rates of L1 adaptive controller show more gradual changes than the PPID. The PPID poorly tracks the trajectory with great strain in the control activity.

The values of the saturation index for the four actuators over the four paths are presented in Tables A5, B5, C5, and D5, respectively. The aileron saturation index of L1 adaptive over the figure 8 path is slightly larger than the PPID controller for all levels of aileron failures, medium stabilator failures, severe stabilator failures, and severe rudder failures. The throttle saturation index for severe aileron and rudder failures of PPID controller is slightly larger than the L1 adaptive controller. The same trends observed for the figure 8 path are present for the oval path with the exception of throttle saturation index, which is zero for both sets of control laws. The results for the OA path have similar trends as for the oval path. The L1 can handle better throttle saturation for severe aileron failure than the PPID controller. The performance of L1 adaptive controller is dominant in the 3D S Turns path. The L1 adaptive controller performs better than the PPID controller in terms of this metric for all aileron and rudder failures, as well as under turbulence conditions.

The values of the composite TTI, CAI, and PI are listed in Tables A6, B6, C6, and D6, for the four paths, respectively.

The results for figure 8 shown in Table A6, lead to the conclusion that the L1 adaptive controller handles better the trajectory tracking than PPID controller under all conditions and the performance of L1 adaptive controller is dominant for the severe aileron and rudder failures. The controller activity performance of L1 adaptive controller is almost equal or slightly less than PPID controller for all conditions except for the values of severe rudder failure. Therefore, the L1 adaptive controller performs better trajectory tracking with less controller activity as compared to 
the PPID controller for all abnormal conditions. The L1 adaptive controller performance index is twice the PPID index for the severe aileron and rudder failures.

The trends for figure 8 path are the same as for the oval and OA path. The only difference is that the PPID controller loses control for severe aileron failures. The most demanding path is 3D S Turns. The L1 adaptive controller tracks better the trajectory with minimal controller activity for all cases. The PPID performance is poor for the severe aileron failure.

Table 4 shows the percentage increase of the TTI of L1 adaptive controller over PPID controller for all four paths. The percentage increase is calculated using the formula:

$$
\% \text { increase }=\frac{\text { TTI of L1 adaptive controller }- \text { TTI of PPID controller }}{\text { TTI of PPID controller }} \times 100
$$

Figure 29, Figure 30, Figure 31 and Figure 32 present the TTI of PPID and the L1 adaptive controller for figure 8 path, oval path, OA path and 3D S-Turns path, respectively. From the Figure 29, the L1 adaptive controller has a better trajectory tracking performance index than PPID under nominal and all abnormal failures. It is observed that in all cases, the percentage increase of TTI of L1 adaptive controller over PPID is 1 to $3 \%$. In particular, the percentage increase of L1 adaptive controller over PPID for severe aileron and severe rudder failure is $125 \%$ and $115 \%$ respectively. Figure 30, Figure 31 show similar trends with drastic percentage increase of 57.197\% and $113.990 \%$ respectively for severe aileron failures. Figure 32 presents the L1 adaptive controller having a better trajectory tracking performance index than PPID under severe aileron and rudder failures. It is also observed that the L1 adaptive controller performs better in adverse conditions while PPID performs better in nominal condition. The percentage increase of L1 over PPID under severe aileron and rudder failures are $81 \%$ and $12 \%$ respectively. 
Table 4. Percentage Increase of TTI for all Four Paths

\begin{tabular}{|c|c|c|c|c|}
\hline \multicolumn{5}{|c|}{ TTI } \\
\hline \multicolumn{7}{|c|}{ Percentage increase of L1 adaptive controller over PPID } \\
\hline Nominal & Figure 8 & Oval & OA & 3D S Turns \\
\hline Aileron stuck at 2 deg & 1.529 & 1.467 & 1.728 & -11.31 \\
\hline Aileron stuck at 5 deg & 2.370 & 1.467 & 2.101 & -8.587 \\
\hline Aileron stuck at 8 deg & 3.721 & 1.096 & 2.481 & -1.049 \\
\hline Stab stuck at 2 deg & 125.0 & 57.20 & 114.0 & 81.04 \\
\hline Stab stuck at 5 deg & 2.387 & 1.220 & 2.112 & 1.389 \\
\hline Stab stuck at 8 deg & 3.281 & 1.225 & 2.125 & 2.028 \\
\hline Rudder stuck at 2 deg & 4.461 & 1.111 & 3.042 & 12.35 \\
\hline Rudder stuck at 5 deg & 0.815 & 1.605 & 1.487 & -12.20 \\
\hline Rudder stuck at 8 deg & 0.579 & 2.642 & 1.619 & -12.06 \\
\hline Light Turbulence & 115.4 & 6.525 & 2.919 & -6.553 \\
\hline Moderate Turbulence & 1.410 & 1.834 & 1.726 & -11.38 \\
\hline Severe Turbulence & 1.178 & 1.838 & 14.53 & -11.57 \\
\hline & 1.070 & 1.854 & -4.075 & -11.05 \\
\hline
\end{tabular}




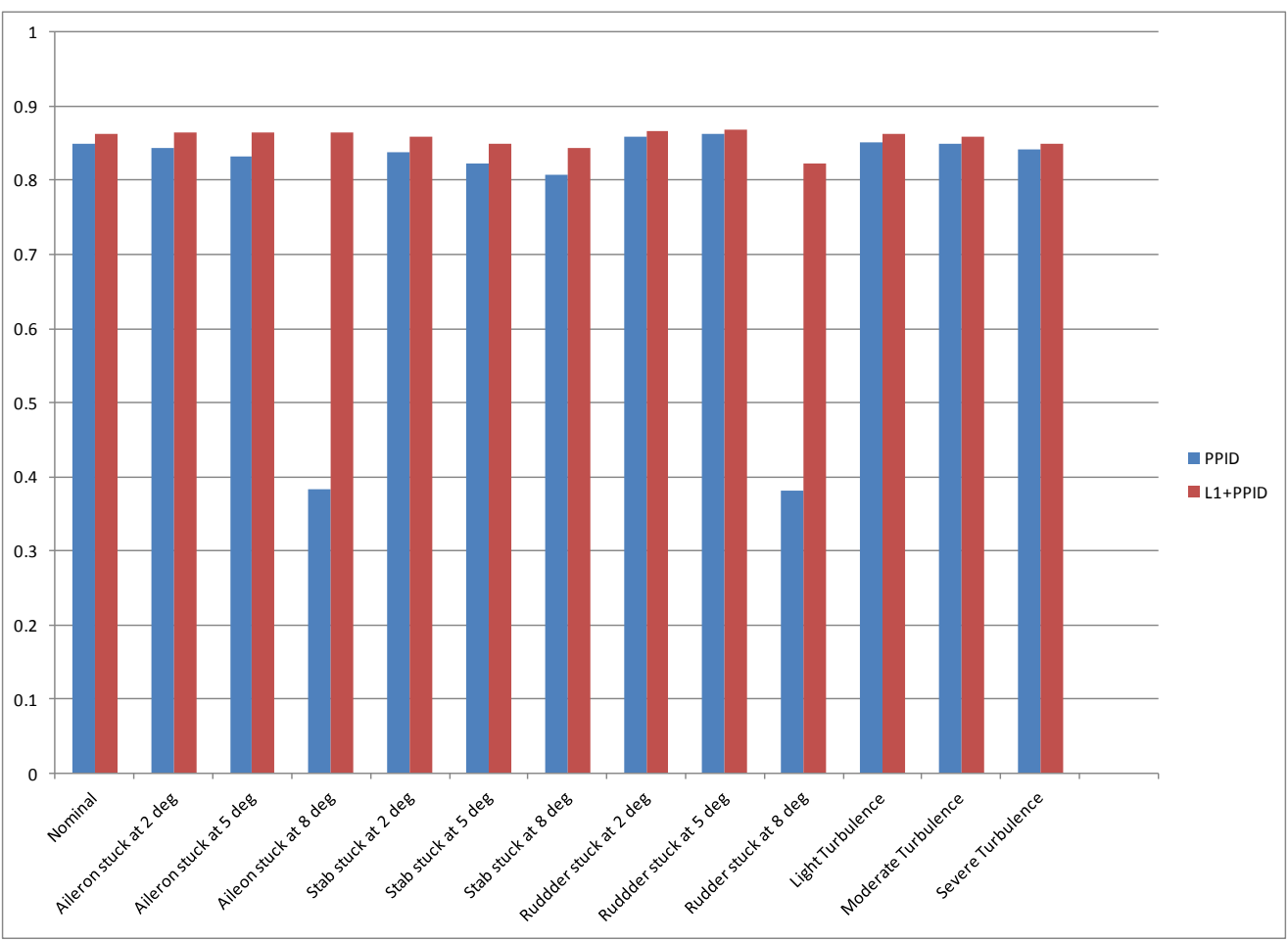

Figure 29. Trajectory Tracking Performance Index of PPID and L1 Adaptive Controller for Figure 8 Path

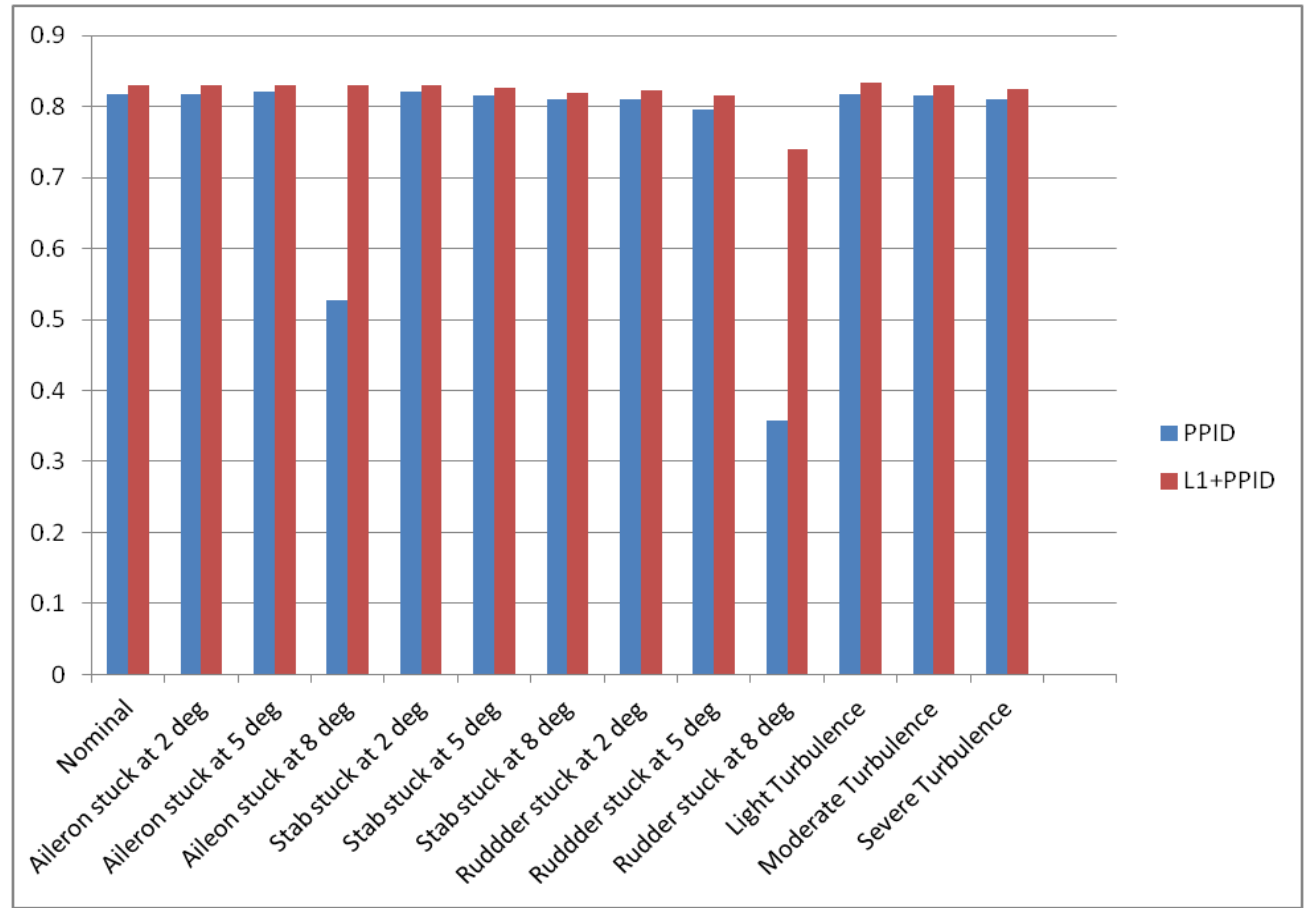

Figure 30. Trajectory Tracking Performance Index of PPID and L1 Adaptive Controller for Oval Path 


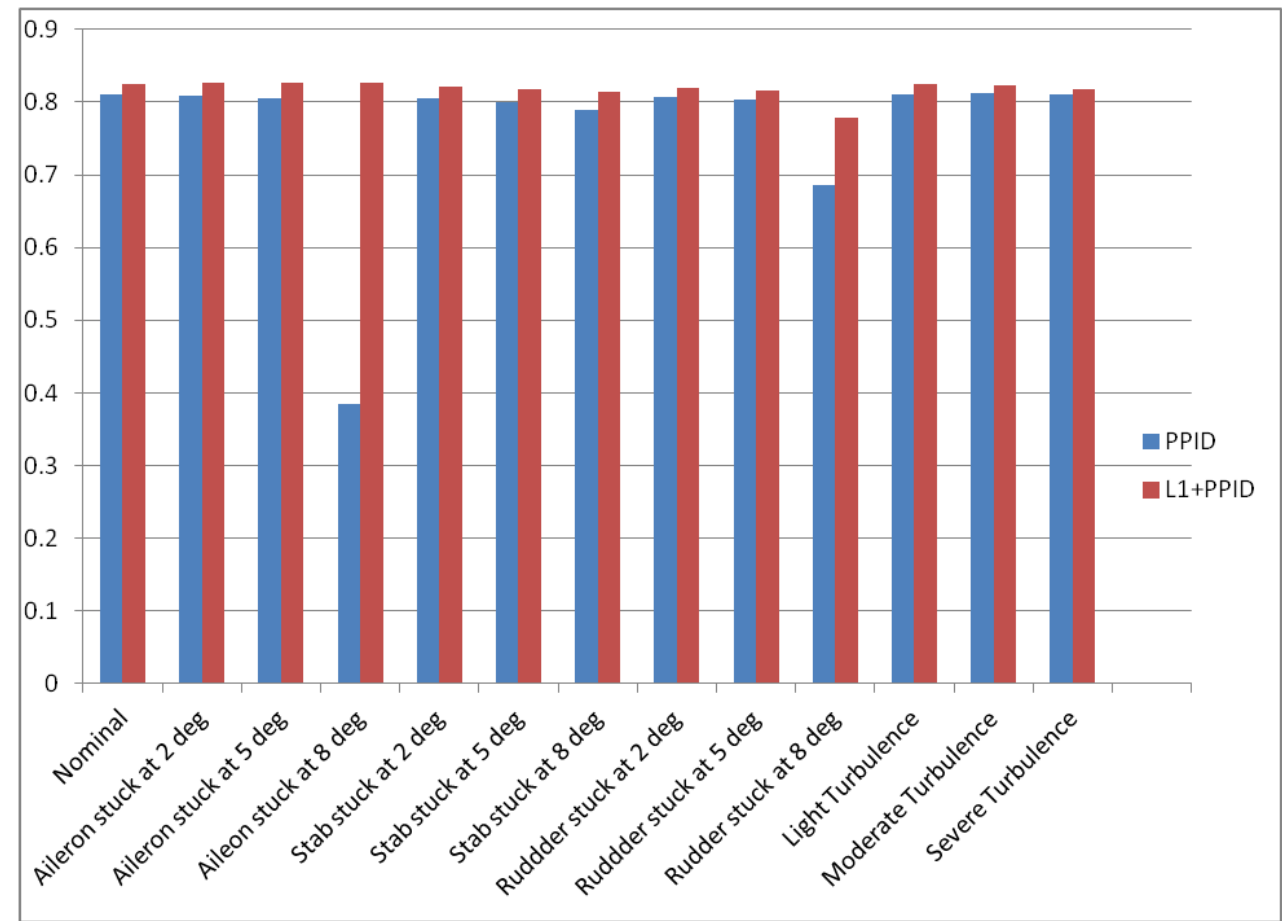

Figure 31. Trajectory Tracking Performance Index of PPID and L1 Adaptive Controller for OA Path

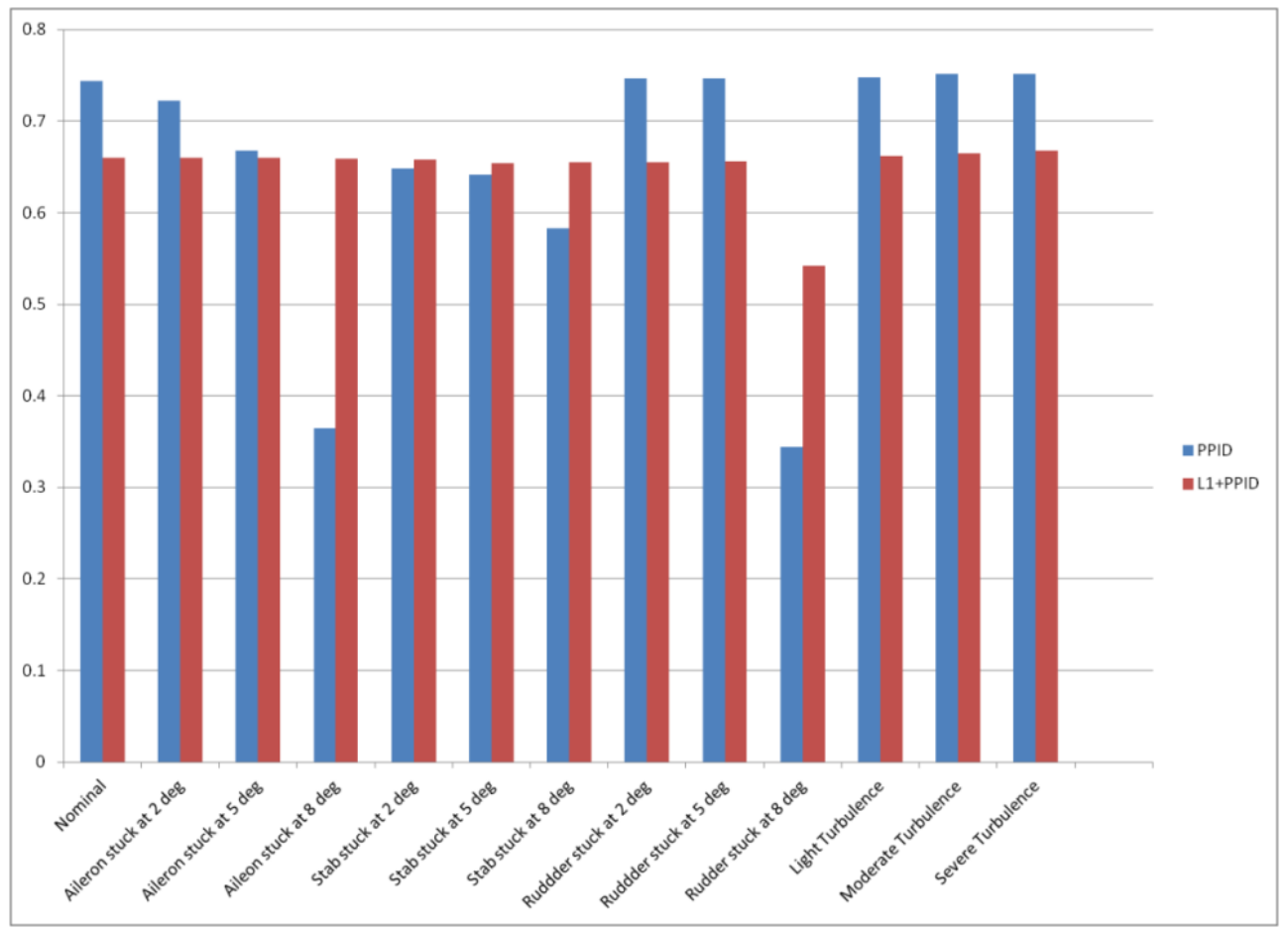

Figure 32. Trajectory Tracking Performance Index of PPID and L1 Adaptive Controller for 3D S Turns Path 
Table 5 shows the percentage increase of the CAI of L1 adaptive controller over PPID controller for all four paths. Figure 33, Figure 34, Figure 35, and Figure 36 show CAI of PPID controller and L1 adaptive controller for figure 8 path, oval path, oa path and 3D S-Turns path, respectively. From Figure 33, the performance index of CAI of L1 adaptive controller is almost equal or little less than the PPID. The percentage increase of L1 adaptive controller over PPID for severe aileron and severe rudder failures are $4.678 \%$ and $65.976 \%$ respectively. Figure 34 shows that L1 adaptive control activity performance is equal or less than the PPID. Figure 35 shows that L1 adaptive controller performs better than PPID for the severe aileron failure. In Figure 36, the CAI of L1 adaptive controller reaches almost twice the value for the PPID controller under nominal conditions, turbulence, and failures of the aileron and rudder. In all mild, moderate, and severe stabilator failure, the CAI of L1 adaptive controller is equal or less than the CAI of PPID controller.

Table 5. Percentage Increase of CAI for all Four Paths

\begin{tabular}{|c|c|c|c|c|}
\hline \multicolumn{5}{|c|}{ CAI } \\
\hline \multicolumn{7}{|c|}{ Percentage increase of L1 adaptive controller over PPID } \\
\hline Nominal & Figure 8 & Oval & OA & 3D S Turns \\
\hline Aileron stuck at 2 deg & 0.101 & 0.203 & 0.101 & 110.1 \\
\hline Aileron stuck at 5 deg & -0.203 & -0.305 & -0.409 & 118.5 \\
\hline Aileron stuck at 8 deg & 0.000 & -0.306 & -0.308 & 113.3 \\
\hline Stab stuck at 2 deg & 4.678 & 0.448 & 338.4 & 554.8 \\
\hline Stab stuck at 5 deg & -0.303 & -0.101 & -0.406 & -0.103 \\
\hline Stab stuck at 8 deg & -0.810 & 0.000 & -0.711 & -1.241 \\
\hline Rudder stuck at 2 deg & -3.760 & 0.102 & -1.531 & -5.280 \\
\hline Rudder stuck at 5 deg & 0.000 & 0.102 & -0.203 & 117.8 \\
\hline Rudder stuck at 8 deg & -0.101 & -0.305 & -0.406 & 117.2 \\
\hline Light Turbulence & 65.98 & -4.094 & -1.427 & 115.8 \\
\hline Moderate Turbulence & -1.019 & -0.817 & -1.745 & 107.1 \\
\hline Severe Turbulence & -2.174 & -2.599 & -1.563 & 101.7 \\
\hline
\end{tabular}




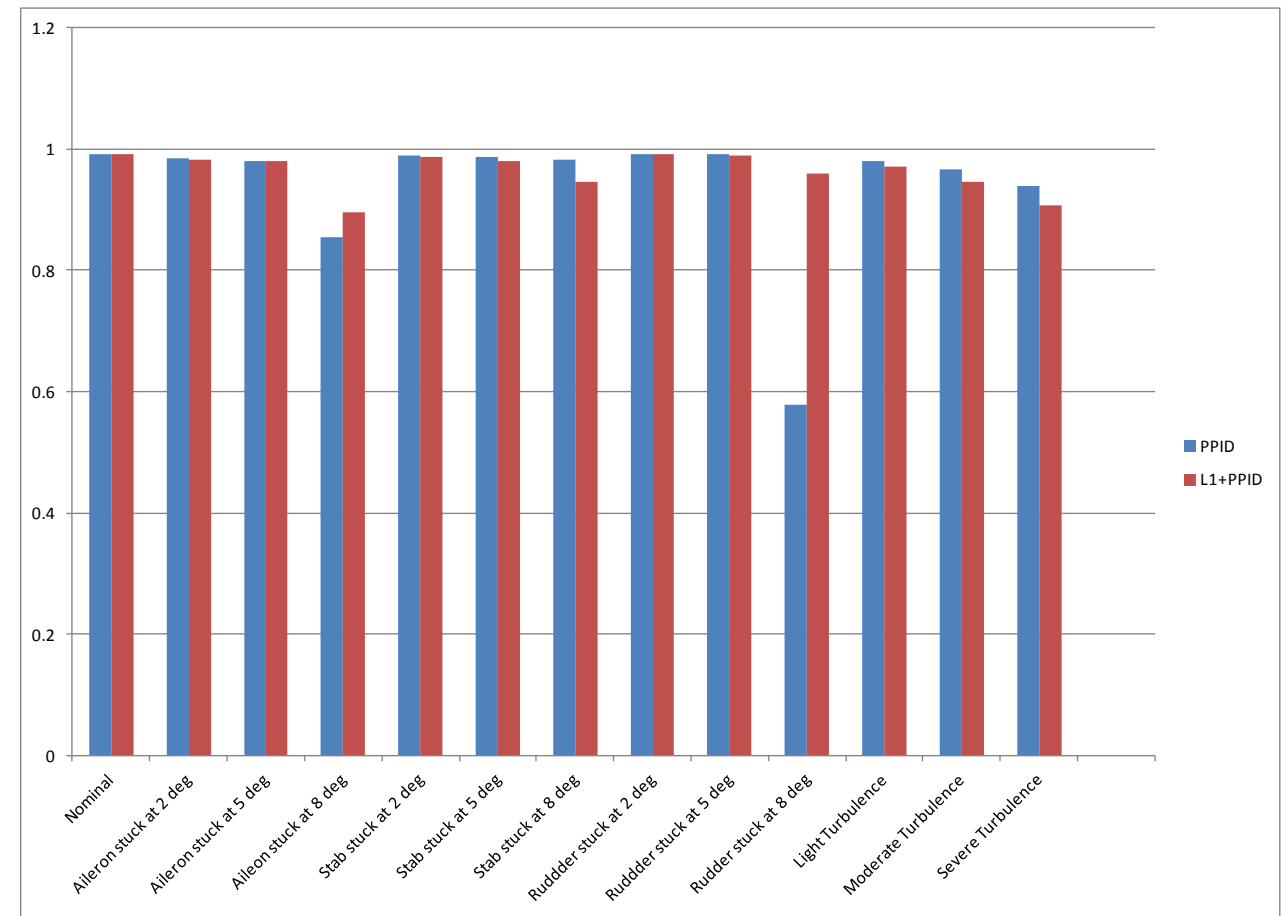

Figure 33. Controller Activity Performance Index of PPID and L1 Adaptive Controller for Figure 8 Path

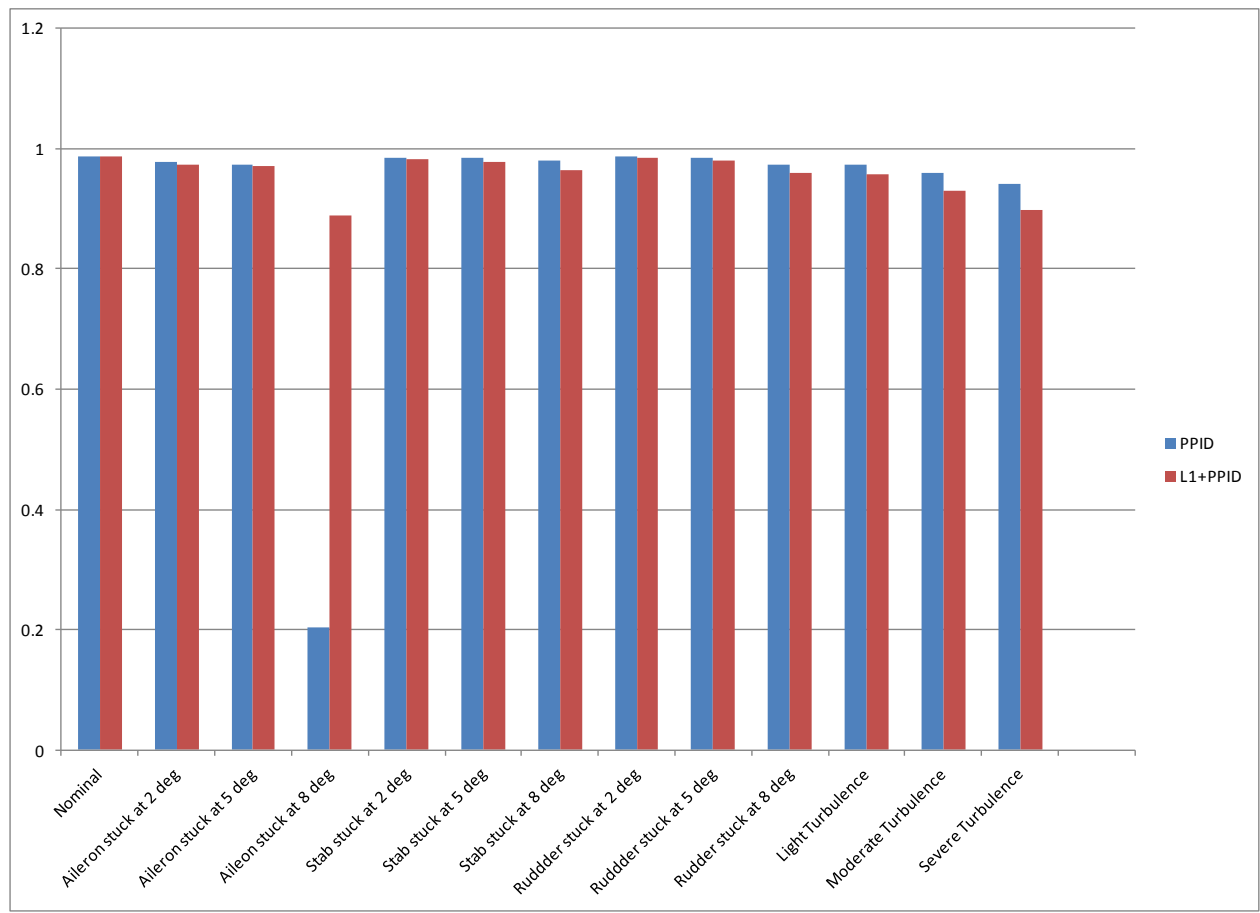

Figure 34. Controller Activity Performance Index of PPID and L1 Adaptive Controller for Oval Path 


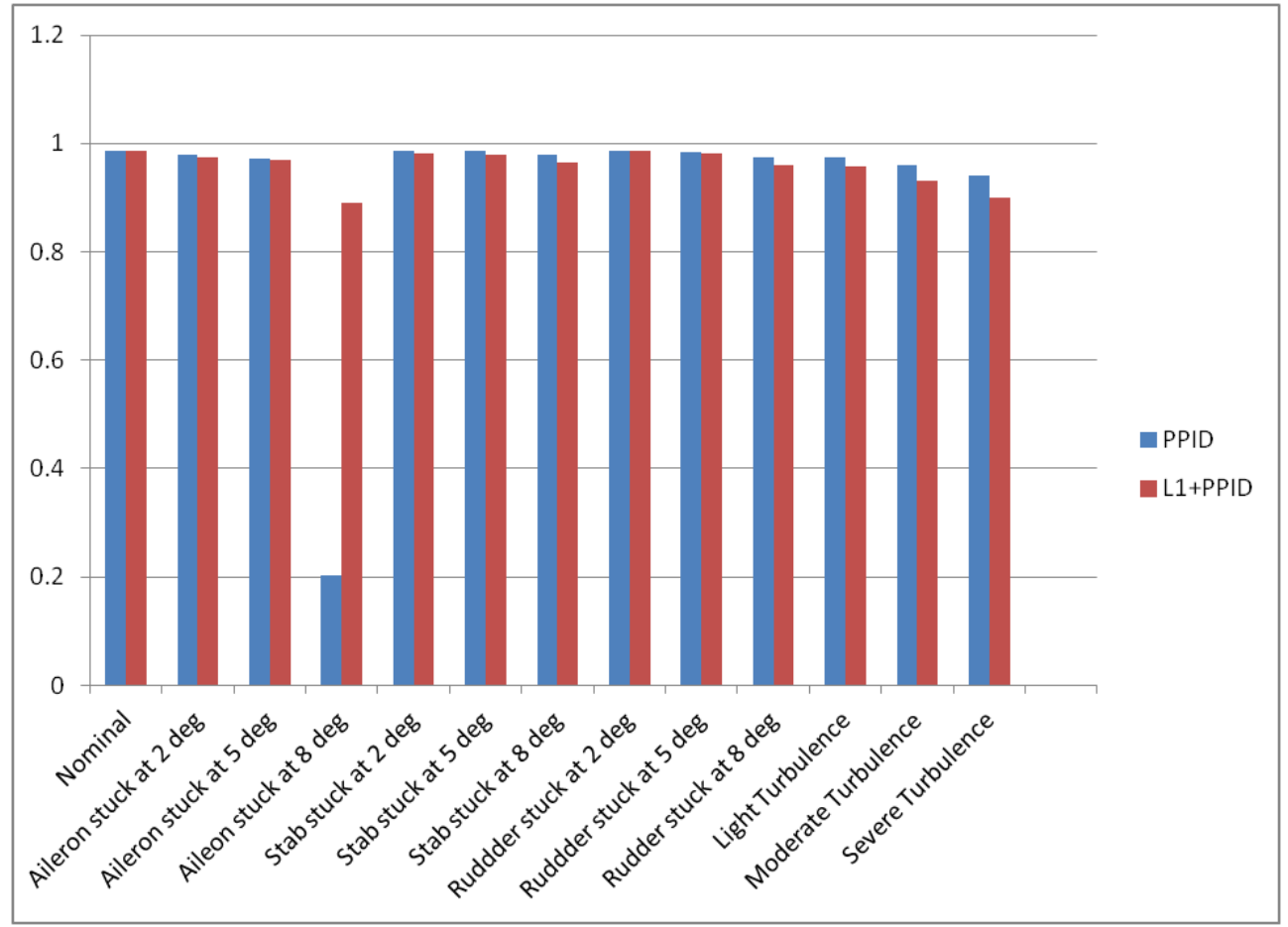

Figure 35. Controller Activity Performance Index of PPID and L1 Adaptive Controller for OA Path

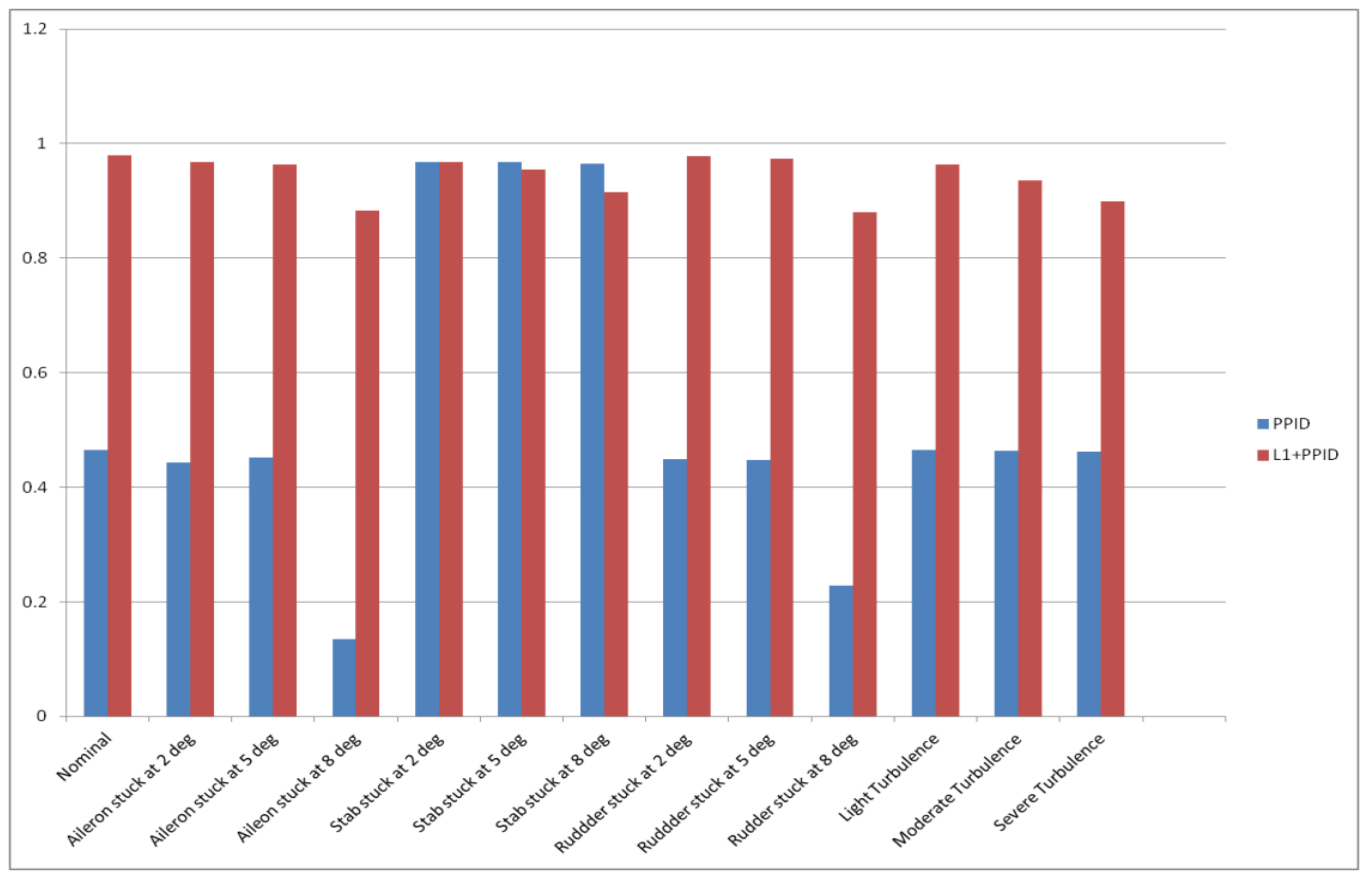

Figure 36. Controller Activity Performance Index of PPID and L1 Adaptive Controller for 3D S Turns Path 
Table 6 shows the percentage increase of L1 adaptive controller over PPID controller of the PI for all four paths. Figure 37, Figure 38, Figure 39, and Figure 40 show the PI of PPID and the L1 adaptive controller for figure 8 path, oval, OA, and 3D S-Turns paths, respectively. From Figure 37 , it is observed that in all cases the total performance index of L1 adaptive controller is better than the PPID controller. In severe aileron and rudder failures, the PI of L1 adaptive controller is twice the value reached with the PPID controller. The PI of L1 adaptive controller shows significant improvement under nominal and turbulence conditions, as well as in the presence of aileron and rudder failures. In the case of stabilator failures, the PI of L1 adaptive controller reaches lower values that those obtained with the PPID control laws. Figure 38, and Figure 39 show the same trends recorded for figure 8 path with a $155 \%$ increase of $\mathrm{L} 1$ adaptive controller performance for the severe aileron failures. From Figure 40, it can be noticed that the PI of L1 is higher in all cases. There is also noticeable increase of PI of L1 over PPID under turbulence conditions.

Table 6. Percentage Increase of PI for all Four Paths

\begin{tabular}{|c|c|c|c|c|}
\hline \multicolumn{5}{|c|}{ PI } \\
\hline \multicolumn{7}{|c|}{ Percentage increase of L1 adaptive controller over PPID } \\
\hline Nominal & Figure 8 & Oval & OA & 3D S Turns \\
\hline Aileron stuck at 2 deg & 1.009 & 1.159 & 1.159 & 14.39 \\
\hline Aileron stuck at 5 deg & 1.467 & 1.281 & 1.281 & 17.87 \\
\hline Aileron stuck at 8 deg & 2.509 & 1.519 & 1.519 & 24.54 \\
\hline Stab stuck at 2 deg & 66.29 & 155.3 & 155.3 & 146.4 \\
\hline Stab stuck at 5 deg & 1.586 & 1.281 & 1.281 & 0.806 \\
\hline Stab stuck at 8 deg & 1.833 & 1.168 & 1.168 & 0.677 \\
\hline Rudder stuck at 2 deg & 1.628 & 1.537 & 1.537 & 5.014 \\
\hline Rudder stuck at 5 deg & 0.445 & 0.929 & 0.929 & 14.46 \\
\hline Rudder stuck at 8 deg & 0.333 & 0.933 & 0.933 & 14.31 \\
\hline Light Turbulence & 0.674 & 0.465 & 0.465 & 13.42 \\
\hline Moderate Turbulence & 0.113 & -0.117 & -0.117 & 12.18 \\
\hline Severe Turbulence & -0.459 & -0.941 & -0.941 & 10.83 \\
\hline
\end{tabular}




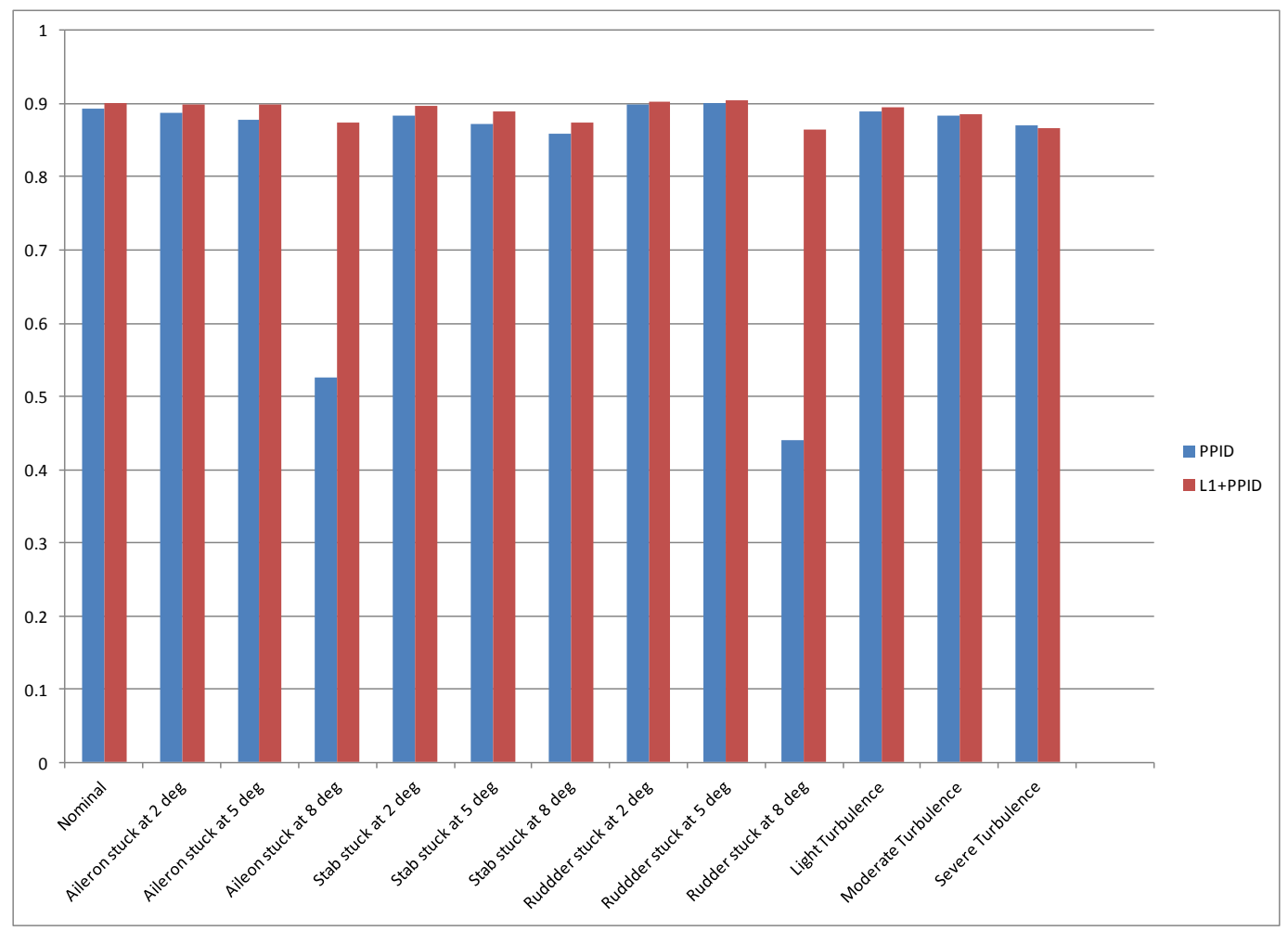

Figure 37. Total Performance Index of PPID and L1 Adaptive Controller for Figure 8 Path

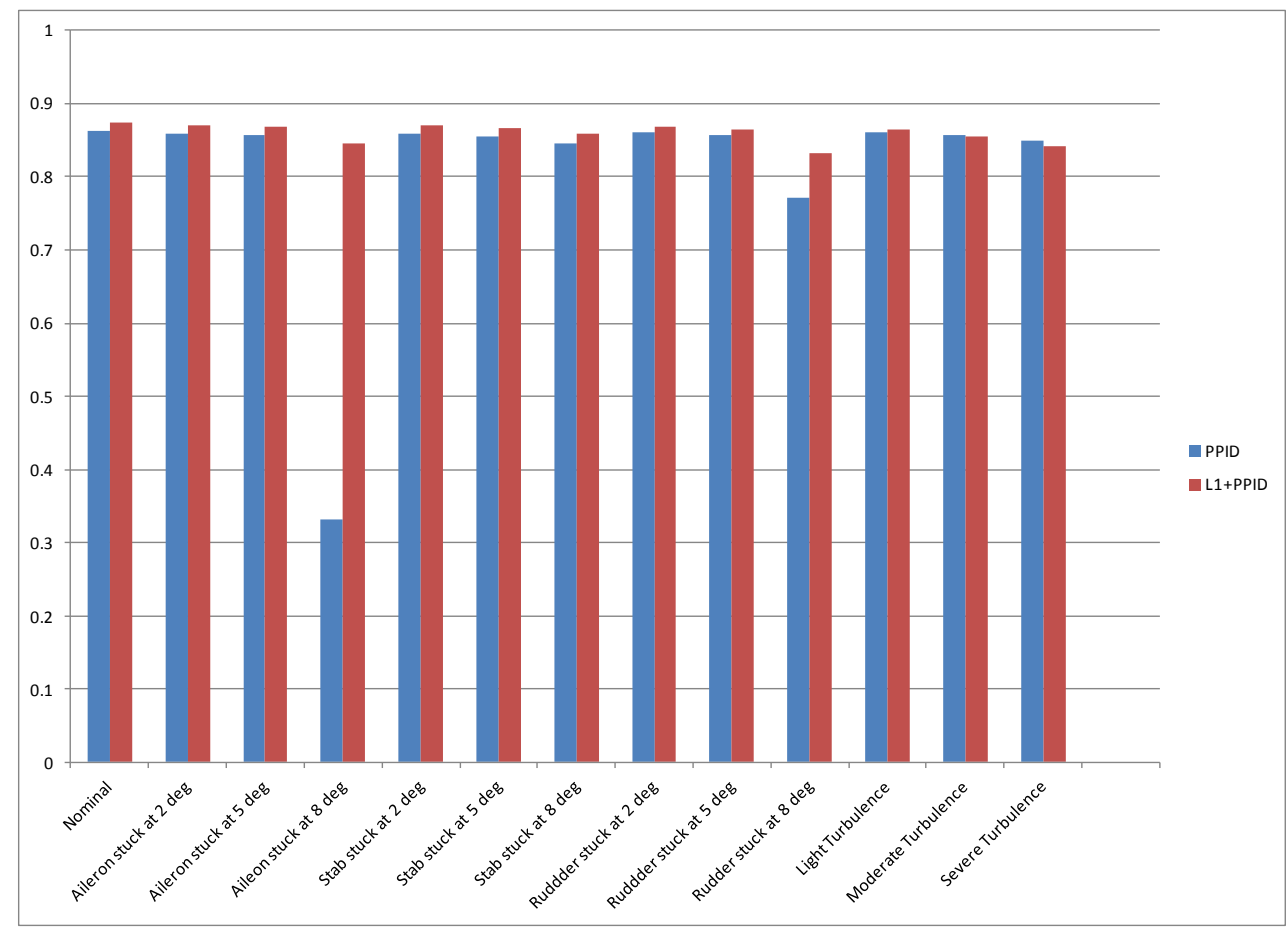

Figure 38. Total Performance Index of PPID and L1 Adaptive Controller for Oval Path 


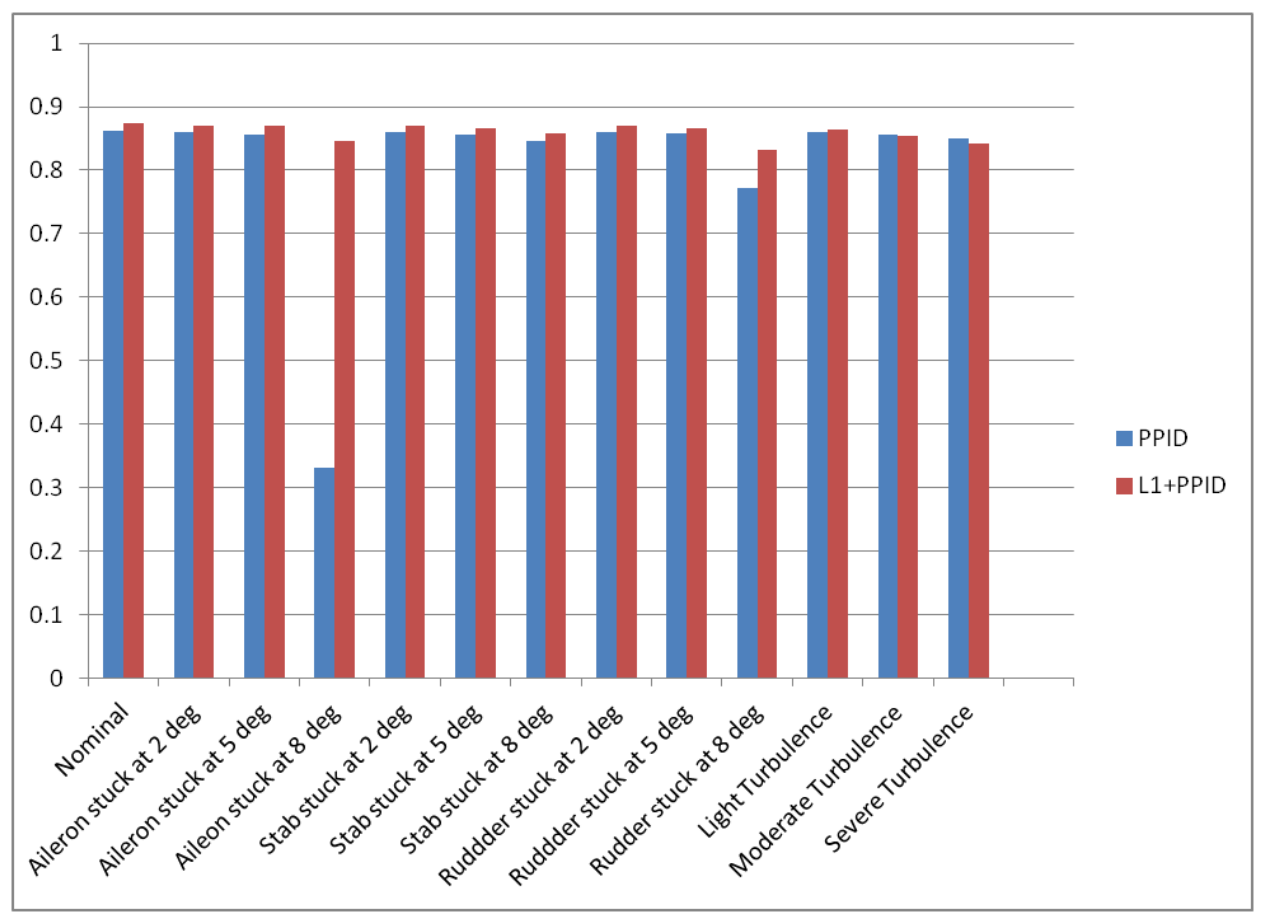

Figure 39. Total Performance Index of PPID and L1 Adaptive Controller for OA Path

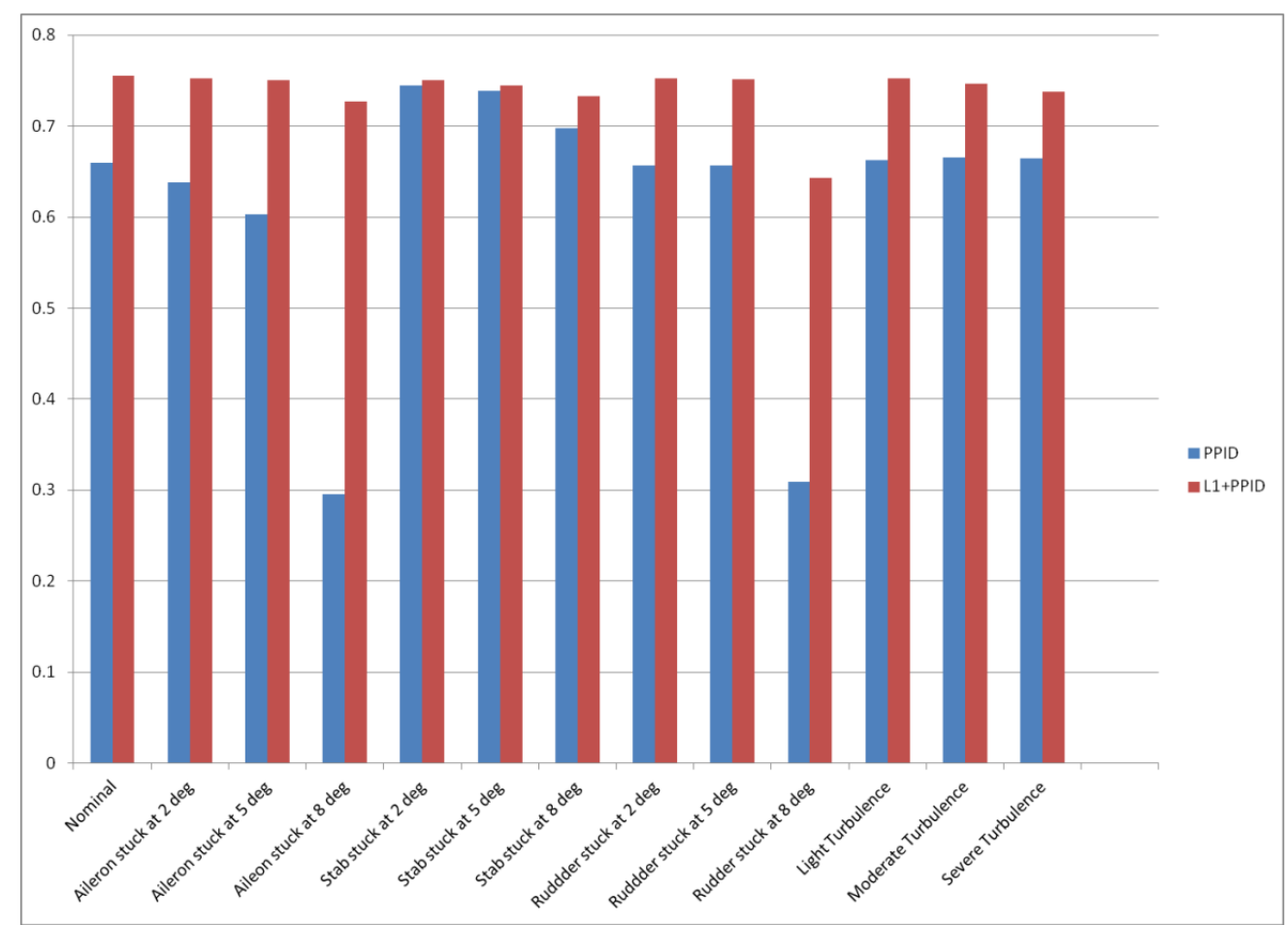

Figure 40. Total Performance Index of PPID and L1 Adaptive Controller for 3D S-Turns Path 
A summary of the performance of the different control laws in terms of the total PI depending on the severity of the abnormal condition is presented in Figures 41 through 44 for figure 8 path. Figure 41 shows the total PI under nominal conditions and mild, moderate, and severe aileron failures. The improvement in total PI achieved with the L1 control laws increases with increasing abnormal condition severity. The most significant improvement is obtained for the severe aileron failure. The comparison between total PI obtained with the PPID and L1 control laws under stabilator failure is presented in Figure 42, which shows similar trends as the aileron failure case. The results under rudder failure are presented in Figure 43. For this abnormal condition both sets of control laws perform similarly for mild and medium severity. However, L1 control laws are capable of reaching significantly higher performance under severe rudder failure. Under low levels of turbulence, the performance of the L1 controller is better; however, under severe turbulence the PPID control always are more robust, as presented in Figure 44.

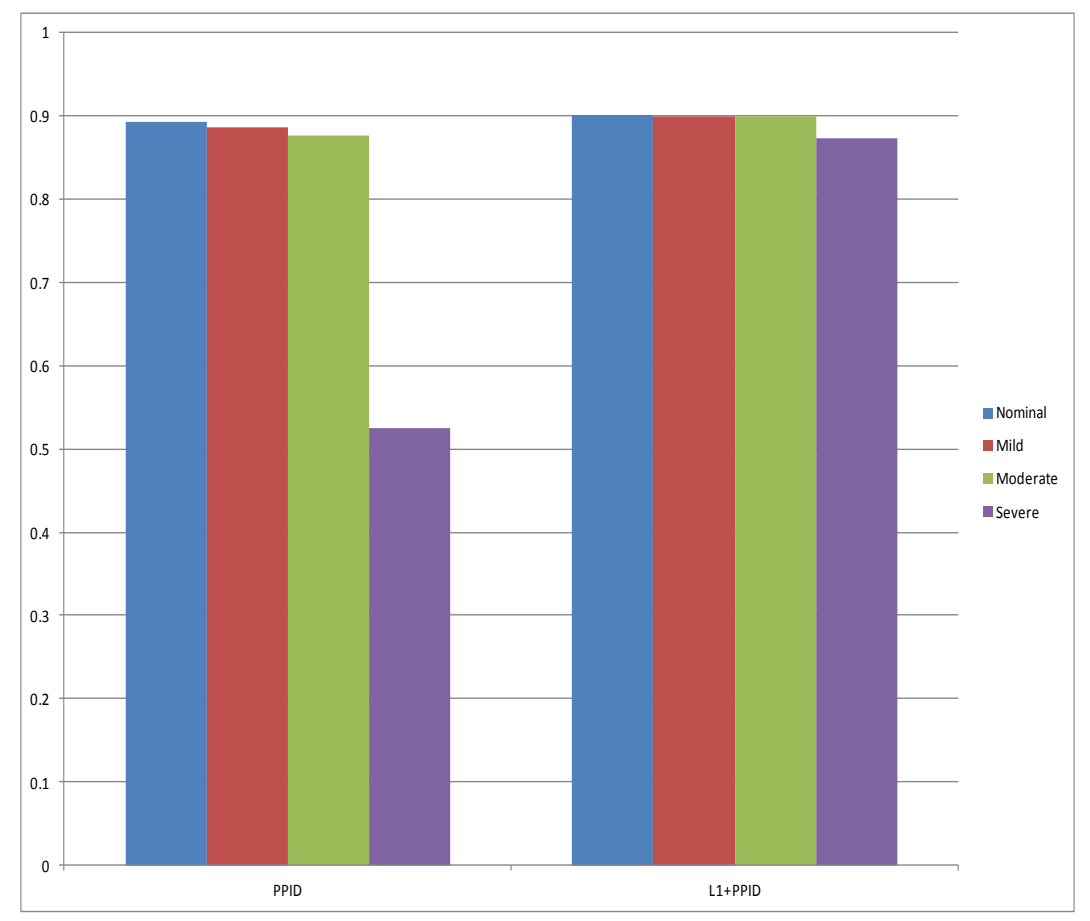

Figure 41. Total Performance Index of PPID and L1 Adaptive Controller for Aileron Failures 


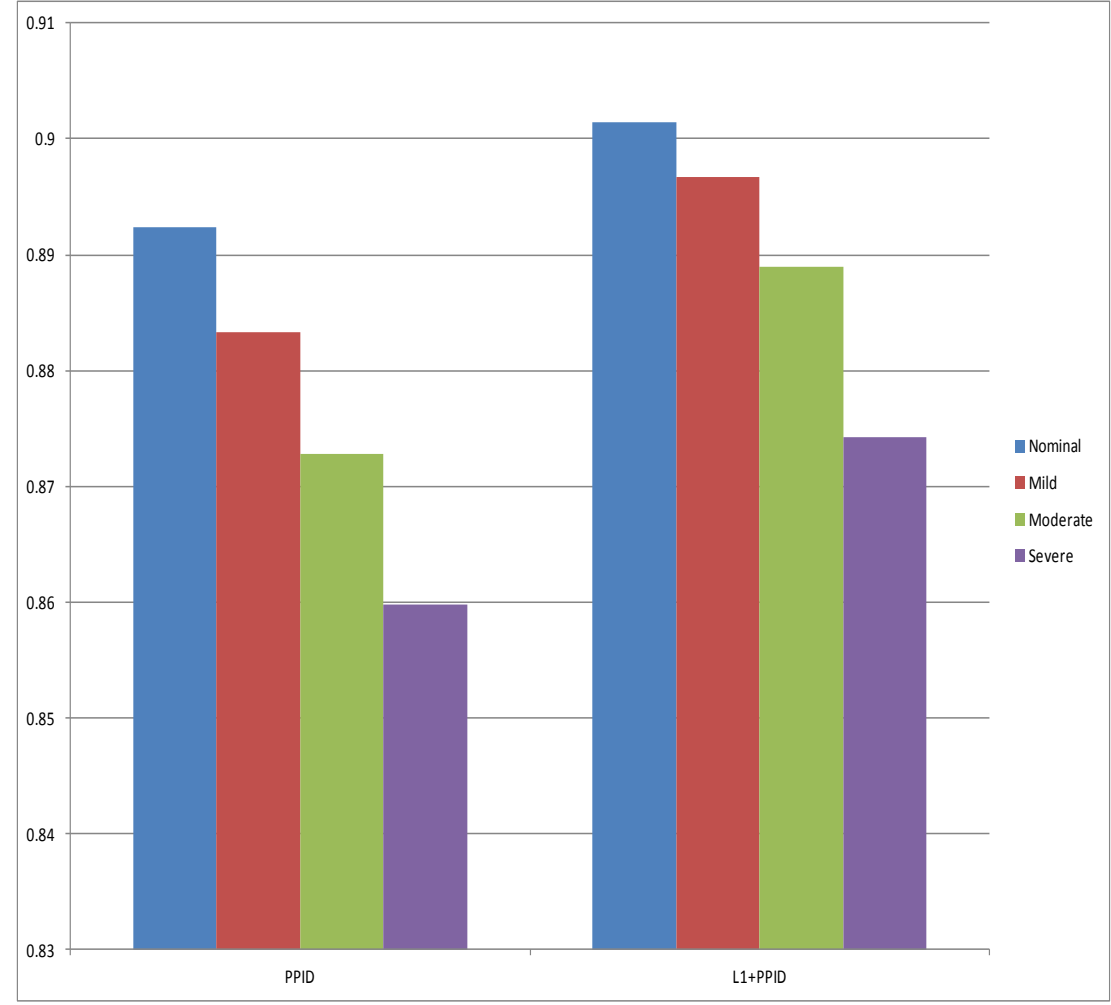

Figure 42. Total Performance Index of PPID and L1 Adaptive Controller for Stabilator Failures

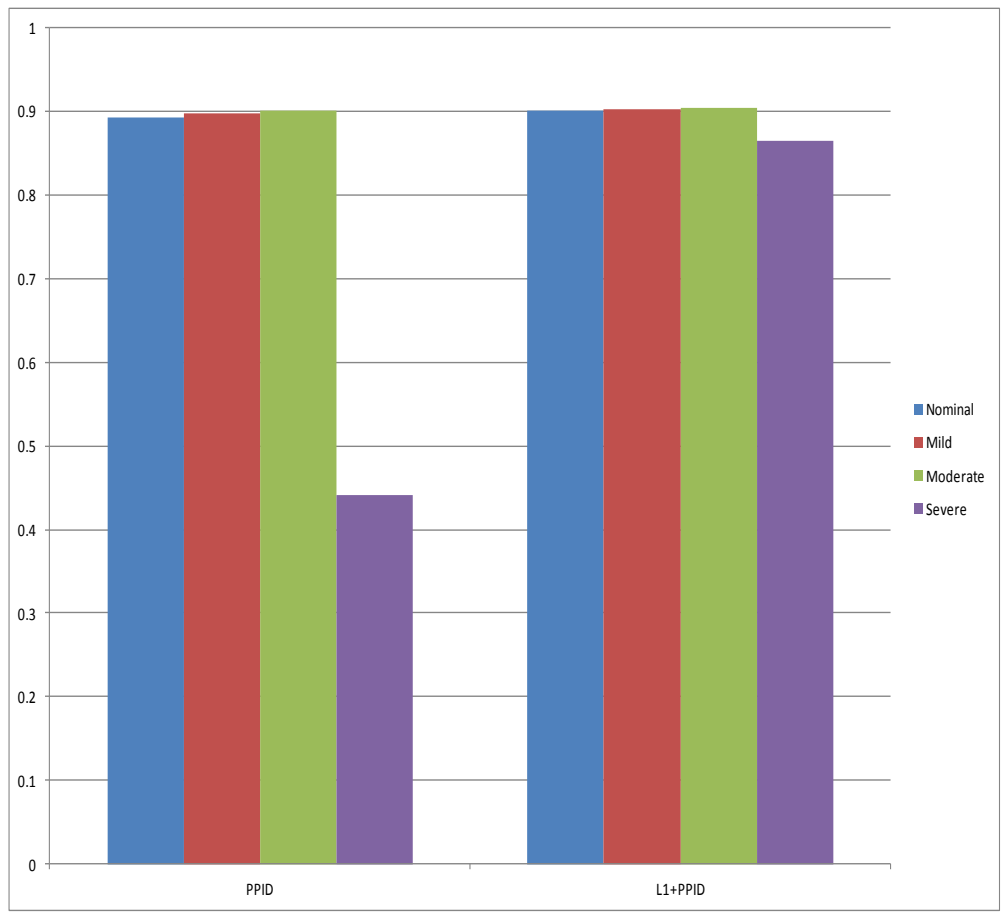

Figure 43. Total Performance Index of PPID and L1 Adaptive Controller for Rudder Failures 


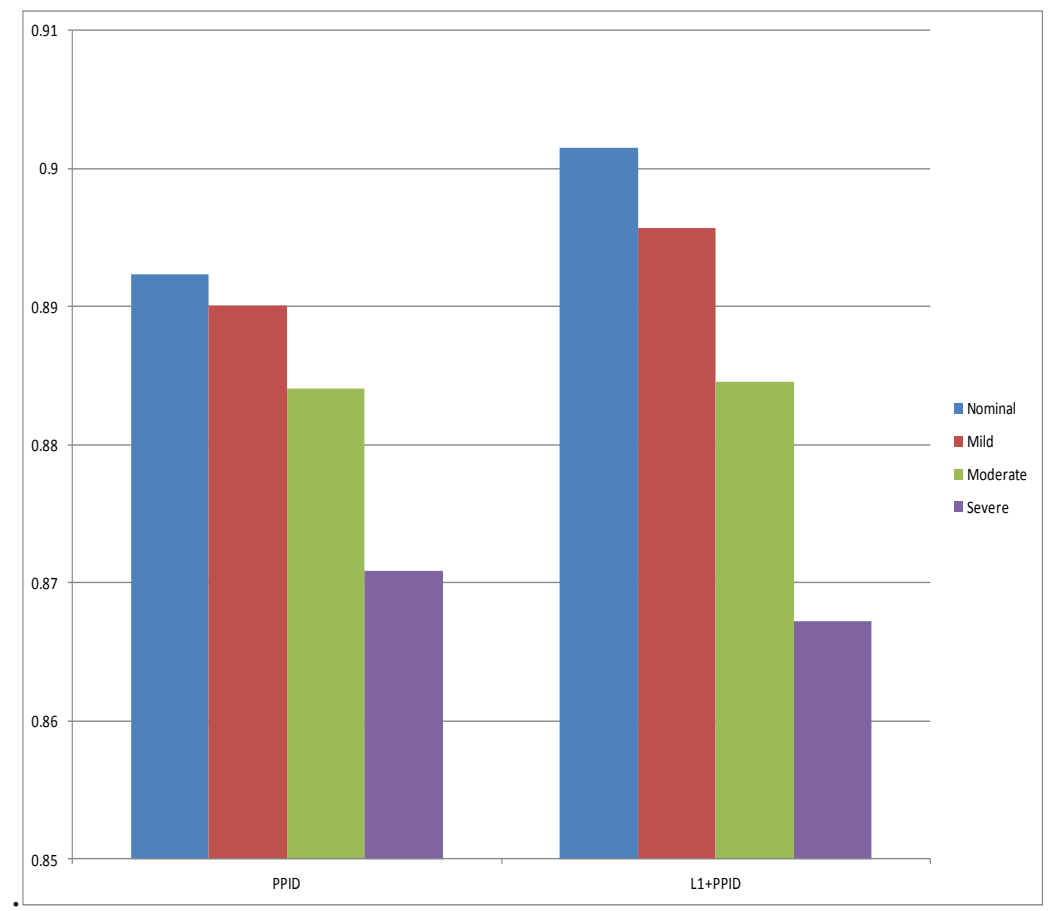

Figure 44. Total Performance Index of PPID andL1 Adaptive Controller under Turbulence Conditions

The performance analysis is extended in finding the average of the severe failures over four paths of the two controllers. That is the average of severe aileron failure of the four paths of PPID and L1+PPID is calculated and shown as red bar in Figure 45. Similarly, the other severe failures and nominal is calculated and presented below. The $\mathrm{L} 1$ adaptive controller tracks the path better than PPID under nominal and all abnormal failures. The prominent increase in the total PI is for severe aileron and severe rudder failures. From the figure, it is evident that L1 controller is capable of handling the most adverse failures, whereas the performance of PPID is not that adequate to handle complicated paths. 


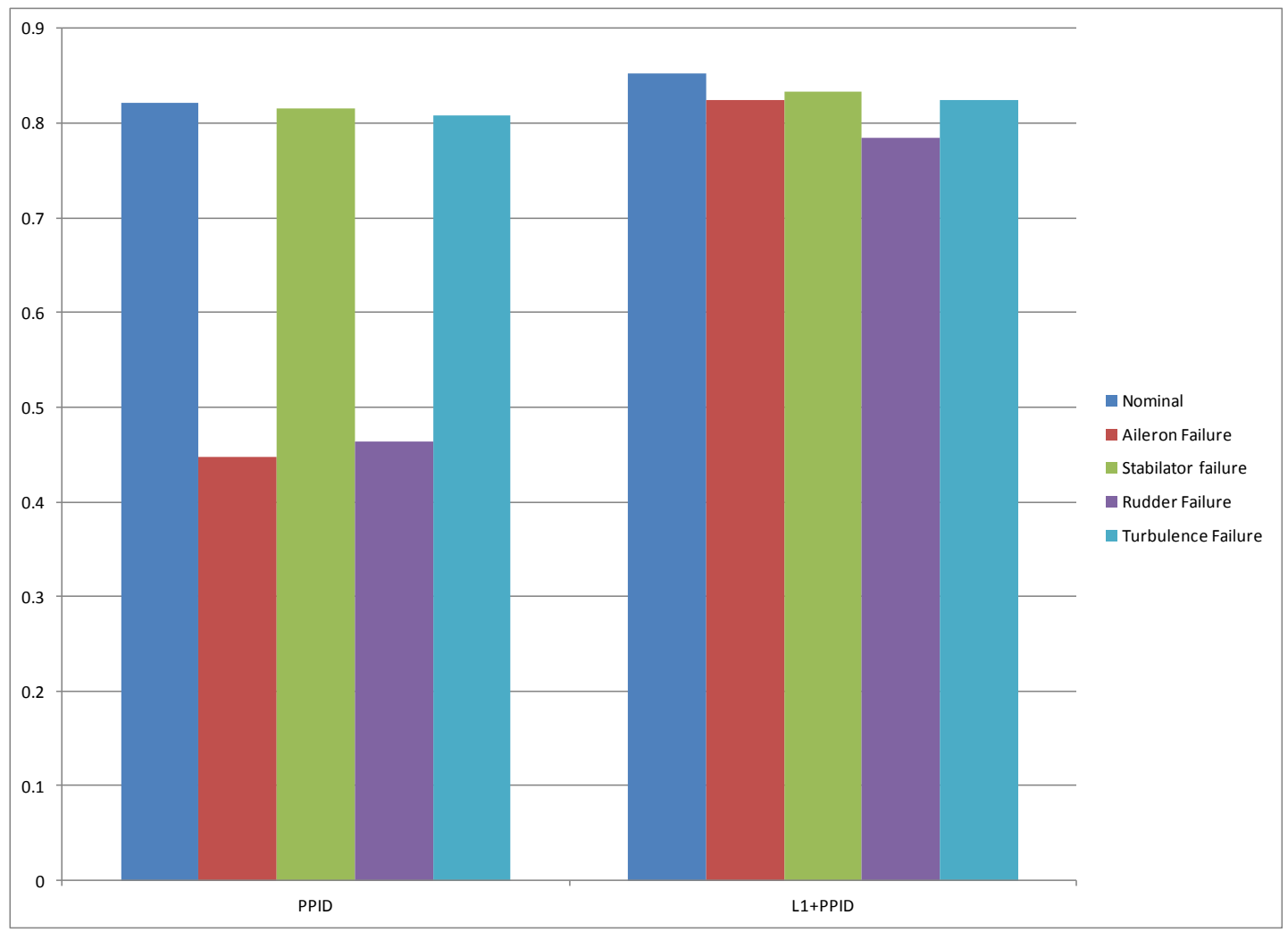

Figure 45. Performance Indices per Type Failure of PPID and L1 Adaptive Controller

The average TTI, CAI and PI over all the four paths for the two controllers have been calculated and listed in Table 7, Table 8, and Table 9 respectively. The same data are also presented graphically in Figure 46, Figure 47, and Figure 48. From Table 7, it can be seen that, in general, the L1 control laws provide improvement in trajectory tracking when the severity of the abnormal condition is high. However, under severe turbulence the PPID proves to be more robust. The adaptation of L1 appears to be too slow in the presence of severe turbulence. Table 8 and Figure 47 support the conclusion that the L1 control laws always require less control activity, although the tracking performance is similar or better. 
Table 7. Average Trajectory Tracking Performance Index of Four Paths for PPID and L1 Adaptive Controller

\begin{tabular}{|c|c|c|c|}
\hline Average PI TT & PPID & L1 +PPID & \% increase of L1 adaptive controller over PPID \\
\hline Nominal & 0.805 & 0.794 & -1.366 \\
\hline Aileron stuck at 2 deg & 0.798 & 0.795 & -0.376 \\
\hline Aileron stuck at 5 deg & 0.782 & 0.795 & 1.662 \\
\hline Aileron stuck at 8 deg & 0.416 & 0.795 & 91.11 \\
\hline Stab stuck at 2 deg & 0.778 & 0.792 & 1.799 \\
\hline Stab stuck at 5 deg & 0.770 & 0.787 & 2.208 \\
\hline Stab stuck at 8 deg & 0.747 & 0.783 & 4.819 \\
\hline Rudder stuck at 2 deg & 0.806 & 0.791 & -1.861 \\
\hline Rudder stuck at 5 deg & 0.802 & 0.789 & -1.621 \\
\hline Rudder stuck at 8 deg & 0.656 & 0.773 & 17.84 \\
\hline Light Turbulence & 0.807 & 0.796 & -1.363 \\
\hline Moderate Turbulence & 0.807 & 0.821 & 1.735 \\
\hline Severe Turbulence & 0.827 & 0.803 & -2.902 \\
\hline
\end{tabular}

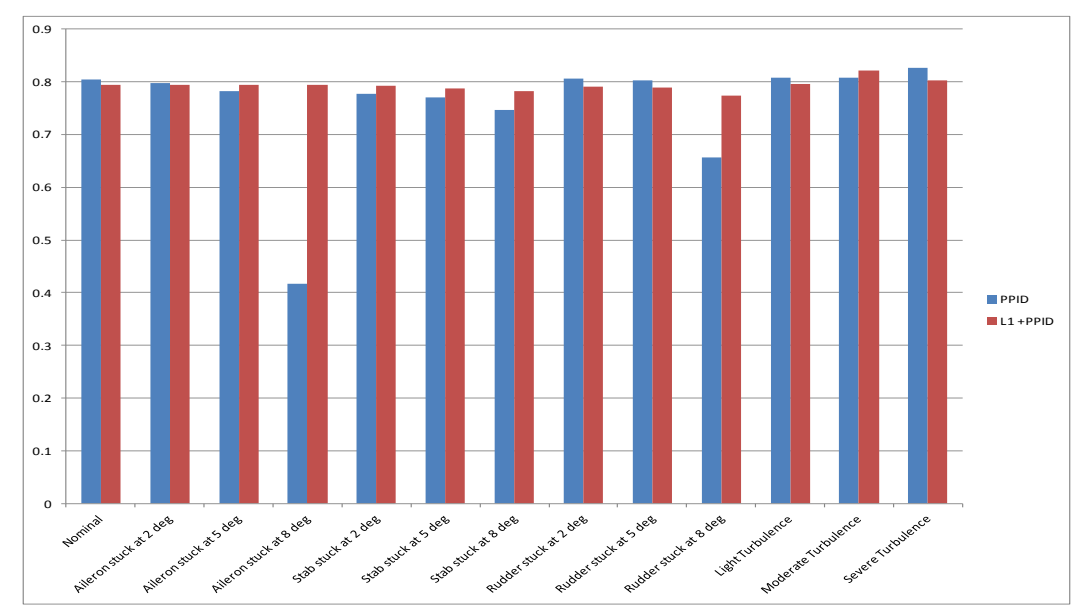

Figure 46. Average Trajectory Tracking Performance Index of Four Paths for PPID and L1 Adaptive Controller 
Table 8. Average Controller Activity Performance Index of Four Paths for PPID and L1 Adaptive Controller

\begin{tabular}{|c|c|c|c|}
\hline Average PI CA & PPID & L1 +PPID & \% increase of L1 adaptive controller over PPID \\
\hline Nominal & 0.858 & 0.987 & 21.21 \\
\hline Aileron stuck at 2 deg & 0.847 & 0.976 & 21.02 \\
\hline Aileron stuck at 5 deg & 0.846 & 0.973 & 22.58 \\
\hline Aileron stuck at 8 deg & 0.521 & 0.891 & 91.17 \\
\hline Stab stuck at 2 deg & 0.983 & 0.980 & 20.55 \\
\hline Stab stuck at 5 deg & 0.981 & 0.974 & 20.80 \\
\hline Stab stuck at 8 deg & 0.977 & 0.952 & 20.98 \\
\hline Rudder stuck at 2 deg & 0.853 & 0.985 & 20.99 \\
\hline Rudder stuck at 5 deg & 0.852 & 0.981 & 21.01 \\
\hline Rudder stuck at 8 deg & 0.743 & 0.952 & 39.84 \\
\hline Light Turbulence & 0.850 & 0.966 & 18.71 \\
\hline Moderate Turbulence & 0.838 & 0.941 & 16.00 \\
\hline Severe Turbulence & 0.820 & 0.903 & 9.268 \\
\hline
\end{tabular}

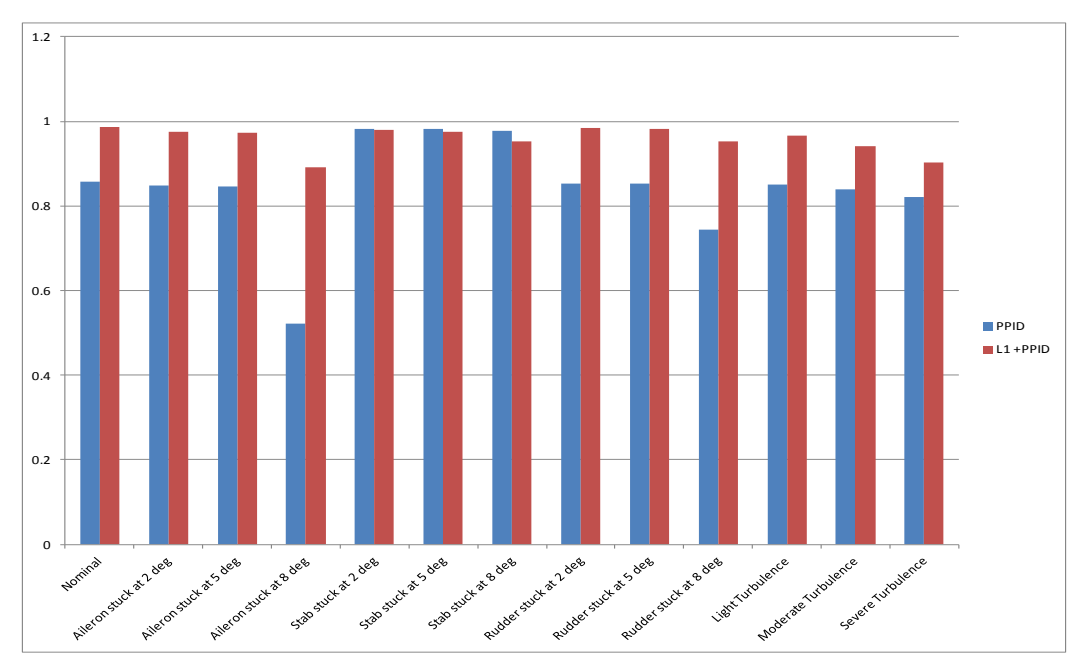

Figure 47. Average Controller Activity Performance Index of Four Paths for PPID and L1 Adaptive Controller 
The results for the PI presented in Table 9 and Figure 48 where obtained with a 0.70/0.30 weight of the tracking and control metrics, which is a typical selection for a large variety of UAV missions and tasks. In Figure 49, the percentage increase of the total PI obtained with the L1 control laws as compared to the PPID is presented. From these data, it can be concluded that the L1 adaptive controller achieves better performance under all nominal and abnormal conditions investigated in this study.

Table 9. Average Total Performance Index of Four Paths for PPID and L1 Adaptive Controller

\begin{tabular}{|c|c|c|c|}
\hline Total PI & PPID & L1 +PPID & $\begin{array}{c}\text { \% increase of L1 adaptive controller over } \\
\text { PPID }\end{array}$ \\
\hline Nominal & 0.820 & 0.851 & 3.780 \\
\hline Aileron stuck at 2 deg & 0.811 & 0.848 & 4.562 \\
\hline Aileron stuck at 5 deg & 0.798 & 0.847 & 6.140 \\
\hline Aileron stuck at 8 deg & 0.371 & 0.823 & 121.8 \\
\hline Stab stuck at 2 deg & 0.836 & 0.847 & 1.316 \\
\hline Stab stuck at 5 deg & 0.831 & 0.841 & 1.203 \\
\hline Stab stuck at 8 deg & 0.813 & 0.831 & 2.214 \\
\hline Rudder stuck at 2 deg & 0.820 & 0.848 & 3.415 \\
\hline Rudder stuck at 5 deg & 0.818 & 0.846 & 3.423 \\
\hline Rudder stuck at 8 deg & 0.689 & 0.831 & 20.61 \\
\hline Light Turbulence & 0.818 & 0.844 & 3.178 \\
\hline Moderate Turbulence & 0.815 & 0.835 & 2.454 \\
\hline Severe Turbulence & 0.809 & 0.822 & 1.607 \\
\hline
\end{tabular}




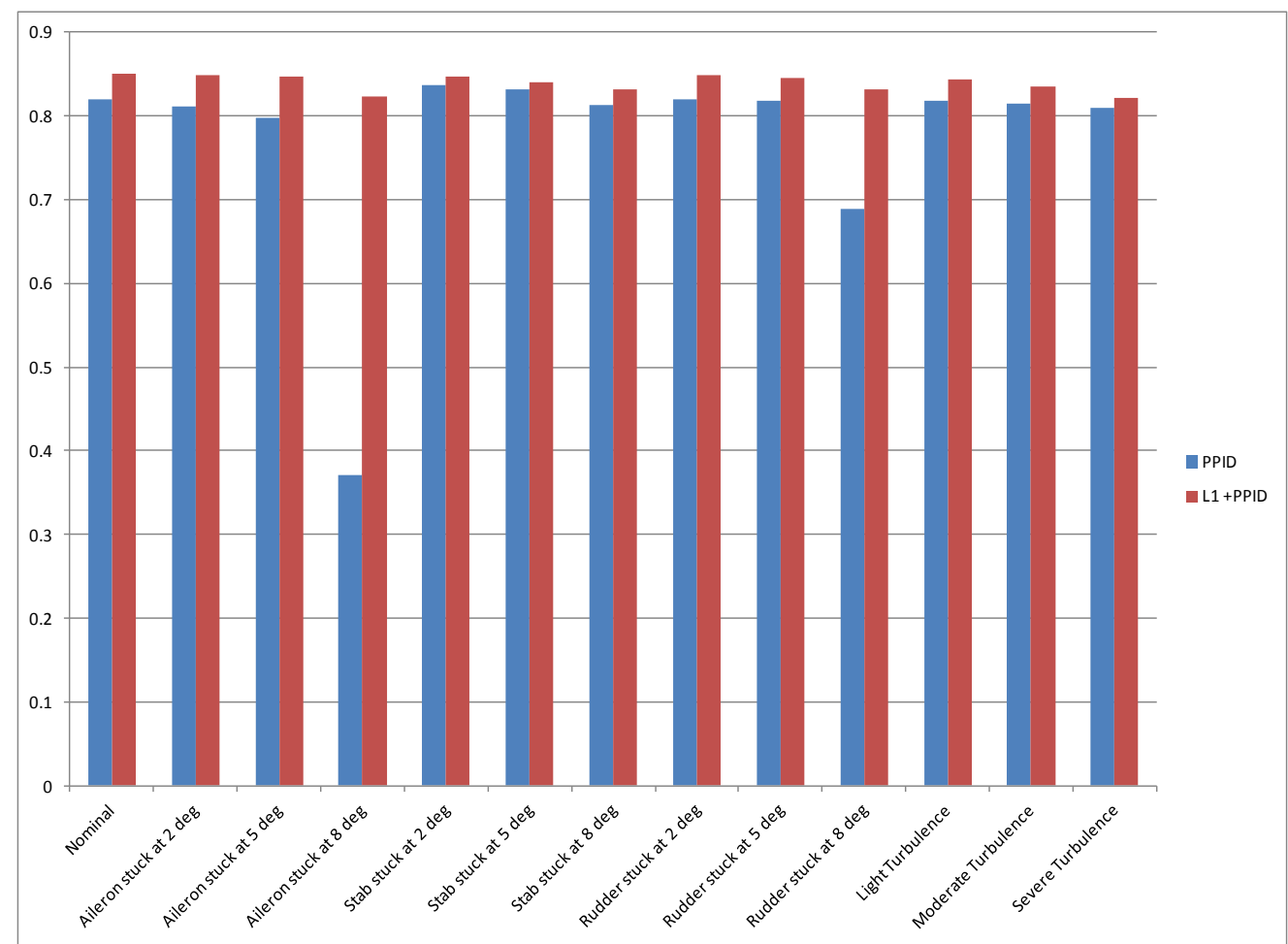

Figure 48. Average Total Performance Index of Four Paths for PPID and L1 Adaptive Controller

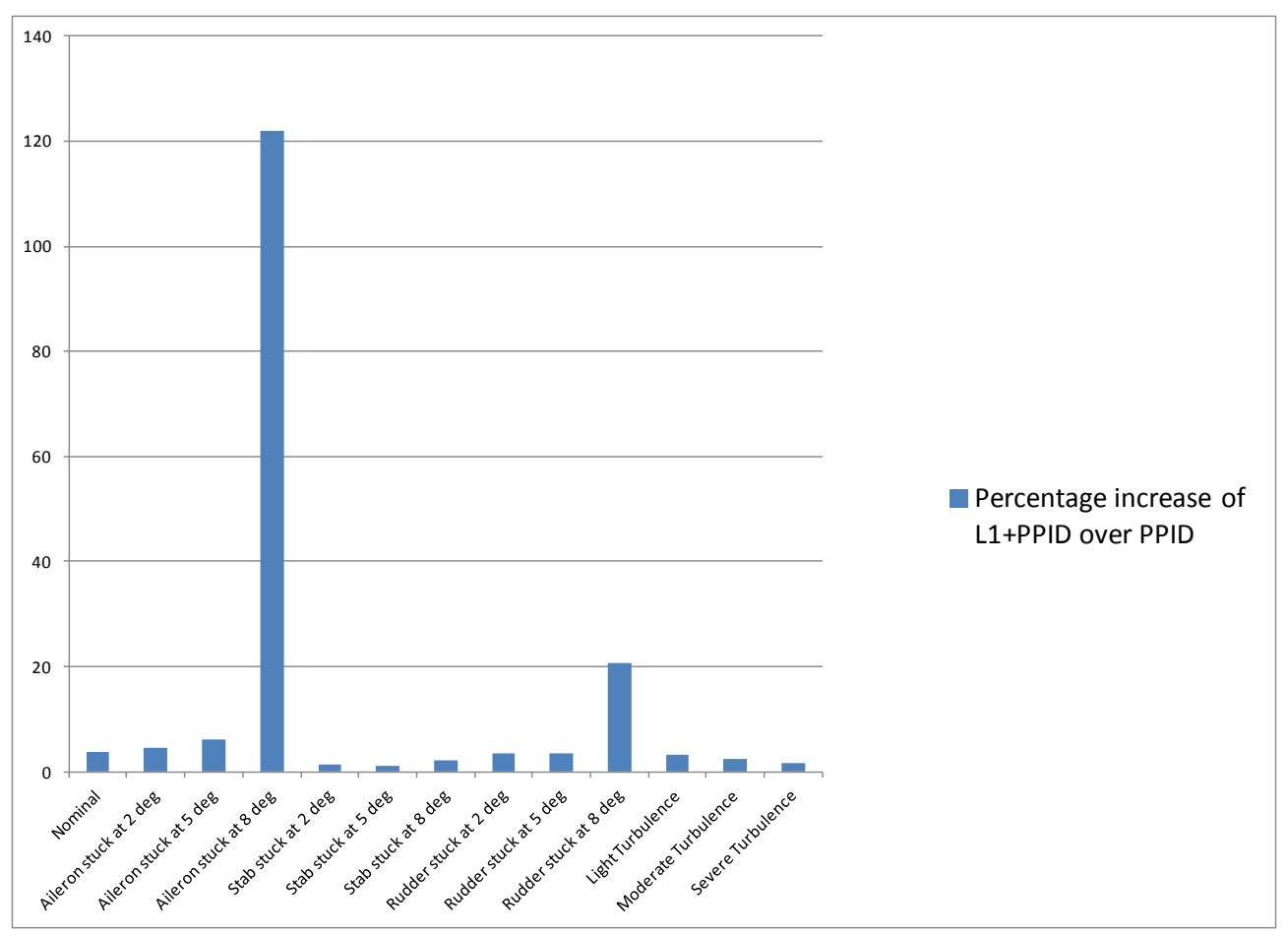

Figure 49. Percentage Total PI Increase of L1 Adaptive Controller over PPID 


\section{CONCLUSION AND FUTURE WORK}

In this thesis, the performance of an L1 augmentation of a baseline PPID controller for autonomous flight was evaluated and analyzed. Four different commanded paths at normal and abnormal conditions were considered. The abnormal conditions include turbulence and lockage of aerodynamic control surfaces on the roll, pitch, and yaw channels. The evaluation was performed in terms of composite evaluation indexes based on trajectory tracking and control activity.

The adaptive augmentation achieved generally better trajectory tracking performance under more severe abnormal conditions. However, it exhibited less robustness to severe turbulence. In the 3D $\mathrm{S}$ Turns path, the L1 control laws produced less control activity and less saturation.

The capability of the fault tolerant control laws to accommodate abnormal conditions is conditioned by the complexity of the commanded trajectory and the nature and severity of the abnormal condition.

The results of this study seem to support the idea that effective fault tolerant control laws should be accompanied by powerful abnormal condition detection, identification, and evaluation schemes that could adjust the nature and level of accommodation on a case by case basis.

All factors considered, shape of commanded paths, type of abnormal conditions and level of severity have an impact on the relative ranking of the two control systems.

This study should be extended to include abnormal conditions of different nature affecting other aircraft subsystems such as sensors, including GPS, structure, or propulsion system. The findings obtained through simulation should be confirmed through actual flight tests. 


\section{BIBLIOGRAPHY}

[1] Chao H., Cao Y., Chen Y. "Autopilots for Small Unmanned Aerial Vehicles: A Survey." International Journal of Control, Automation and Systems 8.1 2010: 36-44. Print.

[2] Nayyerloo M., Chen X., Wang W., Geoffrey J. "Cable-Climbing Robots for Power Transmission Lines Inspection." Mobile Robots - State of the Art in Land, Sea, Air, and Collaborative Missions." Vienna: I-Tech Education, 2009. 63-84. Print.

[3] Puri A.; Valavanis K.P., Kontitsis M., "Statistical profile generation for traffic monitoring using real-time UAV based video data. "Control \& Automation, 2007. MED '07. Mediterranean Conference. vol., no., pp.1,6, 27-29 June 2007.

[4] Martínez-de-Dios J. R., Merino L., Ollero A., Ribeiro L.M., Viegas X., "Multi-UAV Experiments: Application to Forest Fires." Multiple Heterogeneous Unmanned Aerial Vehicles. Vol. 37. Berlin: Springer Berlin Heidelberg 2007. 207 - 228. Print.

[5] Mejias, L.; Campoy, P.; Saripalli, S.; Sukhatme, G. "A visual surveying approach for tracking features in urban areas using an autonomous helicopter."Robotics and Automation. 2006. ICRA 2006. Proceedings 2006 IEEE International Conference. vol., no., pp.2503, 2508. 15-19 May 2006

[6] Marshall M., Neff J., Lao N., Yuhas P. Proc. of AIAA Defense and Civil Space Programs Conference and Exhibit. The Aerospace Corporation. Los Angeles. CA. N.p.: American Institute of Aeronautics and Astronautics. 1998. Print.

[7] Mejias L., Correa J.F., Mondragon I., Campoy P. "COLIBRI: A vision-Guided UAV for Surveillance and Visual Inspection." Robotics and Automation, 2007 IEEE International Conference. vol., no., pp.2760, 2761. 10-14 April 2007.

[8] Iñigo-Blasco P., Diaz-Del-Rio F., Romero-Ternero M.C., Cagigas-Muñiz D, Vicente-Diaz. S. "Robotics Software Frameworks for Multi-agent Robotic Systems Development." Robotics and Autonomous Systems 60.6 2012: 803-21. Print.

[9] Lee, D., Jae-Wook Yoo., Kang-Hee L., Yoon K. "A Real Time Flame and Smoke Detection Algorithm Based on Conditional Test in YCbCr Color Model and Adaptive Differential 
Image." Journal of the Korea Society of Computer and Information 15.5 (2010): 57-65.

Print.

[10] Gupta, S G., Mangesh M. G., Dr. Jawandhiya P M. "Review of Unmanned Aircraft System (UAS)." International Journal of Advanced Research in Computer Engineering \& Technology (IJARCET) 2.4 2013: 1646-658. Print.

[11] Department of Defense. Unmanned Aircraft Systems Roadmap. Washington DC Army Regulation 385-40. 2005.

[12] Cummings M. L., da Silva F B., Scott S D.,"Design Methodology for Unmanned Aerial Vehicle (UAV) Team Coordination." MIT Humans and Automation Laboratory.2007.

[13] Shima T., Rasmussen S.J., Sparks A G., "UAV cooperative multiple task assignments using genetic algorithms."American Control Conference. 2005. Proceedings of the 2005. vol., no., pp.2989.2994 vol. 5. 8-10 June 2005

[14] Wang J., Vijay V P., Chengyu C., Hovakimyan N., "Novel L1 Adaptive Control Methodology for Aerial Refueling with Guaranteed Transient Performance." Journal of Guidance, Control, and Dynamics 31.12008 182-93. Print.

[15] "Accident Threat Categories." Lessons Learned. 7 Apr. 2011. Web. accessed Jan,2014.

[16] "ECFR - Code of Federal Regulations." ECFR - Code of Federal Regulations. 1 Dec. 2011. Web. accessed Jan,2014.

[17] King, David W., Bertapelle, A., Moses, C., "UAV failure rate criteria for equivalent level of safety." International Helicopter Safety Symposium, Montreal Quebec. Canada. September 26-29, 2005.

[18] "Causes of Fatal Accidents by Decade." Accident Statistics. 1 Jan. 2012. Web. accessed Jan,2014

[19] Department of the Army. Accident reporting and records. Washington. DC. Reference no.14-S-0553. 1994a. 
[20] Karas O., "UAV Simulation Environment for Autonomous Flight Control Algorithms." Order No. 1520729 West Virginia University, 2012. Ann Arbor:"ProQuest."Web. 9 Aug. 2014.

[21] Perhinschi M., Wilburn B., Wilburn J., Moncayo H., Karas O. "Simulation Environment for UAV Fault Tolerant Autonomous Control Laws Development." Journal of Modeling, Simulation, Identification, and Control 1.4. 2013: 164-95. Print.

[22] Newcome L.R., "Unmanned Aviation: A brief history of UAV's. American Institute of Aeronautics and Astronautics.” Reston 2004.

[23] Zaloga, S., Ian P., Unmanned Aerial Vehicles: Robotic Air Warfare. 1917-2007. Vol. 144. Oxford: Osprey. 2008. Print.

[24] Dalamagkidis K., Valavanis KimonP., Dr. Piegl LesA."Aviation History and Unmanned Flight." On Integrating Unmanned Aircraft Systems into the National Airspace System. Vol. 54. Springer Netherlands. 2012. 11-42. Print.

[25] Maj. Jones A. C., "Unmanned Aerial Vehicles (UAVS) an Assessment of Historical Operations and Future Possibilities", Research Department Air Command and Staff College. AU/ACSC/0230D/97-03. March 1997.

[26] Gertler J., "U.S. Unmanned Aerial Systems". Congressional Research Service 75700.R42136. January 3. 2012

[27] Jaysen A. Y. "The Vulnerabilities of Unmanned Aircraft System Common Data Links to Electronic Attack".Master of Military Art and Science. U.S. Army. 1998.

[28] DoD. Unmanned Aircraft Systems Roadmap 2005-2030. Office of the Secretary of Defense, Department of Defense, Washington, DC. August 2005.

[29] Helios Solar-Powered UAV Crashes - AVweb flash Article. Web.5 Sep. 2014. <http://www.avweb.com/avwebflash/briefs/185240-1.html?redirected=1 >

[30] Air Combat Command. MQ-1B PREDATOR ACCIDENT REPORT RELEASED. Web. 5 Sep. 2014. 〈http://www.acc.af.mil/news/story.asp?id=123332108>. 
[31] X-51A Waverider spins out of control and crashes into after 15 seconds as $\$ 300 \mathrm{M}$ hypersonic jet program FAILS latest test. Web.5 Sep. 2014. $<$ http://www.dailymail.co.uk/sciencetech/article-2188936/X-51-Waverider-spins-controlcrashes-ocean-15-seconds.html>.

[32] U.S. Navy 2012 Maryland Drone Crash Investigation Report Public Intelligence, 2013. Web.5 Sep. 2014. <https://publicintelligence.net/usnavy-maryland-drone-crash-report/>.

[33] Johnson, Chris W., Shea C., "The Hidden Human Factors in Unmanned Aerial Vehicles." 2008. Print.

[34] Department of Defense. Unmanned Aerial Vehicle Reliability Study. Washington. DC. Feb. 2003.

[35] Tekinalp O., Isik S., Yavrucuk I., "Fault Tolerant Control of an Over Actuated UAV." AIAA Guidance, Navigation, and Control Conference. Oregon. Portland. N.p. AIAA. 2011. Print.

[36] Kaminer I., Pascoal A., Hallberg A.M., Silvestre C. "Trajectory Tracking for Autonomous Vehicles: An Integrated Approach to Guidance and Control." Journal of Guidance, Control, and Dynamics. Vol. 21. No. 1. 1998. pp. 29-38.

[37] Alvis W., Castillo C., Castillo E M., Moreno K., Valavanis K P., "A Tutorial Approach to Small Unmanned Helicopter Controller Design for Non-Aggressive Flights." Advances in Unmanned Aerial Vehicles - State of the Art and the Road to Autonomy. edited by Valavanis. K. P., Vol. 33. Springer. Norwell. MA, 2007. pp. 119-170.

[38] Beard R., McLain T. "Small Unmanned Aircraft: Theory and Practice." Princeton. NJ: Princeton University Press. 2012.

[39] Pfeifer E., Kassab F. "Dynamic Feedback Controller of an Unmanned Aerial Vehicle,"Robotics Symposium and Latin American Robotics Symposium (SBR-LARS). 2012 Brazilian. vol., no., pp.261.266. 16-19 Oct. 2012.

[40] Sung K H., Yoonsu N. "Stable fuzzy control system design with pole-placement constraint: an LMI approach.” Computers in Industry. Volume 51. Issue 1. May 2003. Pages 1-11. 
[41] Chilali M., Gahinet P., "H$H_{\infty}$ design with pole placement constraints: an LMI approach." Automatic Control. IEEE Transactions. vol.41. no.3. pp.358,367. Mar 1996.

[42] Kinoshita T., Imado F., "A Study on the Optimal Flight Control for an Autonomous UAV."Mechatronics Automation, Proceedings of the 2006 IEEE International Conference. vol., no., pp.996.1001. 25-28 June 2006.

[43] S. Franko, "LQR-Based Trajectory Control Of Full Envelope, Autonomous Helicopter," Proceedings of the World Congress on Engineering 2009, London, 1-3, July 2009.

[44] Oner K T., Ertugrul C., Efe S., Cevdet H., Taylan A., Mustafa U. "LQR and SMC Stabilization of a New Unmanned Aerial Vehicle." World Academy of Science, Engineering \& Technology 34 2009: 373-78. Print.

[45] Masar, I., E. Stohr, “Gain-scheduled LQR-control for an Autonomous Airship." Proc. of 18th International Conference on Process Control. Slovakia. Tatranská Lomnica. N.p. n.p. 2011. 197-204. Print.

[46] Hajiyev C., Vural S. "LQR Controller with Kalman Estimator Applied to UAV Longitudinal Dynamics,"Positioning. Vol. 4 No. 1, 2013, pp. 36-41.doi: $\underline{10.4236}$ /pos.2013.41005.

[47] Beard R., Kingston D., Quigley M., Snyder D., Christiansen R., Johnson W., McLain T., Goodrich M. A. "Autonomous Vehicle Technologies for Small Fixed-Wing UAVs." AIAA Journal of Aerospace Computing, Information, and Communications. Vol. 2. No. 1. 2005. pp. 92-108.

[48] Beard R., McLain T. Small Unmanned Aircraft: Theory and Practice. Princeton, NJ: Princeton University Press. 2012.

[49] Kada B., Ghazzawi.Y. Robust PID Controller Design for an UAV Flight Control System. Proc. of World Congress on Engineering and Computer Science 2011, USA, San Francisco. Vol. II. N.p.: n.p., 2011. 945-50. Print. 
[50] Perhinschi M. G., "A Modified Genetic Algorithm for the Design of Autonomous Helicopter Control System." Proceedings of the AIAA Guidance, Navigation and Control Conference. New Orleans LA, USA. August 1997. pp. 1111-1120

[51] Salih A L., Moghavvemi M., Mohamed H A F., Gaeid K S. "Flight PID Controller Design for a UAV Quadrotor." Scientific Research and Essays 5.23 (2010): 3660-667. Print.

[52] Bouabdallah S., Noth A., Siegwart R., "PID vs LQ control techniques applied to an indoor micro quadrotor."Intelligent Robots and Systems. 2004. (IROS 2004). Proceedings. 2004 IEEE/RSJ International Conference . vol.3. no., pp.2451.2456 vol.3. 28 Sept.-2 Oct. 2004.

[53] Jun L., Yuntang L., "Dynamic analysis and PID control for a quadrotor." Mechatronics and Automation (ICMA), 2011 International Conference. vol., no., pp.573.578. 7-10 Aug. 2011

[54] Azinheira J. R., Paivab D. E. C., Ramos J G., Bueno S. S. "Mission Path Following for an Autonomous Unmanned Airship," Proceedings of the 2000 IEEE International Conference on Robotics and Automation. San Francisco. CA. April, 2000. pp. 1269-1275.

[55] Wilburn B., Perhinschi M. G., Moncayo H., Karas O., Wilburn J. "Unmanned Aerial Vehicle Trajectory Tracking Algorithm Comparison.” International Journal of Intelligent Unmanned Systems. Vol. 1. Iss. 3. pp. 276-302. 2013.

[56] Ducard G. Fault-Tolerant Flight Control and Guidance Systems: Practical Methods for Small Unmanned Aerial Vehicles: Springer-Verlag. 2009.

[57] Ducard G., Geering H. P. "Airspeed Control for Unmanned Aerial Vehicles: a Nonlinear Dynamic Inversion Approach." Proceedings of the 16th Mediterranean Conference on Control and Automation. Ajaccio. France. June 2008. 2008. pp. 676-681.

[58] Enns D., Keviczky T. "Dynamic Inversion Based Flight Control for Autonomous RMAX Helicopter." Proceedings of the 2006 American Control Conference. IEEE. Minneapolis. Minnesota. June 14-16. 2006. pp. 3916-3923.

[59] Sadraey M., Colgren R. "2 DOF Robust Nonlinear Autopilot Design for a Small UAV Using a Combination of Dynamic Inversion an H-infinity Loop Shaping." Proceedings of 
the AIAA Guidance, Navigation, and Control Conference and Exhibit. San Francisco. CA. August 2005, 2005.

[60] Moncayo H., Perhinschi M. G., Wilburn, B., Wilburn, J., Karas O. "Extended Nonlinear Dynamic Inversion Control Laws for Unmanned Air Vehicles." Proceedings of the AIAA Guidance, Navigation, and Control Conference. AIAA. Minneapolis. MN. August 13-16. 2012.

[61] Ioannou P.A., Jing S. “Robust Adaptive Control.” Vol. 1. Dover Publications. 2012. Print.

[62] Shahruz S.M., Behtash S. "Design of controllers for linear parameter-varying systems by the gain scheduling technique." Journal of Mathematical Analysis and Applications. Volume 168. Issue 1. 15 July 1992. Pages 195-217.

[63] Clement B., Duc G., Mauffrey S., Biard A. (2001). "Gain scheduling for an aerospace launcher with bending modes". 15th IFAC symposium on automatic control in aerospace, Bologna.

[64] Ito D., Georgie J., Valasek J., Ward D. "Re-Entry Vehicle Flight Controls Design Guidelines: Dynamic Inversion, Final Technical Report", NAG9-1085. Flight Simulation Laboratory. Texas Engineering Experiment Station. Texas A\&M University. 23 May 2000 - 23 May 2001.

[65] Moncayo H., Perhinschi M. G., Wilburn, B., Davis J., Ondrej K. UAV Adaptive Control Laws Using Non-Linear Dynamic Inversion Augmented with an Immunity based Mechanism. AIAA Guidance, Navigation and Control Conference. AIAA-2012-4678, 2012.

[66] Moncayo H., Perhinschi M. G., Wilburn B., Wilburn J., Karas O. “Extended Nonlinear Dynamic Inversion Control Laws for Unmanned Air Vehicles". Proc. of the AIAA Guidance, Navigation, and Control Conference. Minneapolis. MN. August 2012. 
[67] Nicol C.; Macnab C. J B., Ramirez S A. "Robust neural network control of a quadrotor helicopter."Electrical and Computer Engineering, 2008. CCECE 2008. Canadian Conference. vol., no., pp.001233.001238. 4-7 May 2008.

[68] Dierks T.; Jagannathan S. "Output Feedback Control of a Quadrotor UAV Using Neural Networks."Neural Networks, IEEE Transactions. vol.21. no.1. pp.50,66. Jan. 2010.

[69] Zadeh L A. Fuzzy sets as a basis for a theory of possibility. Fuzzy Sets and Systems, Volume 1. Supplement 1. 1978. Pages 9-34.

[70] Kurnaz S., Omer C., Okyay K. "Fuzzy Logic Based Approach to Design of Flight Control and Navigation Tasks for Autonomous Unmanned Aerial Vehicles." Journal of Intelligent and Robotic Systems 54.1-3 (2008): 229-44. Print.

[71] Jing W., Jian L. "Design and Simulation of Fuzzy Control System of UAV Formation Flight." Journal of System Simulation 21.13 (2009): 4183-189. Print.

[72] Tao D; Liao X. H.; Zhang R.; Sun Z.; Song Y.D. "Path Tracking and Obstacles Avoidance of UAVs - Fuzzy Logic Approach,"Fuzzy Systems, 2005. FUZZ '05. The 14th IEEE International Conference. vol., no., pp.43.48. 25 May 2005.

[73] Astrom K J., Wittenmark B. Adaptive Control. Revised/Expanded ed. Mineola. N.Y.: Dover Publications. 2008. Print.

[74] Anderson B D., Arvin D. "Challenges of Adaptive Control-past, Permanent and Future." Annual Reviews in Control 32.2 (2008): 123-35. Print.

[75] Sharma M., Calise A., Corban J. E., "Application of an Adaptive Autopilot Design to a Family of Guided Munitions." Proc. of AIAA Guidance, Navigation, and Control Conference and Exhibit. N.p. n.p. 2000. N. pag. Print.

[76] Ioannou P. A., Jing S. Robust Adaptive Control. Vol. 1. Dover Publications. 2012. Print.

[77] Nguyen T., Krishnakumar K., Boskovic J. "An Optimal Control Modification to ModelReference Control for Fast Adaptation". Honolulu, Hawaii. AIAA Guidance, Navigation and Control Conference and Exhibit. 2008. AIAA 2008-7283. 
[78] Lavretsky E., Adaptive Control (Lecture Notes). s.l. : CalTech. 2005 -2007.

[79] Cao C., Hovakimyan N., "Design and Analysis of a Novel L1 Adaptive Controller, Part I: Control Signal and Asymptotic Stability."American Control Conference. 2006. vol., no., pp.3397.3402. 14-16 June 2006.

[80] Cao C.; Hovakimyan N. "Design and Analysis of a Novel L1 Adaptive Controller, Part II: Guaranteed Transient Performance."American Control Conference. 2006. vol., no., pp.3403.3408. 14-16 June 2006.

[81] Hovakimyan, N., Cao C. "L1 Adaptive Control Theory: Guaranteed Robustness with Fast Adaptation." Philadelphia: Society for Industrial and Applied Mathematics. 2010.

[82] Jiang W., et al. "L1 Adaptive Controller for a Missile longitudinal Autopilot Design." AIAA Guidance, Navigation and Control Conference and Exhibit: American Institute of Aeronautics and Astronautics, 2008. Print.

[83] Cao C., Hovakimyan N., "L1 adaptive controller for a class of systems with unknown nonlinearities: Part I,"American Control Conference. 2008. vol., no., pp.4093.4098. 1113 June 2008.

[84] Cao C., Hovakimyan N., "L1 adaptive controller for nonlinear systems in the presence of unmodelled dynamics: Part II."American Control Conference. 2008. vol., no., pp.4099,4104, 11-13 June 2008.

[85] Michini B. "Modeling and adaptive control of indoor unmanned aerial vehicles." Dept. of Aeronautics and Astronautics. Massachusetts Institute of Technology. 2009. Print.

[86] Moncayo, H., Krishnamoorty, K., Wilburn, B., Wilburn, J., Perhinschi, M. G., Lyons, B., "Performance Analysis of Fault Tolerant UAV Baseline Control Laws with L1 Adaptive Augmentation." Journal of Modeling, Simulation, Identification, and Control 1.4 (2013): 137-63. Print.

[87] Kaminer, I., Pascoal, A., Xargay, E., Hovakimyan, N., Cao, C., Dobrokhodov, V. "Path Following for Small Unmanned Aerial Vehicles Using L1 Adaptive Augmentation of 
Commercial Autopilots." Journal of Guidance, Control, and Dynamics 33.2 (2010): 55064. Print.

[88] Campa G.; Napolitano M.R.; Seanor B.; Perhinschi M.G., "Design of control laws for maneuvered formation flight," American Control Conference, 2004. Proceedings of the 2004 . vol.3, no., pp.2344.2349 vol.3. June 30 2004-July 22004

[89] Lawrence, D., Frew, E., Pisano, W., "Lyapunov Vector Fields for Autonomous UAV Flight Control." AIAA Guidance, Navigation and Control Conference and Exhibit: American Institute of Aeronautics and Astronautics, 2007. Print. Guidance, Navigation, and Control and Co-located Conferences.

[90] R. Kalman., J. Bertram. "Control system analysis and design via the second method of Lyapunov: (I) continuous-time systems (II) discrete time systems".IRE Trans. Automat. Contr.vol. 4. pp.112 -112 1959.

[91] Parks, P."Liapunov redesign of model reference adaptive control systems."Automatic Control. IEEE Transactions on. vol.11. no.3. pp.362.367. Jul 1966.

[92] Shackcloth B., Butchart.R L. "Synthesis of Model Reference Adaptive Systems by Liapunov's Second Method." Theory of Self-Adaptive Control Systems. Ed. P.H Hammond: Springer US, 1966. 145-152. Print..

[93] Phillipson P. H. "Design methods for model-reference adaptive systems."Proceedings of the Institution of Mechanical Engineers 183.35 (1969): 695-706.

[94] Monopoli R. V. "Lyapunov's Method for Adaptive Control Design.” IEEE Transactions on Automatic Control 12.3 (1967): 334-35. Print.

[95] Narendra K S., Annaswamy A. Stable adaptive systems. Englewood Cliffs, N.J. Prentice Hall, 1989. Print. Prentice Hall information and system sciences series.

[96] Litt S G., Frederick D., Guo T H. "The Case for Intelligent Propulsion Control for Fast Engine Response.” AIAA Infotech@Aerospace Conference: American Institute of Aeronautics and Astronautics, 2009. Print. 
[97] Guo T H., Litt S G., "Resilient Propulsion Control Research for the NASA Integrated Resilient Aircraft Control (IRAC) Project”. May 7-10. Rohnert Park, California: Infotech @ Aerospace 2007 Conference and Exhibit: NASA, 2007. Print.

[98] Merrill W., Hoang T V., George M., "Fast Engine Response for Emergency Aircraft Operation”. 20 - 22 April. Atlanta, Georgia: Infotech@ Aerospace 2010: AIAA. 2010. Print.

[99] Zhiyuan Li., Hovakimyan N.; Chengyu Cao., Kaasa G.O. "Integrated estimator and L1 adaptive controller for well drilling systems."American Control Conference, 2009, ACC '09. vol. no. pp.1958.1963. 10-12 June 2009.

[100] Kharisov E., Hovakimyan N. "Application of L1 Adaptive Controller to Wing-Rock." AIAA Infotech@ Aerospace 2010. American Institute of Aeronautics and Astronautics. 2010. Print.

[101] Campbell S. F., Kaneshige J. T. "A Nonlinear Dynamic Inversion L1 Adaptive Controller for a Generic Transport Model." Proceedings of the 2010 American Control Conference, IEEE, Baltimore, MD. 2010. pp. 862-867.

[102] "FlightGear". 2012. [http://www.flightgear.org Accessed 3/21/12.] .last accesses on July 2013.

[103] Perhinschi M. G., Moncayo H., Davis J., Wilburn B., Karas O., Wathen M.“Development of a Simulation Environment for Autonomous Flight Control Algorithms". AIAA Guidance, Navigation, and Control Conference. August 8-11, 2011. Portland. Oregon.

[104] Wilburn J., Perhinschi M. G., Wilburn B., "Implementation of Composite Clothoid Paths for Continuous Curvature Trajectory Generation for UAVs", Proc. of the AIAA Guidance, Navigation, and Control Conference, Boston, MA, August 2013.

[105] Wilburn J., Perhinschi M. G., Wilburn B., "Implementation of a 3-Dimensional DubinsBased UAV Path Generation Algorithm", Proc. of the AIAA Guidance, Navigation, and Control Conference, Boston, MA, August 2013. 


\section{APPENDix A}

Control Laws Performance over Figure 8 Path 
Table A1. Maximum Tracking Errors of PPID and L1 Adaptive Controller for Figure 8 Path

\begin{tabular}{|c|c|c|c|c|c|c|}
\hline \multirow{2}{*}{} & \multicolumn{2}{|c}{ XY [m] } & \multicolumn{2}{c|}{ Z [m] } & \multicolumn{2}{c|}{ XYZ [m] } \\
\cline { 2 - 7 } & PPID & L1+PPID & PPID & L1+PPID & PPID & L1+PPID \\
\cline { 2 - 7 } & 14.23 & 13.84 & 1.903 & 0.235 & 14.25 & 13.84 \\
\hline Nominal & 14.51 & 13.82 & 2.048 & 0.243 & 14.53 & 13.82 \\
\hline Aileron stuck at 5 deg & 16.44 & 13.80 & 2.067 & 0.235 & 16.48 & 13.80 \\
\hline Aileron stuck at 8 deg & 85.06 & 13.78 & 2.645 & 0.228 & 85.07 & 13.78 \\
\hline Stab stuck at 2 deg & 15.21 & 13.96 & 2.335 & 0.484 & 15.28 & 13.96 \\
\hline Stab stuck at 5 deg & 17.40 & 14.81 & 2.580 & 0.943 & 17.50 & 14.82 \\
\hline Stab stuck at 8 deg & 19.74 & 15.54 & 3.048 & 1.543 & 19.86 & 13.34 \\
\hline Rudder stuck at 2 deg & 13.48 & 13.32 & 2.007 & 0.835 & 13.56 & 13.34 \\
\hline Rudder stuck at 5 deg & 13.14 & 12.78 & 2.791 & 1.537 & 13.15 & 12.85 \\
\hline Rudder stuck at 8 deg & 478.2 & 14.32 & 3.545 & 3.858 & 478.2 & 14.80 \\
\hline Light Turbulence & 13.81 & 13.40 & 1.824 & 0.358 & 13.82 & 13.40 \\
\hline Moderate Turbulence & 14.02 & 13.67 & 1.725 & 0.916 & 14.06 & 13.67 \\
\hline Severe Turbulence & 14.64 & 14.19 & 2.409 & 1.822 & 14.67 & 14.19 \\
\hline
\end{tabular}


Table A2. Mean Tracking Errors of PPID and L1 Adaptive Controller for Figure 8 Path

\begin{tabular}{|c|c|c|c|c|c|c|}
\hline \multirow{2}{*}{} & \multicolumn{2}{|c}{ XY [m] } & \multicolumn{2}{c}{ Z [m] } & \multicolumn{2}{c|}{ XYZ [m] } \\
\cline { 2 - 7 } & PPID & L1+PPID & PPID & L1+PPID & PPID & L1+PPID \\
\cline { 2 - 7 } & 5.663 & 5.486 & 0.655 & 0.073 & 5.723 & 5.487 \\
\hline Nominal & 5.878 & 5.498 & 0.675 & 0.070 & 5.941 & 5.499 \\
\hline Aileron stuck at 2 deg stuck at 5 deg & 6.171 & 5.488 & 0.693 & 0.068 & 6.235 & 5.489 \\
\hline Aileron stuck at 8 deg & 26.04 & 5.476 & 0.969 & 0.068 & 26.10 & 5.477 \\
\hline Stab stuck at 2 deg & 6.061 & 5.710 & 0.841 & 0.165 & 6.153 & 5.713 \\
\hline Stab stuck at 5 deg & 6.502 & 5.946 & 0.930 & 0.302 & 6.604 & 5.957 \\
\hline Stab stuck at 8 deg & 7.037 & 6.111 & 1.021 & 0.450 & 7.152 & 6.137 \\
\hline Rudder stuck at 2 deg & 5.197 & 5.169 & 0.556 & 0.270 & 5.259 & 5.179 \\
\hline Rudder stuck at 5 deg & 4.736 & 4.796 & 0.626 & 0.523 & 4.828 & 4.839 \\
\hline Rudder stuck at 8 deg & 123.0 & 8.832 & 0.824 & 1.018 & 123.1 & 8.926 \\
\hline Light Turbulence & 5.627 & 5.472 & 0.696 & 0.138 & 5.711 & 5.479 \\
\hline Moderate Turbulence & 5.729 & 5.539 & 0.808 & 0.328 & 5.851 & 5.582 \\
\hline Severe Turbulence & 6.126 & 5.904 & 1.035 & 0.632 & 6.318 & 6.005 \\
\hline
\end{tabular}


Table A3. Standard Deviation of Tracking Errors of PPID and L1 Adaptive Controller for Figure 8 Path

\begin{tabular}{|c|c|c|c|c|c|c|}
\hline & \multicolumn{6}{|c|}{ Standard Deviation } \\
\hline & \multicolumn{2}{|c|}{$X Y[m]$} & \multicolumn{2}{|c|}{$\mathrm{Z}[\mathrm{m}]$} & \multicolumn{2}{|c|}{$\mathrm{XYZ}[\mathrm{m}]$} \\
\hline & PPID & L1+PPID & PPID & L1+PPID & PPID & L1+PPID \\
\hline Nominal & 4.189 & 4.194 & 0.451 & 0.045 & 4.183 & 4.194 \\
\hline Aileron stuck at 2 deg & 4.414 & 4.104 & 0.473 & 0.043 & 4.406 & 4.104 \\
\hline Aileron stuck at 5 deg & 4.719 & 4.096 & 0.487 & 0.043 & 4.711 & 4.096 \\
\hline Aileron stuck at 8 deg & 27.32 & 4.090 & 0.711 & 0.046 & 27.29 & 4.089 \\
\hline Stab stuck at 2 deg & 4.459 & 4.247 & 0.558 & 0.119 & 4.448 & 4.247 \\
\hline Stab stuck at 5 deg & 4.734 & 4.357 & 0.629 & 0.225 & 4.725 & 4.357 \\
\hline Stab stuck at $8 \mathrm{deg}$ & 5.064 & 4.400 & 0.709 & 0.341 & 5.056 & 4.400 \\
\hline Rudder stuck at 2 deg & 3.977 & 4.005 & 0.529 & 0.211 & 3.970 & 4.007 \\
\hline Rudder stuck at 5 deg & 3.803 & 3.848 & 0.725 & 0.418 & 3.808 & 3.851 \\
\hline Rudder stuck at 8 deg & 157.2 & 2.968 & 0.941 & 0.975 & 157.2 & 3.020 \\
\hline Light Turbulence & 4.220 & 4.153 & 0.449 & 0.088 & 4.189 & 4.147 \\
\hline Moderate Turbulence & 4.182 & 4.171 & 0.495 & 0.223 & 4.120 & 4.132 \\
\hline Severe Turbulence & 4.097 & 4.075 & 0.637 & 0.439 & 3.985 & 3.998 \\
\hline
\end{tabular}


Table A4. Integral of Control Surface Deflection Rate of PPID and L1 Adaptive Controller for Figure 8 Path

\begin{tabular}{|c|c|c|c|c|c|c|c|c|}
\hline & \multicolumn{8}{|c|}{ Integral Of Control Surface Rate Of Change } \\
\hline & \multicolumn{2}{|c|}{$\begin{array}{c}\text { Elevator }[\mathrm{rad} / \mathrm{s}] \mathrm{x} \\
\mathrm{e}-03\end{array}$} & \multicolumn{2}{|c|}{$\begin{array}{l}\text { Aileron }[\mathrm{rad} / \mathrm{s}] \times \mathrm{e}- \\
03\end{array}$} & \multicolumn{2}{|c|}{$\begin{array}{c}\text { Rudder}[\mathrm{rad} / \mathrm{s}] \mathrm{x} \\
\mathrm{e}-03\end{array}$} & \multicolumn{2}{|c|}{ Throttle [\%] } \\
\hline & PPID & L1+PPID & PPID & L1+PPID & PPID & L1+PPID & PPID & L1+PPID \\
\hline Nominal & 2.194 & 2.058 & 12.86 & 18.01 & 4.004 & 0.346 & 0.522 & 0.364 \\
\hline $\begin{array}{c}\text { Aileron stuck at } 2 \\
\text { deg }\end{array}$ & 2.375 & 2.797 & 24.34 & 49.90 & 4.049 & 0.956 & 0.564 & 0.372 \\
\hline $\begin{array}{c}\text { Aileron stuck at } 5 \\
\text { deg }\end{array}$ & 2.514 & 2.784 & 24.80 & 50.34 & 4.241 & 0.965 & 0.606 & 0.372 \\
\hline $\begin{array}{c}\text { Aileron stuck at } 8 \\
\text { deg }\end{array}$ & 3.442 & 3.053 & 25.21 & 53.57 & 4.102 & 1.026 & 2.401 & 0.372 \\
\hline $\begin{array}{c}\text { Stab stuck at } 2 \\
\text { deg }\end{array}$ & 4.722 & 13.10 & 13.59 & 31.68 & 3.949 & 0.610 & 0.602 & 0.392 \\
\hline $\begin{array}{c}\text { Stab stuck at } 5 \\
\text { deg }\end{array}$ & 6.191 & 23.12 & 15.01 & 51.18 & 4.150 & 0.984 & 0.658 & 0.436 \\
\hline $\begin{array}{c}\text { Stab stuck at } 8 \\
\text { deg }\end{array}$ & 7.604 & 56.84 & 16.80 & 119.1 & 4.713 & 2.291 & 0.712 & 0.626 \\
\hline $\begin{array}{c}\text { Rudder stuck at } 2 \\
\text { deg }\end{array}$ & 2.131 & 2.579 & 12.39 & 18.37 & 4.222 & 0.354 & 0.457 & 0.365 \\
\hline $\begin{array}{c}\text { Rudder stuck at } 5 \\
\text { deg }\end{array}$ & 2.259 & 3.615 & 13.12 & 24.42 & 5.031 & 0.470 & 0.465 & 0.403 \\
\hline $\begin{array}{c}\text { Rudder stuck at } 8 \\
\text { deg }\end{array}$ & 2.387 & 22.74 & 9.518 & 89.88 & 6.252 & 1.729 & 0.391 & 0.872 \\
\hline Light Turbulence & 9.480 & 19.28 & 43.50 & 100.7 & 12.03 & 1.862 & 0.571 & 0.430 \\
\hline $\begin{array}{l}\text { Moderate } \\
\text { Turbulence }\end{array}$ & 26.70 & 56.29 & 79.91 & 183.1 & 26.27 & 3.375 & 0.756 & 0.649 \\
\hline $\begin{array}{c}\text { Severe } \\
\text { Turbulence }\end{array}$ & 51.74 & 112.0 & 139.8 & 291.36 & 50.17 & 5.338 & 1.134 & 1.052 \\
\hline
\end{tabular}


Table A5. Saturation Index of PPID and L1 Adaptive Controller for Figure 8 Path

\begin{tabular}{|c|c|c|c|c|c|c|c|c|}
\hline & \multicolumn{8}{|c|}{ Saturation Index } \\
\hline & \multicolumn{2}{|c|}{$\begin{array}{c}\text { Elevator }[\mathrm{rad} / \mathrm{s}] \\
\mathrm{x} \mathrm{e-03}\end{array}$} & \multicolumn{2}{|c|}{$\begin{array}{c}\text { Aileron }[\mathrm{rad} / \mathrm{s}] \times \mathrm{e}- \\
03\end{array}$} & \multicolumn{2}{|c|}{$\begin{array}{c}\text { Rudder[rad } / \mathrm{s}] \mathrm{x} \\
\mathrm{e}-03\end{array}$} & \multicolumn{2}{|c|}{ Throttle [\%] } \\
\hline & PPID & L1+PPID & PPID & L1+PPID & PPID & L1+PPID & PPID & L1+PPID \\
\hline Nominal & 0 & 0 & 0 & 0 & 0 & 0 & 0 & 0 \\
\hline $\begin{array}{c}\text { Aileron stuck at } 2 \\
\text { deg }\end{array}$ & 0 & 0 & 2953 & 2352 & 0 & 0 & 0 & 0 \\
\hline $\begin{array}{c}\text { Aileron stuck at } 5 \\
\text { deg }\end{array}$ & 0 & 0 & 6614 & 4811 & 0 & 0 & 0 & 0 \\
\hline $\begin{array}{c}\text { Aileron stuck at } 8 \\
\text { deg }\end{array}$ & 0 & 0 & 86053 & 79384 & 0 & 0 & 14 & 0 \\
\hline $\begin{array}{c}\text { Stab stuck at } 2 \\
\text { deg }\end{array}$ & 0 & 0 & 0 & 0 & 0 & 0 & 0 & 0 \\
\hline $\begin{array}{c}\text { Stab stuck at } 5 \\
\text { deg }\end{array}$ & 0 & 0 & 287 & 451 & 0 & 0 & 0 & 0 \\
\hline $\begin{array}{c}\text { Stab stuck at } 8 \\
\text { deg }\end{array}$ & 0 & 0 & 3345 & 1085 & 0 & 0 & 0 & 0 \\
\hline $\begin{array}{c}\text { Rudder stuck at } 2 \\
\text { deg }\end{array}$ & 0 & 0 & 0 & 0 & 0 & 0 & 0 & 0 \\
\hline $\begin{array}{c}\text { Rudder stuck at } 5 \\
\text { deg }\end{array}$ & 0 & 0 & 0 & 0 & 0 & 0 & 0 & 0 \\
\hline $\begin{array}{c}\text { Rudder stuck at } 8 \\
\text { deg }\end{array}$ & 0 & 0 & 1654 & 7596 & 0 & 0 & 45 & 0 \\
\hline Light Turbulence & 0 & 0 & 0 & 0 & 0 & 0 & 0 & 0 \\
\hline $\begin{array}{l}\text { Moderate } \\
\text { Turbulence }\end{array}$ & 0 & 0 & 0 & 0 & 0 & 0 & 0 & 0 \\
\hline $\begin{array}{c}\text { Severe } \\
\text { Turbulence }\end{array}$ & 0 & 0 & 0 & 0 & 0 & 0 & 0 & 0 \\
\hline
\end{tabular}


Table A6. Performance Indices of PPID and L1 Adaptive Controller for Figure 8 Path

\begin{tabular}{|c|c|c|c|c|c|c|}
\hline \multirow{2}{*}{} & \multicolumn{2}{|c|}{ PI_TT } & \multicolumn{2}{c|}{ PI_CA } & \multicolumn{2}{c|}{ PI_TOTAL } \\
\cline { 2 - 7 } & PPID & L1+PPID & PPID & L1+PPID & PPID & L1+PPID \\
\hline Nominal & 0.850 & 0.863 & 0.991 & 0.992 & 0.892 & 0.901 \\
\hline Aileron stuck at 2 deg & 0.844 & 0.864 & 0.985 & 0.983 & 0.886 & 0.899 \\
\hline Aileron stuck at 5 deg & 0.833 & 0.864 & 0.981 & 0.981 & 0.877 & 0.899 \\
\hline Aileron stuck at 8 deg & 0.384 & 0.864 & 0.855 & 0.895 & 0.525 & 0.873 \\
\hline Stab stuck at 2 deg & 0.838 & 0.858 & 0.990 & 0.987 & 0.883 & 0.897 \\
\hline Stab stuck at 5 deg & 0.823 & 0.850 & 0.988 & 0.980 & 0.873 & 0.889 \\
\hline Stab stuck at 8 deg & 0.807 & 0.843 & 0.984 & 0.947 & 0.860 & 0.874 \\
\hline Rudder stuck at 2 deg & 0.859 & 0.866 & 0.992 & 0.992 & 0.899 & 0.903 \\
\hline Rudder stuck at 5 deg & 0.863 & 0.868 & 0.991 & 0.990 & 0.901 & 0.904 \\
\hline Rudder stuck at 8 deg & 0.382 & 0.823 & 0.579 & 0.961 & 0.441 & 0.865 \\
\hline Light Turbulence & 0.851 & 0.863 & 0.981 & 0.971 & 0.890 & 0.896 \\
\hline Moderate Turbulence & 0.849 & 0.859 & 0.966 & 0.945 & 0.884 & 0.885 \\
\hline Severe Turbulence & 0.841 & 0.850 & 0.940 & 0.908 & 0.871 & 0.867 \\
\hline
\end{tabular}




\section{APPENDIX B}

Control Laws Performance over Oval Path 
Table B1. Maximum Tracking Errors of PPID and L1 Adaptive Controller for Oval Path

\begin{tabular}{|c|c|c|c|c|c|c|}
\hline \multirow{2}{*}{} & \multicolumn{2}{|c}{ XY [m] } & \multicolumn{2}{c|}{ Z [m] } & \multicolumn{2}{c|}{ XYZ [m] } \\
\cline { 2 - 7 } & PPID & L1+PPID & PPID & L1+PPID & PPID & L1+PPID \\
\cline { 2 - 7 } & 16.29 & 16.14 & 1.811 & 0.166 & 16.31 & 16.14 \\
\hline Nileron stuck at 2 deg & 16.45 & 16.12 & 1.892 & 0.182 & 16.48 & 16.12 \\
\hline Aileron stuck at 5 deg & 16.48 & 16.11 & 1.908 & 0.225 & 16.51 & 16.11 \\
\hline Aileron stuck at 8 deg & 49.17 & 16.10 & 1.963 & 0.268 & 49.17 & 16.10 \\
\hline Stab stuck at 2 deg & 15.88 & 16.10 & 2.555 & 0.765 & 15.94 & 16.10 \\
\hline Stab stuck at 5 deg & 16.17 & 16.45 & 3.381 & 1.250 & 16.24 & 16.45 \\
\hline Stab stuck at 8 deg & 16.56 & 16.89 & 4.146 & 1.770 & 16.66 & 15.80 \\
\hline Rudder stuck at 2 deg & 15.70 & 15.80 & 2.847 & 1.143 & 15.76 & 15.80 \\
\hline Rudder stuck at 5 deg & 16.73 & 15.51 & 3.843 & 2.033 & 16.89 & 15.57 \\
\hline Rudder stuck at 8 deg & 21.35 & 17.52 & 5.349 & 3.324 & 21.76 & 17.68 \\
\hline Light Turbulence & 16.09 & 15.72 & 2.086 & 0.389 & 16.12 & 15.72 \\
\hline Moderate Turbulence & 15.96 & 15.44 & 2.633 & 0.903 & 16.03 & 15.45 \\
\hline Severe Turbulence & 15.91 & 15.44 & 3.436 & 1.643 & 16.08 & 15.47 \\
\hline
\end{tabular}


Table B2. Mean Tracking Errors of PPID and L1 Adaptive Controller for Oval Path

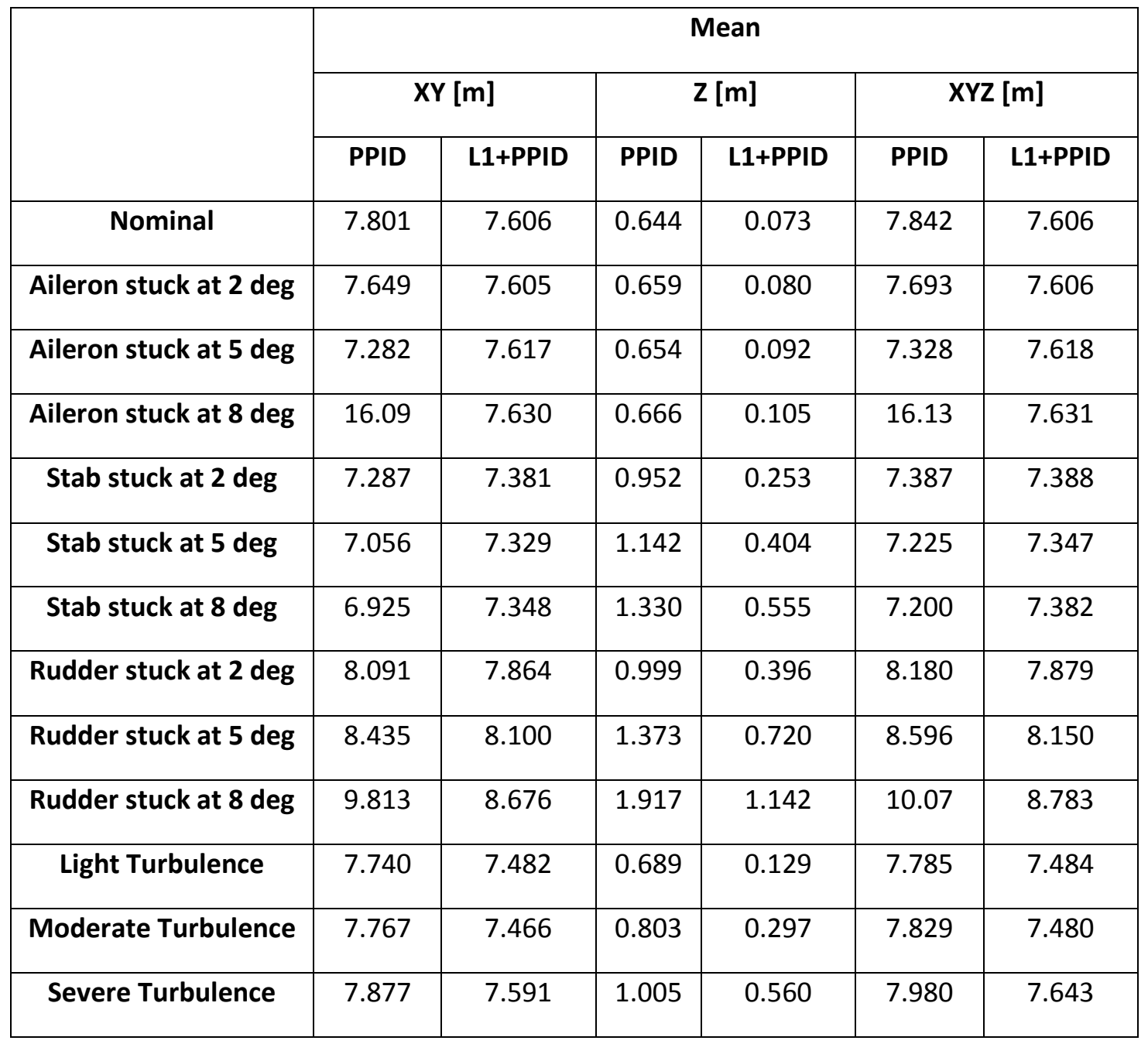


Table B3. Standard Deviation of Tracking Errors of PPID andL1 Adaptive Controller for Oval Path

\begin{tabular}{|c|c|c|c|c|c|c|}
\hline & \multicolumn{6}{|c|}{ Standard Deviation } \\
\hline & \multicolumn{2}{|c|}{$\mathrm{XY}[\mathrm{m}]$} & \multicolumn{2}{|c|}{$\mathrm{Z}[\mathrm{m}]$} & \multicolumn{2}{|c|}{$\mathrm{XYZ}[\mathrm{m}]$} \\
\hline & PPID & L1+PPID & PPID & L1+PPID & PPID & L1+PPID \\
\hline Nominal & 4.782 & 4.744 & 0.485 & 0.046 & 4.783 & 4.744 \\
\hline Aileron stuck at 2 deg & 4.826 & 4.737 & 0.501 & 0.051 & 4.828 & 4.736 \\
\hline Aileron stuck at 5 deg & 4.860 & 4.736 & 0.501 & 0.059 & 4.860 & 4.736 \\
\hline Aileron stuck at $8 \mathrm{deg}$ & 15.68 & 4.737 & 0.502 & 0.068 & 15.67 & 4.736 \\
\hline Stab stuck at 2 deg & 4.603 & 4.688 & 0.716 & 0.179 & 4.598 & 4.687 \\
\hline Stab stuck at 5 deg & 4.721 & 4.786 & 0.885 & 0.303 & 4.687 & 4.785 \\
\hline Stab stuck at $8 \mathrm{deg}$ & 4.982 & 4.958 & 1.056 & 0.439 & 4.879 & 4.958 \\
\hline Rudder stuck at 2 deg & 4.758 & 4.716 & 0.750 & 0.286 & 4.770 & 4.716 \\
\hline Rudder stuck at 5 deg & 4.949 & 4.730 & 1.029 & 0.526 & 4.971 & 4.729 \\
\hline Rudder stuck at 8 deg & 5.753 & 4.573 & 1.460 & 0.849 & 5.822 & 4.590 \\
\hline Light Turbulence & 4.723 & 4.625 & 0.536 & 0.103 & 4.729 & 4.624 \\
\hline Moderate Turbulence & 4.715 & 4.619 & 0.654 & 0.228 & 4.726 & 4.612 \\
\hline Severe Turbulence & 4.784 & 4.671 & 0.853 & 0.429 & 4.797 & 4.639 \\
\hline
\end{tabular}


Table B4. Integral of Control Surface Deflection Rate of PPID and L1 Adaptive Controller for Oval Path

\begin{tabular}{|c|c|c|c|c|c|c|c|c|}
\hline & \multicolumn{8}{|c|}{ Integral Of Control Surface Rate Of Change } \\
\hline & \multicolumn{2}{|c|}{$\begin{array}{c}\text { Elevator }[\mathrm{rad} / \mathrm{s}] \\
x \text { e }-03\end{array}$} & \multicolumn{2}{|c|}{$\begin{array}{c}\text { Aileron }[\mathrm{rad} / \mathrm{s}] \mathrm{x} \\
\mathrm{e}-03\end{array}$} & \multicolumn{2}{|c|}{$\begin{array}{c}\text { Rudder[rad/s] x } \\
\text { e-03 }\end{array}$} & \multicolumn{2}{|c|}{ Throttle [\%] } \\
\hline & PPID & L1+PPID & PPID & L1+PPID & PPID & L1+PPID & PPID & L1+PPID \\
\hline Nominal & 3.076 & 2.871 & 15.65 & 20.24 & 4.951 & 0.390 & 0.820 & 0.621 \\
\hline $\begin{array}{c}\text { Aileron stuck at } 2 \\
\text { deg }\end{array}$ & 3.265 & 3.455 & 27.51 & 56.83 & 4.928 & 1.089 & 0.820 & 0.638 \\
\hline $\begin{array}{c}\text { Aileron stuck at } 5 \\
\text { deg }\end{array}$ & 3.254 & 3.336 & 24.79 & 56.90 & 5.007 & 1.089 & 0.789 & 0.641 \\
\hline $\begin{array}{c}\text { Aileron stuck at } 8 \\
\text { deg }\end{array}$ & 4.252 & 3.359 & 23.69 & 59.31 & 3.902 & 1.134 & 1.802 & 0.645 \\
\hline Stab stuck at 2 deg & 6.449 & 10.68 & 16.02 & 29.52 & 4.658 & 0.569 & 0.906 & 0.671 \\
\hline Stab stuck at 5 deg & 8.386 & 12.73 & 17.22 & 29.91 & 5.107 & 0.575 & 0.989 & 0.736 \\
\hline Stab stuck at $8 \mathrm{deg}$ & 10.37 & 14.68 & 19.06 & 30.78 & 5.653 & 0.591 & 1.085 & 0.822 \\
\hline $\begin{array}{c}\text { Rudder stuck at } 2 \\
\text { deg }\end{array}$ & 3.358 & 3.492 & 16.61 & 28.15 & 6.279 & 0.544 & 0.980 & 0.773 \\
\hline $\begin{array}{c}\text { Rudder stuck at } 5 \\
\text { deg }\end{array}$ & 3.940 & 5.723 & 19.82 & 48.59 & 8.395 & 0.937 & 1.151 & 0.934 \\
\hline $\begin{array}{c}\text { Rudder stuck at } 8 \\
\text { deg }\end{array}$ & 4.358 & 40.35 & 24.42 & 188.0 & 11.76 & 3.630 & 1.346 & 1.351 \\
\hline Light Turbulence & 10.06 & 19.50 & 41.39 & 88.68 & 11.59 & 1.644 & 0.849 & 0.659 \\
\hline $\begin{array}{l}\text { Moderate } \\
\text { Turbulence }\end{array}$ & 28.16 & 57.18 & 83.25 & 213.3 & 27.12 & 3.926 & 0.988 & 0.824 \\
\hline Severe Turbulence & 53.77 & 110.4 & 151.8 & 305.6 & 50.94 & 5.614 & 1.280 & 1.157 \\
\hline
\end{tabular}


Table B5. Saturation Index of PPID and L1 Adaptive Controller for Oval Path

\begin{tabular}{|c|c|c|c|c|c|c|c|c|}
\hline & \multicolumn{7}{|c|}{ Saturation Index } \\
\cline { 2 - 9 } & $\begin{array}{c}\text { Elevator [rad/s] } \\
\text { x e-03 }\end{array}$ & \multicolumn{2}{|c|}{$\begin{array}{c}\text { Aileron [rad/s] x e- } \\
\text { 03 }\end{array}$} & $\begin{array}{c}\text { Rudder[rad/s] x } \\
\text { e-03 }\end{array}$ & \multicolumn{2}{c|}{ Throttle [\%] } \\
\cline { 2 - 9 } & PPID & L1+PPID & PPID & L1+PPID & PPID & L1+PPID & PPID & L1+PPID \\
\hline Nominal & 0 & 0 & 0 & 0 & 0 & 0 & 0 & 0 \\
\hline $\begin{array}{c}\text { Aileron stuck at 2 } \\
\text { deg }\end{array}$ & 0 & 0 & 2595 & 2243 & 0 & 0 & 0 & 0 \\
\hline $\begin{array}{c}\text { Aileron stuck at 5 } \\
\text { deg }\end{array}$ & 0 & 0 & 6717 & 4962 & 0 & 0 & 0 & 0 \\
\hline $\begin{array}{c}\text { Aileron stuck at 8 } \\
\text { deg }\end{array}$ & 0 & 0 & 83908 & 76903 & 0 & 0 & 0 & 0 \\
\hline $\begin{array}{c}\text { Stab stuck at 2 } \\
\text { deg }\end{array}$ & 0 & 0 & 0 & 0 & 0 & 0 & 0 & 0 \\
\hline $\begin{array}{c}\text { Stab stuck at 5 } \\
\text { deg }\end{array}$ & 0 & 0 & 0 & 0 & 0 & 0 & 0 & 0 \\
\hline $\begin{array}{c}\text { Stab stuck at 8 } \\
\text { deg }\end{array}$ & 0 & 0 & 2950 & 2324 & 0 & 0 & 0 & 0 \\
\hline $\begin{array}{c}\text { Rudder stuck at 2 } \\
\text { deg }\end{array}$ & 0 & 0 & 0 & 0 & 0 & 0 & 0 & 0 \\
\hline $\begin{array}{c}\text { Rudder stuck at 5 } \\
\text { deg }\end{array}$ & 0 & 0 & 0 & 811 & 0 & 0 & 0 & 0 \\
\hline $\begin{array}{c}\text { Rudder stuck at 8 } \\
\text { deg }\end{array}$ & 0 & 0 & 1292 & 3492 & 0 & 0 & 0 & 0 \\
\hline $\begin{array}{c}\text { Light Turbulence } \\
\text { Surbulence }\end{array}$ & 0 & 0 & 0 & 0 & 0 & 0 & 0 & 0 \\
\hline $\begin{array}{c}\text { Moderate } \\
\text { Turbulence }\end{array}$ & 0 & 0 & 0 & 0 & 0 & 0 & 0 & 0 \\
\hline & 0 & 0 & 0 & 0 & 0 & 0 & 0 \\
\hline
\end{tabular}


Table B6. Performance Indices of PPID and L1 Adaptive Controller for Oval Path

\begin{tabular}{|c|c|c|c|c|c|c|}
\hline \multirow{2}{*}{} & \multicolumn{2}{|c|}{ PI_TT } & \multicolumn{2}{c|}{ PI_CA } & \multicolumn{2}{c|}{ PI_TOTAL } \\
\cline { 2 - 7 } & PPID & L1+PPID & PPID & L1+PPID & PPID & L1+PPID \\
\hline Nominal & 0.818 & 0.830 & 0.987 & 0.989 & 0.863 & 0.873 \\
\hline Aileron stuck at 2 deg & 0.818 & 0.830 & 0.982 & 0.979 & 0.859 & 0.870 \\
\hline Aileron stuck at 5 deg & 0.821 & 0.830 & 0.979 & 0.976 & 0.856 & 0.869 \\
\hline Aileron stuck at 8 deg & 0.528 & 0.830 & 0.892 & 0.896 & 0.331 & 0.845 \\
\hline Stab stuck at 2 deg & 0.820 & 0.830 & 0.986 & 0.985 & 0.859 & 0.870 \\
\hline Stab stuck at 5 deg & 0.816 & 0.826 & 0.984 & 0.984 & 0.856 & 0.866 \\
\hline Stab stuck at 8 deg & 0.810 & 0.819 & 0.979 & 0.980 & 0.846 & 0.859 \\
\hline Rudder stuck at 2 deg & 0.810 & 0.823 & 0.985 & 0.986 & 0.861 & 0.869 \\
\hline Rudder stuck at 5 deg & 0.795 & 0.816 & 0.982 & 0.979 & 0.857 & 0.865 \\
\hline Rudder stuck at 8 deg & 0.751 & 0.800 & 0.977 & 0.937 & 0.846 & 0.858 \\
\hline Light Turbulence & 0.818 & 0.833 & 0.979 & 0.971 & 0.860 & 0.864 \\
\hline Moderate Turbulence & 0.816 & 0.831 & 0.962 & 0.937 & 0.856 & 0.855 \\
\hline Severe Turbulence & 0.809 & 0.824 & 0.936 & 0.904 & 0.850 & 0.842 \\
\hline
\end{tabular}




\section{Appendix C}

Control Laws Performance over OA Path 
Table C1. Maximum Tracking Errors of PPID and L1 Adaptive Controller for OA Path

\begin{tabular}{|c|c|c|c|c|c|c|}
\hline & \multicolumn{6}{|c|}{ MAX } \\
\hline & \multicolumn{2}{|c|}{$X Y[m]$} & \multicolumn{2}{|c|}{$\mathrm{Z}[\mathrm{m}]$} & \multicolumn{2}{|c|}{$\mathrm{XYZ}[\mathrm{m}]$} \\
\hline & PPID & L1+PPID & PPID & L1+PPID & PPID & L1+PPID \\
\hline Nominal & 19.84 & 19.99 & 2.213 & 0.227 & 19.94 & 19.99 \\
\hline Aileron stuck at 2 deg & 19.83 & 19.83 & 2.344 & 0.277 & 19.93 & 19.83 \\
\hline Aileron stuck at 5 deg & 19.96 & 19.84 & 2.345 & 0.318 & 20.06 & 19.84 \\
\hline Aileron stuck at $8 \mathrm{deg}$ & 2745 & 19.85 & 2.606 & 0.359 & 2745 & 19.85 \\
\hline Stab stuck at 2 deg & 19.94 & 19.95 & 2.951 & 0.893 & 20.06 & 19.95 \\
\hline Stab stuck at 5 deg & 20.02 & 19.93 & 3.319 & 1.436 & 20.12 & 19.93 \\
\hline Stab stuck at $8 \mathrm{deg}$ & 20.97 & 19.78 & 3.712 & 2.005 & 21.04 & 19.87 \\
\hline Rudder stuck at 2 deg & 19.67 & 19.87 & 3.329 & 1.347 & 19.73 & 19.87 \\
\hline Rudder stuck at 5 deg & 19.18 & 19.40 & 4.424 & 2.520 & 19.21 & 19.41 \\
\hline Rudder stuck at 8 deg & 18.47 & 17.85 & 5.757 & 4.319 & 18.88 & 17.88 \\
\hline Light Turbulence & 19.74 & 19.92 & 2.102 & 0.433 & 19.85 & 19.92 \\
\hline Moderate Turbulence & 19.52 & 19.56 & 2.225 & 1.066 & 19.65 & 19.56 \\
\hline Severe Turbulence & 19.14 & 19.02 & 2.556 & 2.096 & 19.29 & 19.03 \\
\hline
\end{tabular}


Table C2. Mean Tracking Errors of PPID and L1 Adaptive Controller for OA Path

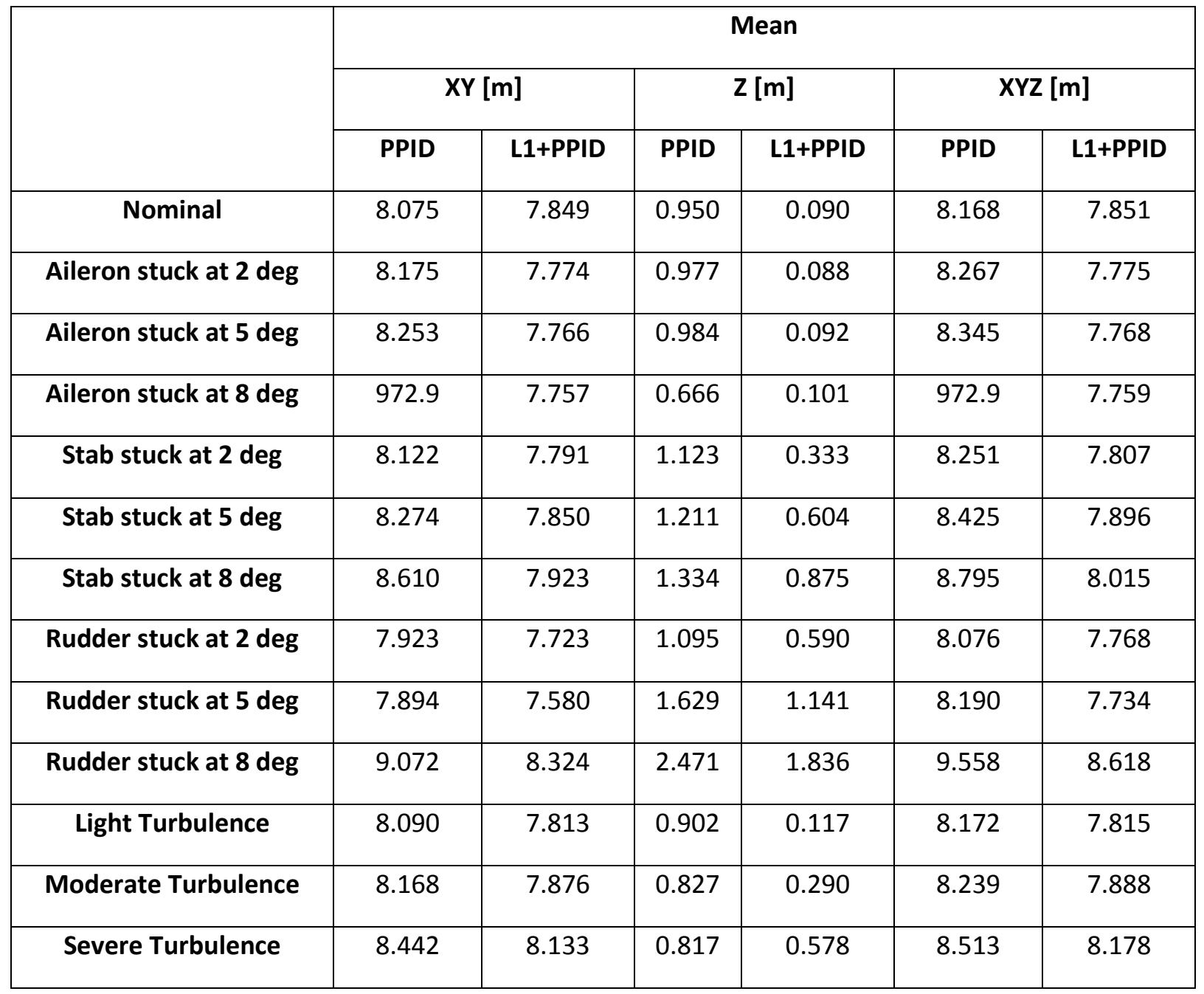


Table C3. Standard Deviation of Tracking Errors of PPID and L1 Adaptive Controller for OA Path

\begin{tabular}{|c|c|c|c|c|c|c|}
\hline \multirow{2}{*}{} & \multicolumn{4}{|c}{ Xtandard Deviation } \\
\cline { 2 - 7 } & \multicolumn{2}{|c|}{ XY [m] } & \multicolumn{2}{c|}{ Z [m] } & \multicolumn{2}{c|}{ XYZ [m] } \\
\cline { 2 - 7 } & PPID & L1+PPID & PPID & L1+PPID & PPID & L1+PPID \\
\hline Nominal & 4.182 & 4.252 & 0.586 & 0.058 & 4.151 & 4.251 \\
\hline Aileron stuck at 2 deg & 4.179 & 4.203 & 0.604 & 0.058 & 4.156 & 4.202 \\
\hline Aileron stuck at 5 deg & 4.286 & 4.196 & 0.607 & 0.065 & 4.264 & 4.195 \\
\hline Aileron stuck at 8 deg & 892.1 & 4.189 & 0.748 & 0.079 & 892.1 & 4.187 \\
\hline Stab stuck at 2 deg & 4.218 & 4.209 & 0.725 & 0.201 & 4.179 & 4.198 \\
\hline Stab stuck at 5 deg & 4.331 & 4.205 & 0.834 & 0.354 & 4.287 & 4.177 \\
\hline Stab stuck at 8 deg & 4.604 & 4.179 & 0.971 & 0.515 & 4.549 & 4.126 \\
\hline Rudder stuck at 2 deg & 4.131 & 4.181 & 0.898 & 0.346 & 4.076 & 4.154 \\
\hline Rudder stuck at 5 deg & 4.007 & 3.994 & 1.114 & 0.670 & 3.899 & 3.918 \\
\hline Rudder stuck at 8 deg & 3.458 & 3.171 & 1.471 & 1.087 & 3.342 & 3.103 \\
\hline Light Turbulence & 4.138 & 4.202 & 0.558 & 0.092 & 4.113 & 4.200 \\
\hline Moderate Turbulence & 4.085 & 4.116 & 0.556 & 0.236 & 4.065 & 4.110 \\
\hline Severe Turbulence & 4.004 & 3.941 & 0.628 & 0.476 & 3.985 & 3.920 \\
\hline
\end{tabular}


Table C4. Integral of Control Surface Deflection Rate of PPID and L1 Adaptive Controller for OA Path

\begin{tabular}{|c|c|c|c|c|c|c|c|c|}
\hline & \multicolumn{8}{|c|}{ Integral Of Control Surface Rate Of Change } \\
\hline & \multicolumn{2}{|c|}{$\begin{array}{c}\text { Elevator }[\mathrm{rad} / \mathrm{s}] \\
\times \mathrm{e}-03\end{array}$} & \multicolumn{2}{|c|}{$\begin{array}{c}\text { Aileron }[\mathrm{rad} / \mathrm{s}] \mathrm{x} \\
\mathrm{e}-03\end{array}$} & \multicolumn{2}{|c|}{$\begin{array}{c}\text { Rudder}[\mathrm{rad} / \mathrm{s}] \mathrm{x} \\
\mathrm{e}-03\end{array}$} & \multicolumn{2}{|c|}{ Throttle [\%] } \\
\hline & PPID & L1+PPID & PPID & L1+PPID & PPID & L1+PPID & PPID & L1+PPID \\
\hline Nominal & 2.636 & 2.985 & 23.87 & 30.85 & 7.766 & 0.594 & 0.688 & 0.574 \\
\hline $\begin{array}{c}\text { Aileron stuck at } 2 \\
\text { deg }\end{array}$ & 2.916 & 3.977 & 42.61 & 78.13 & 7.632 & 1.498 & 0.729 & 0.580 \\
\hline $\begin{array}{c}\text { Aileron stuck at } 5 \\
\text { deg }\end{array}$ & 3.051 & 4.168 & 42.58 & 79.08 & 7.822 & 1.516 & 0.737 & 0.578 \\
\hline $\begin{array}{c}\text { Aileron stuck at } 8 \\
\text { deg }\end{array}$ & 3.099 & 4.851 & 12.75 & 82.39 & 3.467 & 1.579 & 1.196 & 0.575 \\
\hline Stab stuck at 2 deg & 5.658 & 14.00 & 23.92 & 44.73 & 6.874 & 0.861 & 0.688 & 0.582 \\
\hline Stab stuck at 5 deg & 6.790 & 18.71 & 25.04 & 54.31 & 7.108 & 1.046 & 0.700 & 0.631 \\
\hline Stab stuck at $8 \mathrm{deg}$ & 7.868 & 30.63 & 26.46 & 72.99 & 7.526 & 1.404 & 0.737 & 0.737 \\
\hline $\begin{array}{c}\text { Rudder stuck at } 2 \\
\text { deg }\end{array}$ & 2.921 & 5.297 & 23.17 & 37.11 & 7.644 & 0.716 & 0.662 & 0.607 \\
\hline $\begin{array}{c}\text { Rudder stuck at } 5 \\
\text { deg }\end{array}$ & 3.446 & 9.589 & 25.32 & 48.46 & 8.843 & 0.935 & 0.781 & 0.752 \\
\hline $\begin{array}{c}\text { Rudder stuck at } 8 \\
\text { deg }\end{array}$ & 4.086 & 22.50 & 28.64 & 75.40 & 10.64 & 1.452 & 1.050 & 1.045 \\
\hline Light Turbulence & 9.205 & 18.30 & 69.64 & 164.6 & 15.42 & 3.038 & 0.683 & 0.577 \\
\hline $\begin{array}{l}\text { Moderate } \\
\text { Turbulence }\end{array}$ & 24.68 & 53.83 & 105.9 & 254.4 & 30.41 & 4.668 & 0.764 & 0.721 \\
\hline Severe Turbulence & 48.64 & 107.6 & 141.6 & 338.3 & 50.29 & 6.193 & 1.074 & 1.075 \\
\hline
\end{tabular}


Table C5. Saturation Index of PPID and L1 Adaptive Controller for OA Path

\begin{tabular}{|c|c|c|c|c|c|c|c|c|}
\hline & \multicolumn{9}{|c|}{ Saturation Index } \\
\cline { 2 - 10 } & $\begin{array}{c}\text { Elevator [rad/s] x e- } \\
\text { 03 }\end{array}$ & \multicolumn{2}{c|}{$\begin{array}{c}\text { Aileron [rad/s] x } \\
\text { e-03 }\end{array}$} & $\begin{array}{c}\text { Rudder[rad/s] x } \\
\text { e-03 }\end{array}$ & \multicolumn{2}{c|}{ Throttle [\%] } \\
\cline { 2 - 9 } & PPID & L1+PPID & PPID & L1+PPID & PPID & L1+PPID & PPID & L1+PPID \\
\hline Nominal & 0 & 0 & 0 & 0 & 0 & 0 & 0 & 0 \\
\hline $\begin{array}{c}\text { Aileron stuck at 2 } \\
\text { deg }\end{array}$ & 0 & 0 & 3692 & 3053 & 0 & 0 & 0 & 0 \\
\hline $\begin{array}{c}\text { Aileron stuck at 5 } \\
\text { deg }\end{array}$ & 0 & 0 & 8925 & 6895 & 0 & 0 & 0 & 0 \\
\hline $\begin{array}{c}\text { Aileron stuck at 8 } \\
\text { deg }\end{array}$ & 0 & 0 & 93050 & 80547 & 0 & 0 & 80 & 0 \\
\hline $\begin{array}{c}\text { Stab stuck at 2 } \\
\text { deg }\end{array}$ & 0 & 0 & 0 & 0 & 0 & 0 & 0 & 0 \\
\hline $\begin{array}{c}\text { Stab stuck at 5 } \\
\text { deg }\end{array}$ & 0 & 0 & 0 & 444 & 0 & 0 & 0 & 0 \\
\hline $\begin{array}{c}\text { Stab stuck at 8 } \\
\text { deg }\end{array}$ & 0 & 0 & 4241 & 6171 & 0 & 0 & 0 & 0 \\
\hline $\begin{array}{c}\text { Rudder stuck at 2 } \\
\text { deg }\end{array}$ & 0 & 0 & 0 & 0 & 0 & 0 & 0 & 0 \\
\hline $\begin{array}{c}\text { Rudder stuck at 5 } \\
\text { deg }\end{array}$ & 0 & 0 & 0 & 0 & 0 & 0 & 0 & 0 \\
\hline $\begin{array}{c}\text { Rudder stuck at 8 } \\
\text { deg }\end{array}$ & 0 & 0 & 0 & 2187 & 0 & 0 & 0 & 0 \\
\hline $\begin{array}{c}\text { Light Turbulence } \\
\text { Moderate } \\
\text { Turbulence }\end{array}$ & 0 & 0 & 0 & 0 & 0 & 0 & 0 & 0 \\
\hline $\begin{array}{c}\text { Severe } \\
\text { Turbulence }\end{array}$ & 0 & 0 & 0 & 0 & 0 & 0 & 0 & 0 \\
\hline
\end{tabular}


Table C6. Performance Indices of PPID and L1 Adaptive Controller for OA Path

\begin{tabular}{|c|c|c|c|c|c|c|}
\hline \multirow{2}{*}{} & \multicolumn{2}{|c|}{ PI_TT } & \multicolumn{2}{c|}{ PI_CA } & \multicolumn{2}{c|}{ PI_TOTAL } \\
\cline { 2 - 7 } & PPID & L1+PPID & PPID & L1+PPID & PPID & L1+PPID \\
\hline Nominal & 0.810 & 0.824 & 0.986 & 0.987 & 0.863 & 0.873 \\
\hline Aileron stuck at 2 deg & 0.809 & 0.826 & 0.978 & 0.974 & 0.859 & 0.870 \\
\hline Aileron stuck at 5 deg & 0.806 & 0.826 & 0.973 & 0.970 & 0.856 & 0.869 \\
\hline Aileron stuck at 8 deg & 0.386 & 0.826 & 0.203 & 0.890 & 0.331 & 0.845 \\
\hline Stab stuck at 2 deg & 0.805 & 0.822 & 0.986 & 0.982 & 0.859 & 0.870 \\
\hline Stab stuck at 5 deg & 0.800 & 0.817 & 0.985 & 0.978 & 0.856 & 0.866 \\
\hline Stab stuck at 8 deg & 0.789 & 0.813 & 0.980 & 0.965 & 0.846 & 0.859 \\
\hline Rudder stuck at 2 deg & 0.807 & 0.819 & 0.987 & 0.985 & 0.861 & 0.869 \\
\hline Rudder stuck at 5 deg & 0.803 & 0.816 & 0.985 & 0.981 & 0.857 & 0.865 \\
\hline Rudder stuck at 8 deg & 0.788 & 0.811 & 0.981 & 0.967 & 0.846 & 0.858 \\
\hline Light Turbulence & 0.811 & 0.825 & 0.974 & 0.957 & 0.860 & 0.864 \\
\hline Moderate Turbulence & 0.812 & 0.930 & 0.960 & 0.945 & 0.856 & 0.855 \\
\hline Severe Turbulence & 0.908 & 0.871 & 0.941 & 0.899 & 0.850 & 0.842 \\
\hline
\end{tabular}




\section{APPENDIX D}

Control Laws Performance over 3D S Turns Path 
Table D1. Maximum Tracking Errors of PPID and L1 Adaptive Controller for 3D S-Turns

\begin{tabular}{|c|c|c|c|c|c|c|}
\hline \multirow{2}{*}{} & \multicolumn{2}{|c}{ XY [m] } & \multicolumn{2}{c}{ Z [m] } & \multicolumn{2}{c|}{ XYZ [m] } \\
\cline { 2 - 7 } & PPID & L1+PPID & PPID & L1+PPID & PPID & L1+PPID \\
\cline { 2 - 7 } & 26.58 & 35.43 & 5.453 & 3.387 & 26.60 & 35.43 \\
\hline Nominal & 28.93 & 35.44 & 6.379 & 3.419 & 29.02 & 35.45 \\
\hline Aileron stuck at 5 deg & 35.70 & 35.44 & 6.233 & 3.471 & 35.76 & 35.44 \\
\hline Aileron stuck at 8 deg & 849.1 & 35.43 & 6.733 & 3.523 & 849.2 & 35.44 \\
\hline Stab stuck at 2 deg & 36.03 & 35.66 & 4.437 & 3.991 & 36.09 & 35.69 \\
\hline Stab stuck at 5 deg & 36.46 & 35.99 & 5.252 & 4.477 & 36.54 & 36.03 \\
\hline Stab stuck at 8 deg & 44.81 & 35.85 & 6.011 & 4.868 & 44.81 & 35.09 \\
\hline Rudder stuck at 2 deg & 25.85 & 35.04 & 5.188 & 4.574 & 25.89 & 35.09 \\
\hline Rudder stuck at 5 deg & 23.91 & 33.77 & 7.075 & 5.857 & 24.07 & 33.90 \\
\hline Rudder stuck at 8 deg & 28.64 & 31.11 & 7.662 & 7.878 & 28.85 & 31.45 \\
\hline Light Turbulence & 25.89 & 35.01 & 5.399 & 3.394 & 25.90 & 35.01 \\
\hline Moderate Turbulence & 25.29 & 34.27 & 5.368 & 3.422 & 25.32 & 34.28 \\
\hline Severe Turbulence & 25.47 & 33.57 & 6.082 & 3.549 & 25.49 & 33.59 \\
\hline
\end{tabular}


Table D2. Mean Tracking Errors of PPID and L1 Adaptive Controller for 3D S Turns

\begin{tabular}{|c|c|c|c|c|c|c|}
\hline \multirow{2}{*}{} & \multicolumn{2}{|c}{ XY [m] } & \multicolumn{2}{c}{ Z [m] } & \multicolumn{2}{c|}{ XYZ [m] } \\
\cline { 2 - 7 } & PPID & L1+PPID & PPID & L1+PPID & PPID & L1+PPID \\
\cline { 2 - 7 } & 10.49 & 14.53 & 1.310 & 0.748 & 10.65 & 14.59 \\
\hline Nominal & 11.17 & 14.51 & 1.292 & 0.757 & 11.34 & 14.57 \\
\hline Aileron stuck at 5 deg & 12.96 & 14.51 & 1.336 & 0.770 & 13.13 & 14.57 \\
\hline Aileron stuck at 8 deg & 159.7 & 14.51 & 1.992 & 0.784 & 159.7 & 14.57 \\
\hline Stab stuck at 2 deg & 14.52 & 14.35 & 1.188 & 0.948 & 14.64 & 14.43 \\
\hline Stab stuck at 5 deg & 14.50 & 14.23 & 1.340 & 1.150 & 14.66 & 14.34 \\
\hline Stab stuck at 8 deg & 15.83 & 13.94 & 1.442 & 1.343 & 16.04 & 14.09 \\
\hline Rudder stuck at 2 deg & 10.56 & 14.60 & 1.433 & 1.175 & 10.75 & 14.71 \\
\hline Rudder stuck at 5 deg & 10.71 & 14.54 & 1.789 & 1.674 & 10.98 & 14.72 \\
\hline Rudder stuck at 8 deg & 12.33 & 14.66 & 2.298 & 2.415 & 12.70 & 14.98 \\
\hline Light Turbulence & 10.31 & 14.41 & 1.351 & 0.789 & 10.49 & 14.47 \\
\hline Moderate Turbulence & 10.04 & 14.21 & 1.420 & 0.918 & 10.24 & 14.29 \\
\hline Severe Turbulence & 9.633 & 13.91 & 1.658 & 1.170 & 9.932 & 14.03 \\
\hline
\end{tabular}


Table D3. Standard Deviation of Tracking Errors of PPID and L1 Adaptive Controller for 3D S Turns

\begin{tabular}{|c|c|c|c|c|c|c|}
\hline & \multicolumn{6}{|c|}{ Standard Deviation } \\
\hline & \multicolumn{2}{|c|}{$\mathrm{XY}[\mathrm{m}]$} & \multicolumn{2}{|c|}{$\mathrm{Z}[\mathrm{m}]$} & \multicolumn{2}{|c|}{$\mathrm{XYZ}[\mathrm{m}]$} \\
\hline & PPID & L1+PPID & PPID & L1+PPID & PPID & L1+PPID \\
\hline Nominal & 5.517 & 8.272 & 1.069 & 0.805 & 5.461 & 8.241 \\
\hline Aileron stuck at 2 deg & 6.129 & 8.250 & 1.120 & 0.812 & 6.054 & 8.218 \\
\hline Aileron stuck at 5 deg & 7.881 & 8.250 & 1.145 & 0.821 & 7.800 & 8.217 \\
\hline Aileron stuck at $8 \mathrm{deg}$ & 127.0 & 8.249 & 1.530 & 0.830 & 126.9 & 8.215 \\
\hline Stab stuck at 2 deg & 8.588 & 8.287 & 0.984 & 0.897 & 8.522 & 8.245 \\
\hline Stab stuck at 5 deg & 8.858 & 8.356 & 1.113 & 0.963 & 8.762 & 8.301 \\
\hline Stab stuck at 8 deg & 10.74 & 8.352 & 1.250 & 1.034 & 10.60 & 8.284 \\
\hline Rudder stuck at 2 deg & 5.267 & 8.115 & 1.151 & 0.995 & 5.213 & 8.072 \\
\hline Rudder stuck at 5 deg & 4.801 & 7.719 & 1.472 & 1.263 & 4.751 & 7.671 \\
\hline Rudder stuck at 8 deg & 5.758 & 7.076 & 1.718 & 1.765 & 5.673 & 7.049 \\
\hline Light Turbulence & 5.426 & 8.264 & 1.086 & 0.783 & 5.366 & 8.229 \\
\hline Moderate Turbulence & 5.333 & 8.229 & 1.107 & 0.765 & 5.262 & 8.178 \\
\hline Severe Turbulence & 5.343 & 8.196 & 1.268 & 0.839 & 5.201 & 8.109 \\
\hline
\end{tabular}


Table D4. Integral of Control Surface Deflection Rate of PPID and L1 Adaptive Controller for 3D S Turns

\begin{tabular}{|c|c|c|c|c|c|c|c|c|}
\hline & \multicolumn{8}{|c|}{ Integral Of Control Surface Rate Of Change } \\
\hline & \multicolumn{2}{|c|}{$\begin{array}{c}\text { Elevator }[\mathrm{rad} / \mathrm{s}] \mathrm{x} \\
\mathrm{e}-03\end{array}$} & \multicolumn{2}{|c|}{$\begin{array}{c}\text { Aileron }[\mathrm{rad} / \mathrm{s}] \mathrm{x} \\
\mathrm{e}-03\end{array}$} & \multicolumn{2}{|c|}{$\begin{array}{c}\text { Rudder }[\mathrm{rad} / \mathrm{s}] \mathrm{x} \\
\mathrm{e}-03\end{array}$} & \multicolumn{2}{|c|}{ Throttle [\%] } \\
\hline & PPID & L1+PPID & PPID & L1+PPID & PPID & L1+PPID & PPID & L1+PPID \\
\hline Nominal & 2895 & 12.22 & 938.8 & 28.30 & 369.4 & 0.545 & 15.31 & 1.245 \\
\hline $\begin{array}{c}\text { Aileron stuck at } \\
2 \mathrm{deg}\end{array}$ & 2758 & 12.89 & 977.5 & 70.08 & 286.3 & 1.342 & 17.07 & 1.246 \\
\hline $\begin{array}{c}\text { Aileron stuck at } \\
5 \mathrm{deg}\end{array}$ & 2760 & 12.81 & 842.4 & 69.58 & 220.0 & 1.333 & 17.11 & 1.247 \\
\hline $\begin{array}{c}\text { Aileron stuck at } \\
8 \mathrm{deg}\end{array}$ & 3180 & 12.85 & 430.3 & 70.37 & 123.9 & 1.347 & 1.911 & 1.248 \\
\hline $\begin{array}{c}\text { Stab stuck at } 2 \\
\text { deg }\end{array}$ & 39.97 & 27.78 & 37.62 & 68.10 & 8.976 & 1.308 & 1.381 & 1.289 \\
\hline $\begin{array}{c}\text { Stab stuck at } 5 \\
\text { deg }\end{array}$ & 38.05 & 44.10 & 36.59 & 102.3 & 8.915 & 1.965 & 1.407 & 1.415 \\
\hline $\begin{array}{c}\text { Stab stuck at } 8 \\
\text { deg }\end{array}$ & 34.52 & 81.46 & 34.03 & 177.1 & 8.267 & 3.403 & 1.494 & 1.747 \\
\hline $\begin{array}{c}\text { Rudder stuck at } \\
2 \text { deg }\end{array}$ & 2886 & 12.82 & 831.3 & 32.64 & 453.9 & 0.629 & 15.36 & 1.290 \\
\hline $\begin{array}{c}\text { Rudder stuck at } \\
5 \mathrm{deg}\end{array}$ & 2848 & 15.22 & 843.9 & 46.28 & 414.2 & 0.891 & 15.94 & 1.380 \\
\hline $\begin{array}{c}\text { Rudder stuck at } \\
8 \mathrm{deg}\end{array}$ & 2826 & 29.29 & 799.8 & 103.1 & 414.5 & 1.989 & 14.58 & 1.598 \\
\hline Light Turbulence & 2895 & 29.04 & 941.6 & 91.29 & 369.0 & 1.698 & 15.34 & 1.231 \\
\hline $\begin{array}{l}\text { Moderate } \\
\text { Turbulence }\end{array}$ & 2895 & 68.31 & 954.0 & 182.2 & 371.4 & 3.367 & 15.38 & 1.320 \\
\hline $\begin{array}{c}\text { Severe } \\
\text { Turbulence }\end{array}$ & 2873 & 125.2 & 887.5 & 292.4 & 363.2 & 5.371 & 15.74 & 1.584 \\
\hline
\end{tabular}


Table D5. Saturation Index of PPID and L1 Adaptive Controller for 3D S Turns

\begin{tabular}{|c|c|c|c|c|c|c|c|c|}
\hline & \multicolumn{8}{|c|}{ Saturation Index } \\
\hline & \multicolumn{2}{|c|}{$\begin{array}{c}\text { Elevator }[\mathrm{rad} / \mathrm{s}] \mathrm{x} \\
\mathrm{e}-03\end{array}$} & \multicolumn{2}{|c|}{$\begin{array}{c}\text { Aileron }[\mathrm{rad} / \mathrm{s}] \times \mathrm{e}- \\
03 \\
\end{array}$} & \multicolumn{2}{|c|}{$\begin{array}{c}\text { Rudder[rad/s] x } \\
\text { e-03 }\end{array}$} & \multicolumn{2}{|c|}{ Throttle [\%] } \\
\hline & PPID & L1+PPID & PPID & L1+PPID & PPID & L1+PPID & PPID & L1+PPID \\
\hline Nominal & 83360 & 0 & 23958 & 0 & 0 & 0 & 0 & 0 \\
\hline $\begin{array}{c}\text { Aileron stuck at } \\
2 \text { deg }\end{array}$ & 84630 & 0 & 44415 & 3162 & 0 & 0 & 0 & 0 \\
\hline $\begin{array}{c}\text { Aileron stuck at } \\
5 \mathrm{deg}\end{array}$ & 84770 & 0 & 48628 & 7166 & 0 & 0 & 0 & 0 \\
\hline $\begin{array}{c}\text { Aileron stuck at } \\
8 \mathrm{deg}\end{array}$ & 83985 & 0 & 79337 & 77082 & 0 & 0 & 84 & 0 \\
\hline $\begin{array}{c}\text { Stab stuck at } 2 \\
\text { deg }\end{array}$ & 252 & 0 & 266 & 245 & 0 & 0 & 0 & 0 \\
\hline $\begin{array}{c}\text { Stab stuck at } 5 \\
\text { deg }\end{array}$ & 292 & 0 & 1530 & 1336 & 0 & 0 & 0 & 0 \\
\hline $\begin{array}{c}\text { Stab stuck at } 8 \\
\text { deg }\end{array}$ & 358 & 0 & 3789 & 14650 & 0 & 0 & 0 & 0 \\
\hline $\begin{array}{c}\text { Rudder stuck at } \\
2 \text { deg }\end{array}$ & 83469 & 0 & 23691 & 0 & 0 & 0 & 0 & 0 \\
\hline $\begin{array}{c}\text { Rudder stuck at } \\
5 \mathrm{deg}\end{array}$ & 83801 & 0 & 25076 & 338 & 0 & 0 & 0 & 0 \\
\hline $\begin{array}{c}\text { Rudder stuck at } \\
8 \mathrm{deg} \\
\end{array}$ & 84003 & 0 & 34612 & 1358 & 0 & 0 & 9 & 7 \\
\hline Light Turbulence & 83379 & 0 & 24046 & 0 & 0 & 0 & 0 & 0 \\
\hline $\begin{array}{l}\text { Moderate } \\
\text { Turbulence }\end{array}$ & 83376 & 0 & 24179 & 0 & 0 & 0 & 0 & 0 \\
\hline $\begin{array}{c}\text { Severe } \\
\text { Turbulence }\end{array}$ & 83611 & 0 & 20953 & 0 & 0 & 0 & 2 & 0 \\
\hline
\end{tabular}


Table D6. Performance Indices of PPID and L1 Adaptive Controller for 3D S Turns

\begin{tabular}{|c|c|c|c|c|c|c|}
\hline \multirow{2}{*}{} & \multicolumn{2}{|c|}{ PI_TT } & \multicolumn{2}{c}{ PI_CA } & \multicolumn{2}{c|}{ PI_TOTAL } \\
\cline { 2 - 7 } & PPID & L1+PPID & PPID & L1+PPID & PPID & L1+PPID \\
\hline Nominal & 0.743 & 0.659 & 0.466 & 0.979 & 0.660 & 0.755 \\
\hline Aileron stuck at 2 deg & 0.722 & 0.660 & 0.443 & 0.968 & 0.638 & 0.752 \\
\hline Aileron stuck at 5 deg & 0.667 & 0.660 & 0.452 & 0.964 & 0.603 & 0.751 \\
\hline Aileron stuck at 8 deg & 0.364 & 0.659 & 0.135 & 0.885 & 0.295 & 0.727 \\
\hline Stab stuck at 2 deg & 0.648 & 0.657 & 0.968 & 0.967 & 0.744 & 0.750 \\
\hline Stab stuck at 5 deg & 0.641 & 0.654 & 0.967 & 0.955 & 0.739 & 0.744 \\
\hline Stab stuck at 8 deg & 0.583 & 0.655 & 0.966 & 0.915 & 0.698 & 0.733 \\
\hline Rudder stuck at 2 deg & 0.746 & 0.655 & 0.449 & 0.978 & 0.657 & 0.752 \\
\hline Rudder stuck at 5 deg & 0.746 & 0.656 & 0.448 & 0.973 & 0.657 & 0.751 \\
\hline Rudder stuck at 8 deg & 0.702 & 0.656 & 0.436 & 0.941 & 0.622 & 0.741 \\
\hline Light Turbulence & 0.747 & 0.662 & 0.465 & 0.963 & 0.663 & 0.752 \\
\hline Moderate Turbulence & 0.752 & 0.665 & 0.464 & 0.936 & 0.665 & 0.746 \\
\hline Severe Turbulence & 0.751 & 0.668 & 0.462 & 0.900 & 0.665 & 0.737 \\
\hline
\end{tabular}

